Portland State University

PDXScholar

$7-27-2020$

\title{
Short- and Long-term Impacts of a Deliberative Pedagogy in Introductory Biology and Chemistry Courses
}

Liz Rain-Griffith

Portland State University

Follow this and additional works at: https://pdxscholar.library.pdx.edu/open_access_etds

Part of the Biology Commons, Higher Education Commons, and the Science and Mathematics Education Commons

Let us know how access to this document benefits you.

\section{Recommended Citation}

Rain-Griffith, Liz, "Short- and Long-term Impacts of a Deliberative Pedagogy in Introductory Biology and Chemistry Courses" (2020). Dissertations and Theses. Paper 5557.

https://doi.org/10.15760/etd.7431

This Thesis is brought to you for free and open access. It has been accepted for inclusion in Dissertations and Theses by an authorized administrator of PDXScholar. Please contact us if we can make this document more accessible: pdxscholar@pdx.edu. 


\begin{abstract}
Short- and Long-term
Impacts of a Deliberative Pedagogy

in Introductory Biology and Chemistry Courses
\end{abstract}

by

Liz Rain-Griffith

A thesis submitted in partial fulfillment of the requirements of the degree of

Master of Science
in
Biology

Thesis Committee:

Erin E. Shortlidge, Chair

Jack Barbera

Susan Masta

Portland State University

2020 
(C) 2020 Liz Rain-Griffith 


\section{ABSTRACT}

There have been multiple national calls for curricular reform in college-level science, technology, engineering, and mathematics (STEM), including a need to instill democratic skills in students. Democratic skill building can be embedded in STEM classrooms through intentional "deliberative pedagogies" which include skills in: communication, collaboration, and application. We developed and implemented a deliberative pedagogy, Deliberative Democracy (DD), across introductory majors and non-majors biology courses and a majors chemistry course. In two separate studies, I took a longitudinal, qualitative research approach to understand introductory biology and chemistry students' experiences and perceptions of DD.

For the first study, I tracked a cohort of majors and non-majors introductory biology students over two academic years (2016-17 and 2017-18). Via online surveys, I asked students to respond to open-ended prompts about their experiences and perceptions of DD modules used in their courses. A follow-up online survey was sent to the same cohort of biology students one year after their course. I also recruited a subset of students for semi-structured interviews with the intent to gather additional qualitative data. I found that students' perceptions of DD were lasting and generally positive. Positive perception themes included: awareness of "real-world applications of science" and increased "scientific literacy". The negative perceptions of DD predominantly had to do with "group dynamics" and "class time use". I detected a few significant differences between student perceptions in the majors and non-majors courses, including "scientific literacy" and how "class time" was used. 
For the second study, I tracked an additional cohort of introductory biology and chemistry students over one academic year (2017-18). Via online surveys, I asked students to respond to open-ended prompts about their experiences and perceptions of DD modules used in their courses. These prompts asked students to reflect on their beliefs regarding why their instructor chose to use DD in their course, their views on applying science to the real-world, and their confidence in applying science to the real world, and in communicating with their peers. The top two reasons students believed their instructor was using DD was 1) to introduce real-world applications of scienceespecially if it was tied to course content and 2) to build community in the classroom with peer interaction and discussions. Overall, students reported that DD had positively impacted their views of real-world applications and had increased their scientific literacy, among other important skills (e.g., critical thinking). DD was described by many students as an opportunity to build their own discourse skills, an experience that may otherwise not arise during an introductory STEM lecture course. Additionally, I wanted to examine what led to a successful DD module being implemented, as determined by student perceptions. What made a DD module successful was that the course content and DD topic presented must be closely aligned. Lastly, providing the students a chance to have an open forum to talk about the DD topics in small groups and collectively as a class, was a memorable aspect of the student experience. I believe that other instructors can implement DD modules in their own introductory STEM courses with a relatively low barrier to adoption and see positive impacts of the pedagogy. 


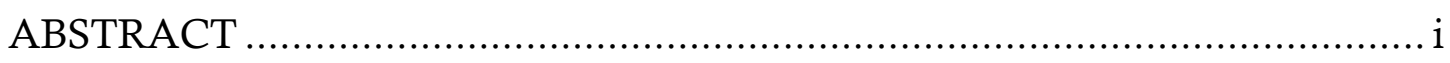

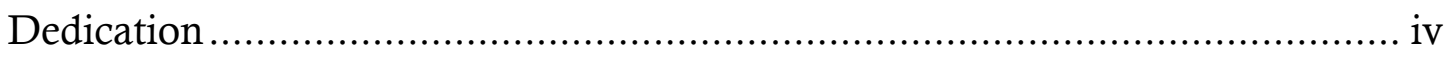

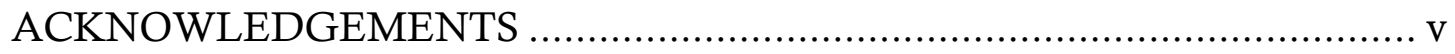

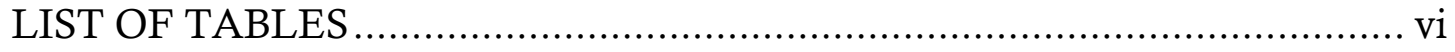

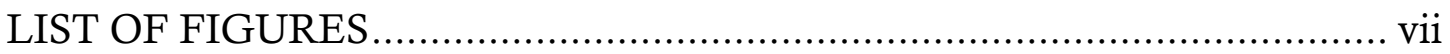

CHAPTER 1: Overview \& General Information ............................................ 1

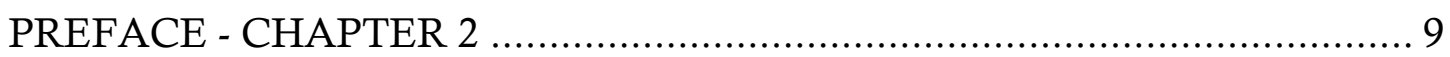

CHAPTER 2: Deliberative Democracy: Investigating the Longitudinal Impacts of Democratic Activities in Introductory Biology Courses ............................... 10

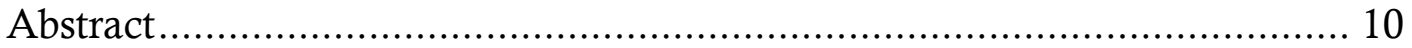

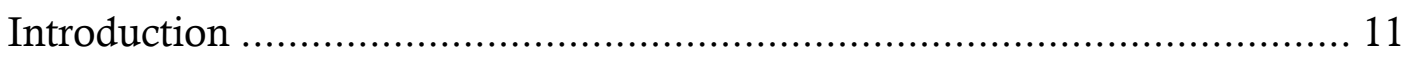

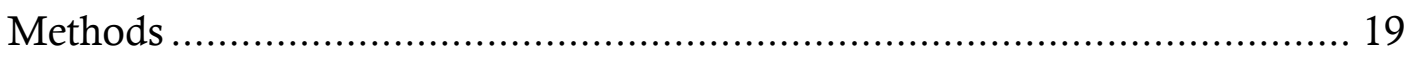

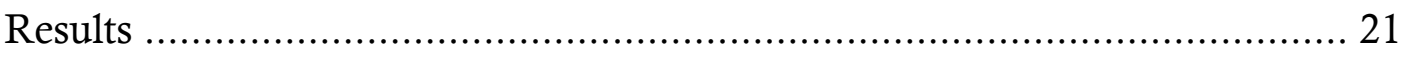

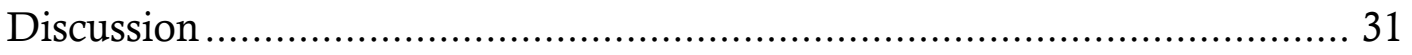

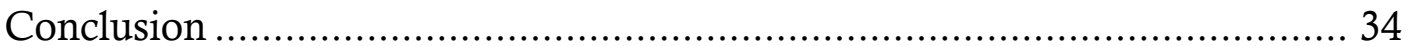

CHAPTER 3: To Implement or Not to Implement? Investigation of a Deliberative Pedagogy's Impacts on Introductory Biology and Chemistry Course

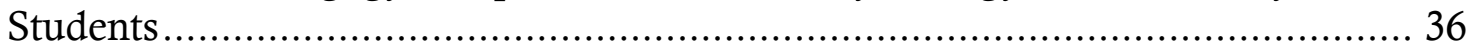

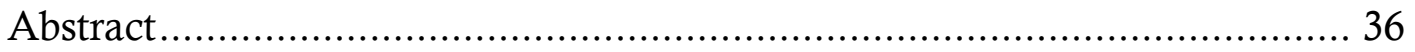

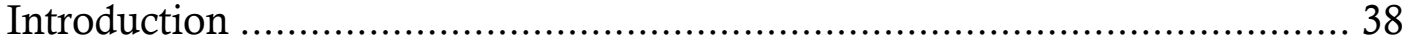

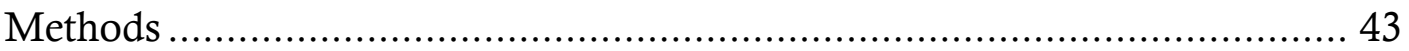

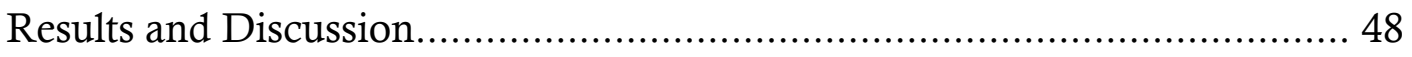

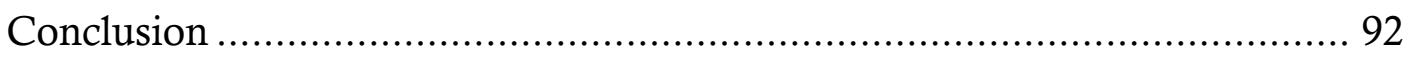

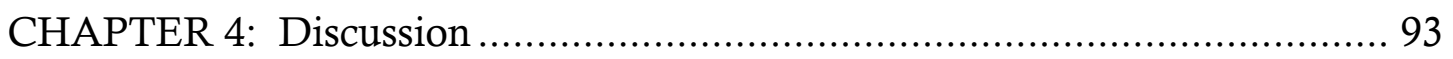

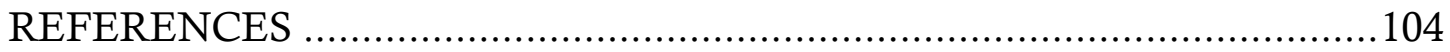

APPENDIX A: Chapter 2 - Extended Methods ........................................108

APPENDIX B: Sample demographics for respondents of the survey immediately after their course.

APPENDIX C: Sample demographics for respondents of the survey one year

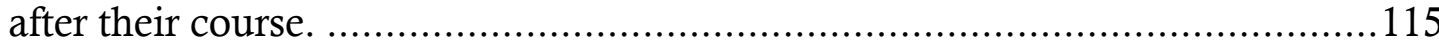

APPENDIX D: Spring 2018 Interview Questions ……............................116 


\section{Dedication}

For my lucky cat, Maneki

\section{$2 / 17 / 2006-12 / 20 / 2018$}

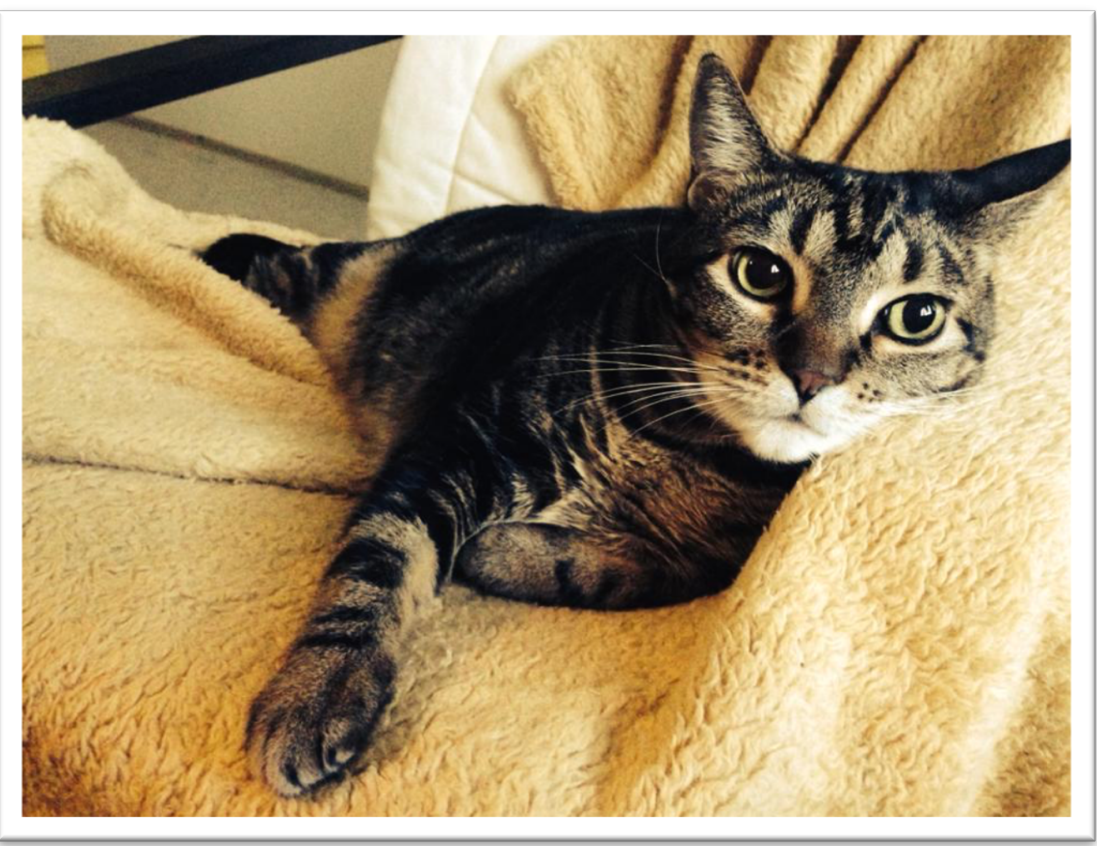




\section{ACKNOWLEDGEMENTS}

I have many individuals to thank for my persistence and success of this Master's project.

First and foremost, I must thank the numerous students and instructors who were part of these studies. Without you, none of this would have been possible.

Dr. Erin Shortlidge: it feels like yesterday when I met with you to talk about researchthe date was actually February 9, 2016! You have supported me since day one, and for that I'm a better researcher and even a better teacher. Thank you, this experience has been life changing.

I must thank my other committee members: Dr. Jack Barbera and Dr. Susan Masta. Thank you both for your guidance and helpful thesis edits and suggestions.

I would like to thank Dr. Gwen Shusterman, my "unofficial" fourth committee member. Thank you for giving me countless opportunities these last few years.

To the three undergraduate student researchers who have helped me: Chloe Shelby, Sarah Sheghewi, and Phoebe Huynh. Thank you for the tremendous help you have provided over the years. Qualitative research is difficult-you are all rock stars!

To my BER lab-sisters: Brie Tripp and Emma Goodwin. I couldn't have done it without you! Thank you for your friendship.

To the rest of the Shortlidge BER group, you all are amazing.

To the Barbera CER group, you are all amazing too! Especially thanks to Dr. Katy Hosbein and Dr. Regis Komperda for your endless help with my project.

To my PSU Biology family, especially my cohort, all the other graduates, professors, and advisors/staff. You know who you are, and I love you all.

To the many other friends and colleagues, I've made at PCC and PSU.

To my best friend Sabrina Simila and her family. You guys have been my rock these last couple of years.

My non-academic friends, thank you for understanding my crazy schedule and life.

Last and certainly not least, my family: Mom, Dad, Wendy, and Samantha. 
Table 2.1 Components of DD modules

Table 2.2 Aggregated biology students' positive and memorable perceptions ....21

Table 2.3 Aggregated biology students' negative and frustrating perceptions .....22

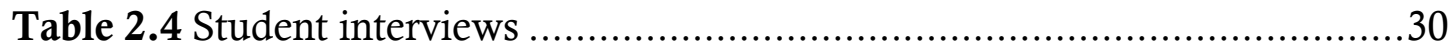

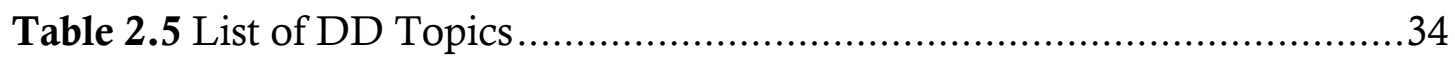

Table 3.1 Fall 2017 DD activity details for each course type.....................49

Table 3.2 Fall 2017 sample demographics.................................................52

Table 3.3 Top themes and their definitions regarding "Why do you believe your instructor used Deliberative Democracy in this class?"

Table 3.4 Top themes and their definitions regarding 1) "How did participating in the DD activities in this class impact your thinking regarding the role of science as it applies to real-world problems?" 2) "How did participating in the DD activities in this class impact your confidence in applying scientific knowledge to real-world problems?" and 3) "How did participating in the DD activities in this class impact your confidence in communicating scientific topics with your peers?"

Table 3.5 Winter 2018 DD activity details for each course type

Table 3.6 Winter 2018 sample demographics ........Error! Bookmark not defined. Table 3.7 Spring 2018 DD activity details for each course type ........................78

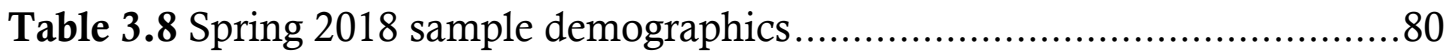




\section{LIST OF FIGURES}

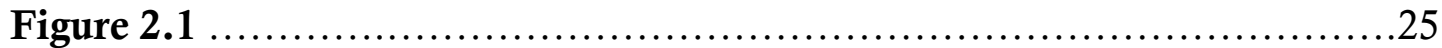

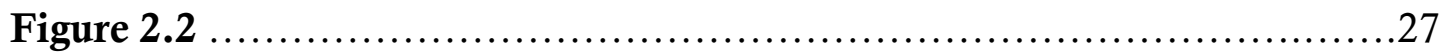

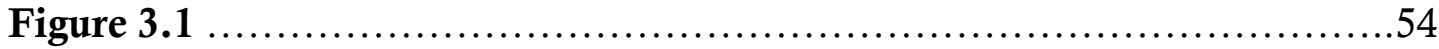

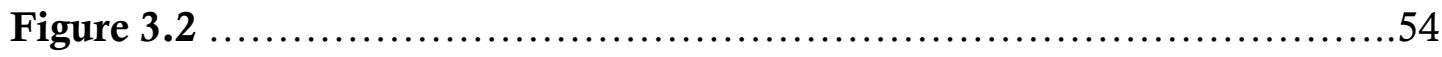

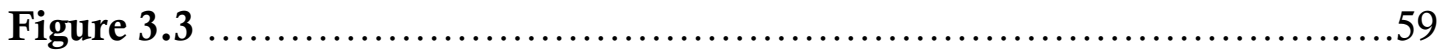

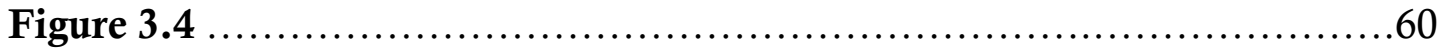

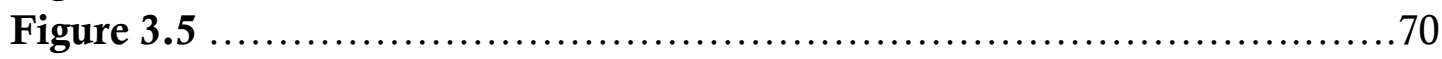

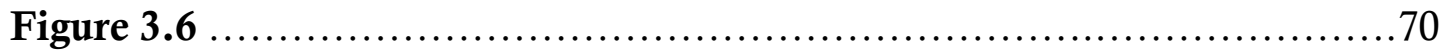

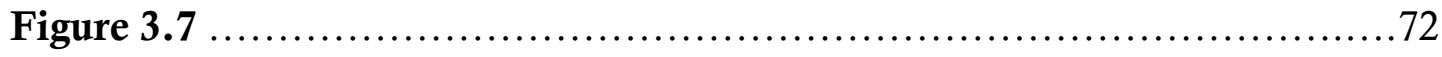

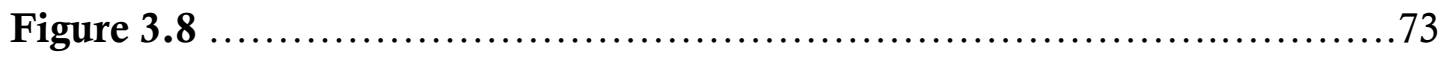

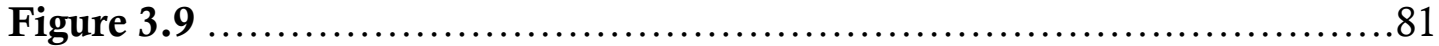

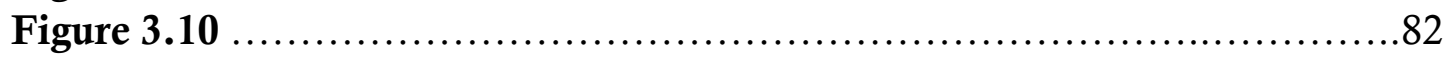

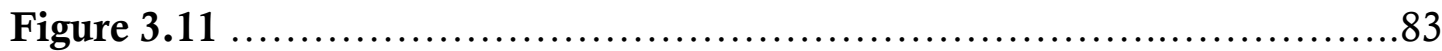

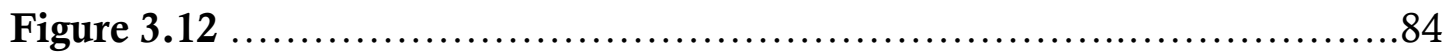


CHAPTER 1: Overview \& General Information

Science, technology, engineering, and mathematics (STEM) higher education has been undergoing a transformation due to national calls for improving introductory coursework by implementing evidence-based teaching practices (National Research Council, 2004; President's Council of Advisors on Science and Technology, 2012). One such practice is introducing active learning activities that are more student centered than instructor centered (Meyers and Jones, 1993; Michael, 2006; Haak et al., 2011; Freeman et al., 2014). Active learning has been defined as "instructional activities involving students in doing things and thinking about what they are doing" (Bonwell and Eison, 1991, p. 3). Some examples of active learning are embedding engaging activities for students during lecture (Prince, 2004) to getting students to work in small groups (Johnson et al., 1998; Tanner et al., 2003). Active learning has been shown to decrease failure rates for undergraduate students in STEM courses compared to traditional lecture (Freeman et al., 2014). Although there is a general agreement that active learning pedagogies are supporting students in their STEM courses, it is less known how active learning is actually "working" (Prince, 2004; Tanner. 2011). A next step in STEM education reform is to investigate what it means to "work", more specifically, what is happening during these pedagogies we are utilizing that result in student gains (Dolan, 2015).

One way to begin to understand how active learning "works" is to start by collecting students' perceptions and experiences (Ames, 1992). Student perceptions of active learning are seldomly taken into consideration. It is important to consider that students are individuals each with diverse ways of learning (Towns et al., 2000). 
Perceptions, like students, are diverse and should not be boiled down to one opinion and applied to all students (Brazeal et al., 2016). However, even in a diverse classroom, student perceptions of what is important to their learning and interest in the subject may fall into a relatively small number of common overarching themes (Shortlidge et al., 2018).

As instructors and researchers, we aim to reform STEM courses to engage and retain all students in scientific disciplines, but we are also educating members of society. STEM students will likely participate in civic activities, such as attending community meetings and voting on ballot measures-activities that will affect our collective future. According to The Center for Information \& Research on Civic Learning \& Engagement (CIRCLE) there has been a downward trend of participation in civic activities since the mid-70s (Thomas, 2010). It is thought that younger generations have been participating less in civic activities as evidenced by declined rates of attendance at public meetings and community projects (Thomas, 2010). Because of this observed decline in civic engagement, there have been national calls to instill "democratic skills and culture" in higher education (CIRCLE, 2010; Colby and Sullivan, 2009; Association of American Colleges and Universities, 2007; Kirlin, 2003). The literature regarding students and civic engagement can be summarized into three critical skills that college students should obtain (adapted from Thomas 2010):

1) Communication: Students will gain effective communication skills (written and oral) in a variety of contexts and among diverse groups of people.

2) Collaboration: Students will use effective dialogue, deliberation, public reasoning, and collaborative decision-making skills. 
3) Application of information: Students will be able to competently understand and critically analyze gained knowledge and information (e.g., research skills, evaluating the quality of arguments).

There is an immense amount of effort to change STEM teaching to meet national calls for engaging and retaining students (National Research Council, 2003; President's Council of Advisors on Science and Technology [PCAST], 2012). One of those crucial changes is to instill democratic skills in the classroom. More specifically, in effort to reform biology, the seminal publication Vision and Change (2009) outlines six fundamental core competencies that students are expected to develop by the time they graduate with an undergraduate degree in biology. One of which states that students will have the "ability to understand the relationship between science and society" (American Association for the Advancement of Science (AAAS), 2009). Biology students should be exposed to the science they are learning in a societal context and to be able to address real-world problems and be prepared for their future endeavors (AAAS, 2009).

One way of accomplishing this educational reform call to instill democratic skills is to integrate a "deliberative pedagogy" (DP) into a course. DP can be described as a "democratic educational process and a way of thinking that encourages students to encounter and consider multiple perspectives, weigh trade-offs and tensions, and move towards action through informed judgment" (Shaffer et al., 2017).

There are likely many examples of DP across curricula and discipline, but in the literature, interventions are typically published when the researchers also assess the outcome of the pedagogy. Researchers test for various gains, including in the cognitive 
domain (content related), and the affective domain (interest and attitude), was well as "soft skills" such as communication and working in groups. For example, a study in 2014 examined a DP used in a non-majors chemistry course where students and the general public deliberated about nanotechnology (Jones et al., 2014). With the use of pre- and post-tests, the researchers found that the participants overall had an increased knowledge of, and confidence in their knowledge, of nanotechnology. Additionally, participants reflected about their appreciation for the opportunity to have discussions on real-world topics with others. In another example in a non-majors biology course, students deliberated about global climate change in a two-day activity (Drury, 2015). With the use of pre- and post-deliberation surveys, the researchers found that having a DP in their non-majors course gave students an opportunity to cultivate communication skills, consider real-world problems, and use critical thinking.

In this Masters' project, I evaluated the outcomes of a deliberative pedagogy called "Deliberative Democracy" (DD), which was first developed at Portland State University (PSU) for a non-majors biology course. In the original course, the bulk of the biology concepts were structured around DD activities (Weasel and Finkel, 2016). For example, while studying macromolecules content (specifically carbohydrates), the class deliberated on soft drink size regulation and its impacts on human health. Weasel and Finkel (2016) reported that the modules increased students' learning of course content, and engagement. The success of DD in this non-majors biology course led to an expanded initiative to implement DD in majors biology, chemistry, and physics classrooms at PSU. In this new setting, DD was implemented to facilitate an 
engaging learning environment, and to provide students the opportunity to gain important democratic skills to be carried with them beyond the classroom.

\section{Pilot Study}

We first aimed to gain a coarse-grained understanding of students' perceptions of the DD pedagogy in the majors introductory courses at PSU during the 2016-2017 academic year. We found that student perceptions of DD activities used in biology were generally positive (e.g., learning about real-world applications) $(\mathrm{n}=173,80 \%)$, yet some had negative experiences (e.g., difficult group dynamics such as group members not participating) as well ( $\mathrm{n}=173,42 \%)$ (Shortlidge et al., 2018). Chemistry students' perceptions of DD $(\mathrm{n}=95)$ were more equally divided between positive (39\%) and negative (31\%) (Komperda et al., 2018). While initially investigating these data of student perceptions of $\mathrm{DD}$, we hypothesized that students who reported positive experiences would have had higher final course grades than students who reported negative experiences. DD activities are designed to line up with course content and was found to increase students engagement and understanding of course materials (Weasel and Finkel, 2016). With this logic, we made the assumption that grades would be impacted. For example, if a student had positive experiences with $\mathrm{DD}$, they would have a higher final course grade than students who had negative experiences. In our previous work, we found that regardless of student perceptions (positive or negative), students had similar final course grades (average final course grade $=85 \%)($ Shortlidge et al., 2018). We were surprised to find that DD activities did not seem to have an impact on student performance. 


\section{Masters' Project}

With the pilot study findings, I wanted to ask the question: what type of nonperformance related outcomes are resulting from students participating in DD exercises? This broad question ultimately inspired this Masters' project. To dive deeper into understanding potential student outcomes from a deliberative intervention, I took a qualitative approach into understanding student perceptions and impacts from their DD experiences. I employed qualitative methods including open-ended survey items and semi-structured interviews, to gather data about student experiences with DD over the course of two academic years. I also conducted classroom observations to identify course-level differences in DD implementation and in-class student responses/behavior.

This Masters' research project addresses five questions regarding outcomes of deliberative pedagogy interventions in introductory biology and chemistry courses at PSU:

Research Question 1: a. What were the similarities and/or differences in students' perceptions of DD immediately after their course and a year later? b. How were these selfreported perceptions aligned with expected DD outcomes/democratic skills?

Research Question 2: Which of these perceptions (found in Research Question 1) differ by course type (majors vs. non-majors biology courses)?

Research Question 3: Why do students believe that their instructors use DD activities in the classroom? 
Research Question 4: What do students perceive they gain from participating in DD activities, and does this differ among course-types?

Research Question 5: How can we use these data to make recommendations for broader implementation of DD modules?

In Chapter 2 I tracked a cohort of majors and non-majors introductory biology students over two academic years (2016-17 and 2017-18). Via online surveys, I asked students to respond to open-ended prompts about their experiences and perceptions of DD modules used in their courses. A follow-up online survey was sent to the same cohort of biology students one year after their course. I also recruited a subset of students to participate in semi-structured interviews to gather additional qualitative data. I found that students' perceptions of DD were lasting and generally positive. Positive perception themes included: awareness of "real-world applications of science" and increased "scientific literacy". The negative perceptions of DD mostly related to "group dynamics". I did detect a few significant differences between the majors and non-majors courses, including "scientific literacy" and how "class time" was used. Majors students reflected on these aspects of DD one year later significantly more than non-majors.

In Chapter 3 I tracked a different cohort of introductory biology and chemistry students who participated in DD activities over one academic year (2017/2018). Via online surveys, I asked students to respond to open-ended prompts about their experiences and perceptions of DD modules used in their courses. These prompts asked students to reflect on: their beliefs on why their instructor chose to use DD in 
their class, their view on the applications of science to the real-world; and their confidence in applying science to the real-world, and communicating science with their peers. The top two reasons students believed their instructor was using DD was 1) to introduce real-world applications of science, and 2) to build community in the classroom with peer-to-peer interactions and discussions. Overall, students reported that DD had positively impacted their views of real-world applications of science, and had increased their scientific literacy confidence. DD was described by many students as an opportunity to build their own discourse skills, an experience otherwise not usually provided during an introductory STEM lecture course. Additionally, I wanted to examine what led to a DD module implementation being successful, as determined by student perceptions. I found that when course content and the DD topic were aligned, students reflected more often on the connections of social impacts, current events, consumerism, and human health. Further, providing the students a chance to have an open forum to talk about these problems during class in small groups and as a collective has positive impacts on students' DD experiences. Evidence suggests that our strategy in development and implementation of DD is an achievable way for instructors across disciplines to introduce civic-minded skill building in their own introductory STEM courses. 
PREFACE - CHAPTER 2

Chapter 2 was accepted for publication on November 6, 2019 to the journal The American Biology Teacher. Permission to reprint was granted on November 15, 2019.

Rain-Griffith, Liz; Sheghewi, Sarah; Barbera, Jack; Shusterman, Gwendolyn; \& Shortlidge, Erin E. "Deliberative Democracy: Investigating the Longitudinal Impacts of Democratic Activities in Introductory Biology Courses". 
CHAPTER 2: Deliberative Democracy: Investigating the Longitudinal Impacts of Democratic Activities in Introductory Biology Courses

\section{Abstract}

There have been multiple national calls for curricular reform in higher education science, technology, engineering, and mathematics (STEM), including a need to instill democratic skills in our students. Democratic skill building can be embedded in STEM classrooms through intentional "deliberative pedagogies" which include: communication, collaboration, and application of information. We developed and implemented a deliberative pedagogy, Deliberative Democracy (DD), across introductory majors and non-majors biology courses and took a longitudinal, qualitative research approach to understand our students' experiences and perceptions of DD. We asked students to respond to open-ended survey questions about DD at two timepoints and conducted semi-structured follow-up interviews. All data was iteratively open-coded using content analysis. Students' perceptions of DD were lasting and generally positive, including self-reported themes related to DD promoting their awareness of the "real-world applications of science", and increased "scientific literacy". Negative perceptions of DD mostly had to do with "group dynamics". We detected differences between majors and non-majors student perceptions of DD including "scientific literacy" and "class time use". DD is a replicable pedagogy that can assist in instilling democratic skills in biology students. 


\section{Introduction}

As educators, we aim to improve science, technology, engineering, and mathematics (STEM) courses to engage and retain students, yet it is important to remember that we are also educating members of society (NRC, 2003; PCAST, 2012). Our students will likely participate in civic activities, such as attending community meetings and voting - activities that will affect our collective future. In Educating for Deliberative Democracy, Thomas (2010) summarized three democratic skills that undergraduates should obtain: 1) effective communication, 2) effective collaboration, and 3) competent application of information. Further, Vision and Change (2009) prescribes that students understanding the relationship between science and society is a core competency for students to gain before graduating with an undergraduate degree in biology.

One way of working to integrate democratic skills into the undergraduate classroom is through deliberative pedagogies. Deliberative pedagogies are relatively new to post-secondary education (Shaffer et al., 2017). Yet, a small number of investigations on the impacts of deliberative pedagogies for non-STEM majors courses have emerged in the literature (e.g., Jones et al., 2014; Drury, 2015). Jones et al. (2014) used a nanotechnology deliberation and found as a result, that participants had increased knowledge in the specific content and described appreciating the opportunity to have discussions with their peers. In another example, researchers documented a climate change deliberation where students reflected positively on the opportunity to work on their communication and critical thinking skills (Drury, 2015). 
The deliberative pedagogy implemented in this study, "Deliberative Democracy" (DD), was first developed at Portland State University (PSU) for a nonmajors biology course, where the bulk of course content was structured around DD activities (Weasel and Finkel, 2016). Researchers reported that the modules increased both students' learning and engagement in the class. The success of DD in this nonmajors biology course led to an expanded initiative to implement DD in majors biology, chemistry, and physics classrooms at PSU. In this new setting, DD was implemented to facilitate an engaging learning environment, and to provide students the opportunity to gain important democratic skills to be carried with them beyond the classroom. We first aimed to gain a coarse-grain understanding of students' perceptions of the DD pedagogy in the majors biology and chemistry courses at PSU, finding that student perceptions were generally positive (e.g., seeing real-world applications of the pedagogy), yet many had negative experiences as well (e.g., difficult group dynamics) (Shortlidge et al., 2018; Komperda et al., 2018). Here we took a finer-grain approach to detect evidence of students gaining the aforementioned democratic skills as a result of the DD experiences. To identify if DD interventions could have lasting impacts, we asked our students directly about their perceptions of DD over time. We took a qualitative approach and conducted a two-year study of majors and non-majors introductory biology courses implementing DD at PSU (Supplemental Table 2.5). This study is guided by the following research questions:

1) What were the similarities and/or differences in students' perceptions of DD immediately after their course and a year later? How were these self- 
reported perceptions aligned with expected DD outcomes/democratic skills?

2) Which of these perceptions differ by course type (majors vs. non-majors)?

\section{Characteristics of DD Modules}

DD is a small-group active learning strategy that includes a deliberation exercise.

Students are introduced to a real-world problem that correlates with their course content, and through reading, deliberation and research, students are asked to come to consensus on a policy recommendation. They are assigned related readings, quizzes, and group worksheets to build their consensus statement (Table 2.1). 
Table 2.1 Components of DD modules with expected outcomes, democratic skills, and examples. 


\begin{tabular}{|c|c|c|c|c|c|}
\hline 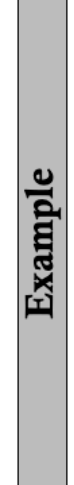 & 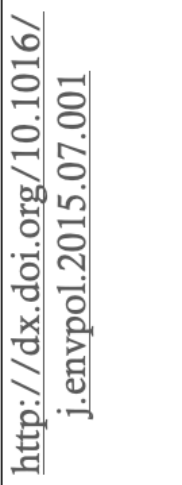 & 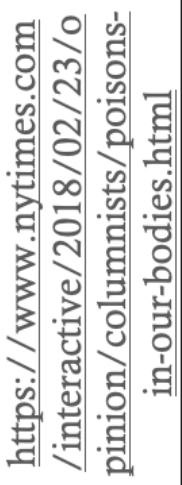 & & 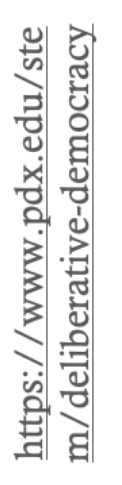 & \\
\hline 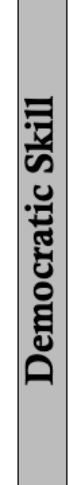 & 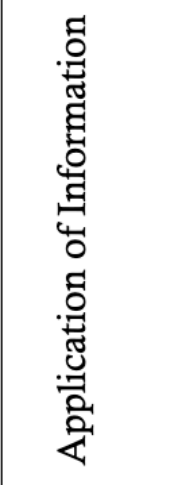 & 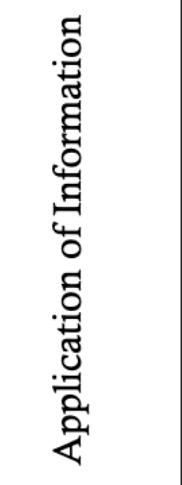 & 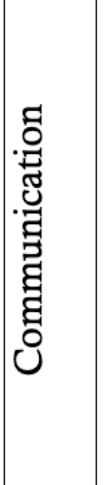 & 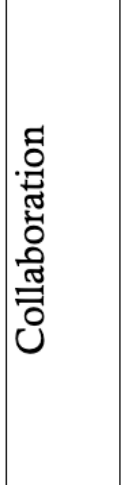 & 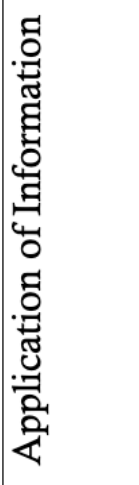 \\
\hline 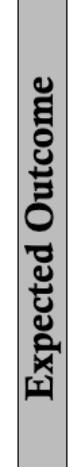 & 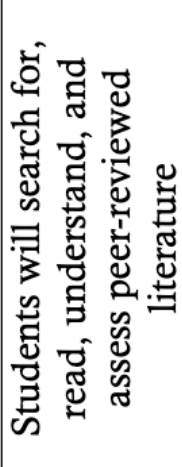 & 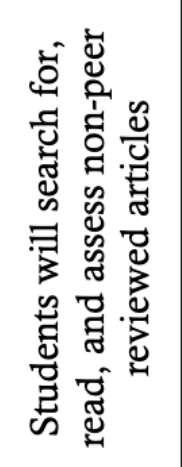 & 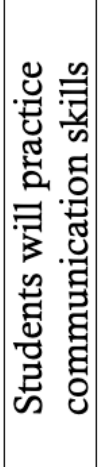 & 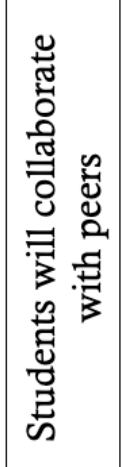 & 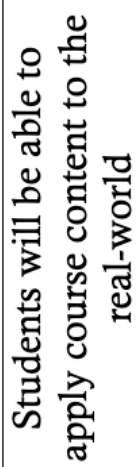 \\
\hline 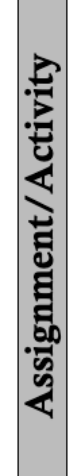 & 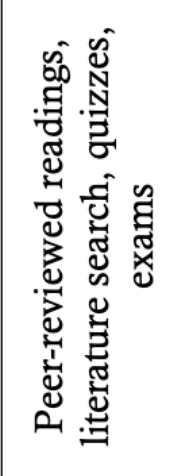 & 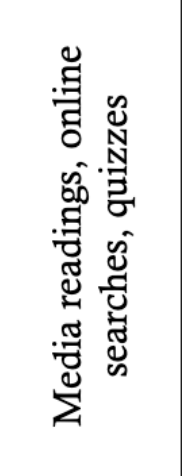 & 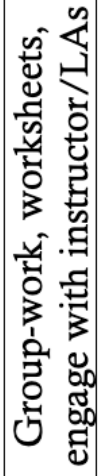 & 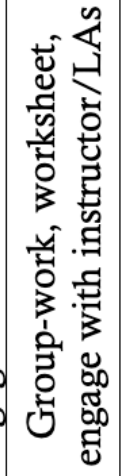 & 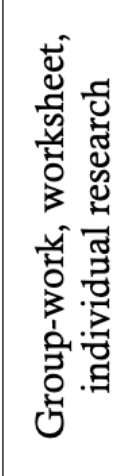 \\
\hline
\end{tabular}




\section{Real-world Problems}

A key component of DD is connecting the course content to real-world problems. For example, while teaching the endocrine system and hormone signaling in biology, evidence of suspected endocrine disruptors being common ingredients of household products such as cosmetics was introduced. We developed a DD module where students were asked to determine "How should cosmetic products that contain potential endocrine disrupting chemicals be regulated?" These questions are meant to be broad, with no clear-cut answers. As a deliberative pedagogy, we aim for the question to inherently evoke multiple levels of discussion that cross disciplines from basic to cutting-edge science, to social issues, economics, and environmental safety.

\section{Readings}

Students were assigned two readings, a media article (e.g., from the New York Times) and a peer-reviewed article focusing on the problem. The two articles may be directly linked such that the media article was written in direct response to and includes a link to the primary research article, however, this is not required. The media article demonstrates how science is presented through a media lens, oftentimes revealing possible cascading effects to the general public. The peer-reviewed articles are used to demonstrate how scientific research is conducted and communicated in writing. Online quizzes were assigned to assess students' understanding of the readings. 


\section{In-class Activities}

DD is designed to be conducted by small groups (typically 3-6 students) and may be done as a one- or two-day module. Learning assistants (LAs) can be used to facilitate small groupwork in large classrooms (Otero et al., 2006; Talbot et al., 2015). Student roles can be utilized to assign tasks and encourage equitable conversation (e.g., leader, recorder, spokesperson, facilitator, summarizer, and devil's advocate). Typically, on day one of a two-day module, students complete a worksheet outlining their collective knowledge gaps and assign topics for further, out-of-class, research (see Table 1 for weblink to worksheet examples). Groups are asked to come to an initial consensus statement addressing the problem before they convene. On the second day, students return with the materials they found, discuss them in their group, and complete a second worksheet. This sheet asks them to document their evidence and tie each topic back to the course material. The last section of the worksheet is a refined consensus statement where students can incorporate new information and design follow-up experiments to test unanswered questions. During the module, instructors have students report out their thoughts and findings in a whole class discussion and between small groups. Instructors pace class time and address possible misconceptions through clicker questions, when needed. For a one-day module, students are guided through a similar worksheet based on previously assigned readings and research performed in class, and they form a consensus statement at the end of the period. Expected outcomes and example components of a DD from a majors-level biology course on endocrine-disrupting chemicals (EDCs) and their potential impacts are outlined in Table 2.1. In our study, non-majors and Fall term majors courses implemented one- 
day modules. Winter and Spring term majors courses implemented two-day modules.

Further, LAs were used in the majors courses during the entire academic year. 


\section{Methods}

Collecting and Coding Student Perceptions of DD After Their Course We collected students' perceptions via an online survey (Qualtrics) at the end of the term from six introductory biology courses, three for majors and three for non-majors. For each course, we asked the open-ended prompt: "How do you feel about the Deliberative Democracy strategy used in this class?" Two researchers performed an inductive content analysis of the open-ended student responses (Krippendorff, 2012). We first sorted responses into positive, negative, and neutral bins, then applied codes to responses. Codes were then sorted into overarching themes. Neutral/noninformative responses (i.e., "it [DD] was fine") were not included in further analyses. To assess reliability and objectivity in the coding of responses, we performed interrater reliability via Cohen's Kappa until we reached a value of 0.61 or greater (substantial agreement) (Cohen, 1960). This study was approved by the PSU Institutional Review Board, \#153524 and \#184471.

\section{Collecting and Coding Student Perceptions of DD One Year Later}

We recruited participant responses from the same cohort of students one year later through an online survey. The survey asked students which DD they remembered participating in, and then asked: 1) "Reflecting on these activities [course-specific DD activities], what was the most memorable aspect of them and why?" and 2) "What was the most frustrating aspect of them and why?" We omitted any student responses that did not accurately cite the activities they participated in. 
We used the same process as described above to code student responses into salient themes within the memorable and frustrating categories. We continued iterative coding analysis until we achieved a Kappa of 0.61 or greater.

\section{Student Interviews}

To gather more nuanced perceptions of DD, we conducted semi-structured interviews (Cohen and Crabtree, 2006). These were completed after the second survey with a subset of participants $(n=19)$, who were recruited from the previous survey administrations. We asked questions such as: "Did participating in DD influence you outside of the classroom in any way?" We used content analysis to categorize responses into salient themes. Example interview quotes can be found below in Table 2.4. We continued analysis until we achieved a Kappa of 0.61 or greater.

\section{Statistical Analysis}

Pearson's Chi Square tests were used when comparing two groups. All reported significance was determined by $p$-values $\leq 0.05$.

\section{Additional Methods}

Please refer to Appendix A for the extended methods for Chapter 2 that were not included in this submitted manuscript. 


\section{Results}

\section{Student Perceptions of DD are Generally Positive}

Overall, 470 students responded to the survey ( $n=290$ majors; $n=180$ non-majors; $66 \%$ response rate). Of those, a total of $82 \%(n=385)$ across courses offered positive perceptions of DD immediately after their course. A smaller proportion of students, $(44 \% ; n=206)$ offered negative perceptions. A subset, $(25 \% ; n=117)$ of respondents had both positive and negative perceptions in their responses. Lastly, $5 \%(n=24)$ had neutral perceptions which were removed from the analysis. Table 2.2 describes the salient themes of positive perceptions, and how the themes align with expected democratic skill outcomes. Table 2.3 describes the salient themes of negative perceptions. Themes are expressed as percentage of students who mentioned that specific theme. Two themes of the positive and three of the negative perceptions did not align explicitly with any of the democratic skills outcomes. 
Table 2.2 Aggregated biology students' positive and memorable perceptions of DD themes and the applicable democratic skill that aligns with each theme. Significant differences in proportion of responses that fell into a particular category between the two time points are indicated: ${ }^{*} p \leq 0.05{ }^{* *} p \leq 0.0001$. Students often had responses that fell into more than one theme. Table 2.2 continued on next page.

\begin{tabular}{|c|c|c|c|c|c|}
\hline 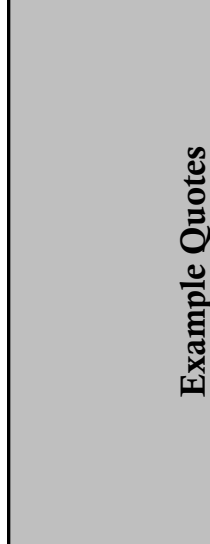 & 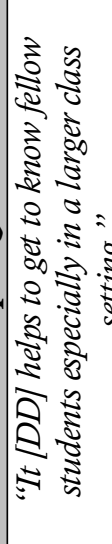 & 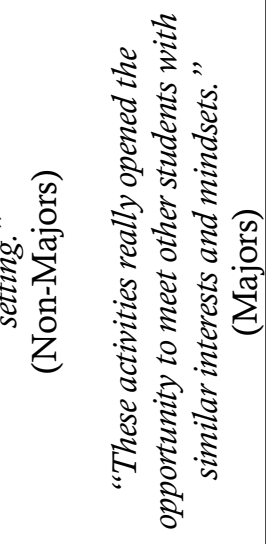 & 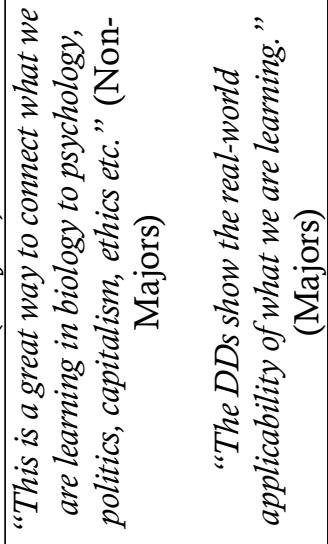 & 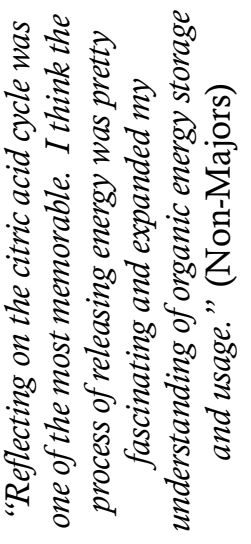 & 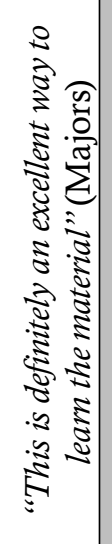 \\
\hline 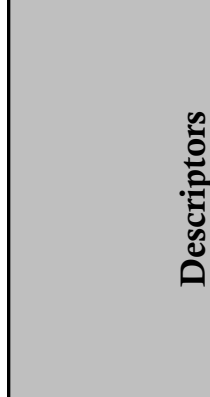 & & 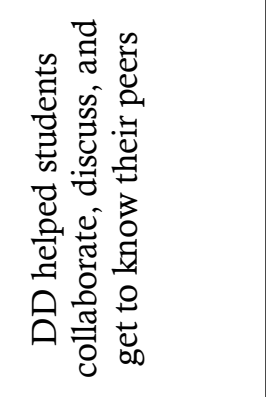 & 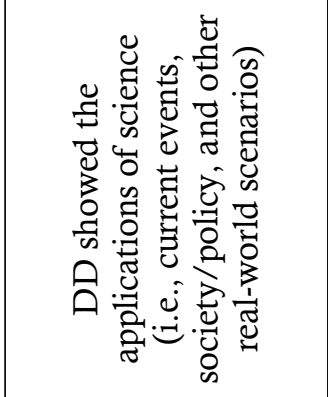 & 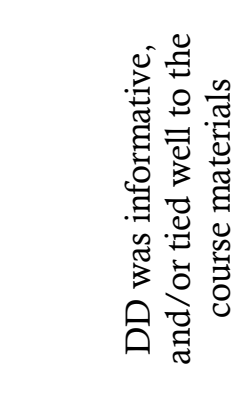 & \\
\hline 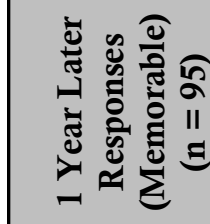 & & ڤे & ठి̊ & ڤั & \\
\hline 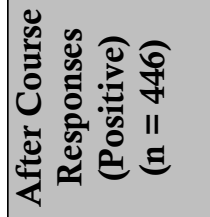 & & $\stackrel{\circ}{\stackrel{2}{\prime}}$ & ठें & ஓे & \\
\hline 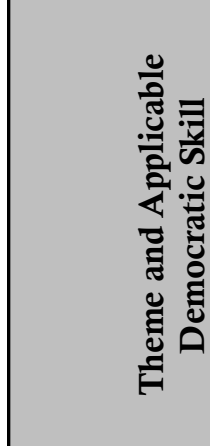 & & 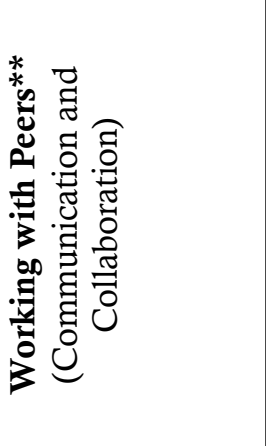 & 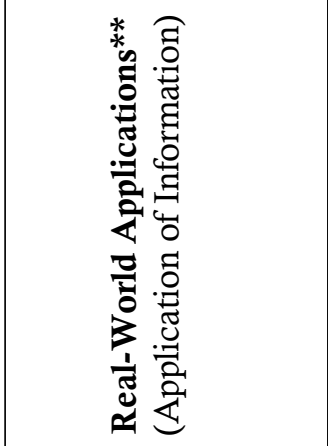 & 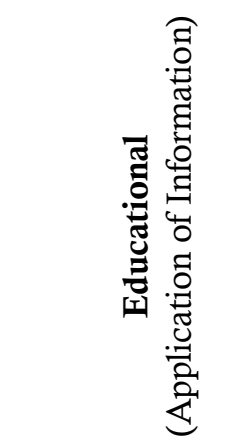 & \\
\hline
\end{tabular}
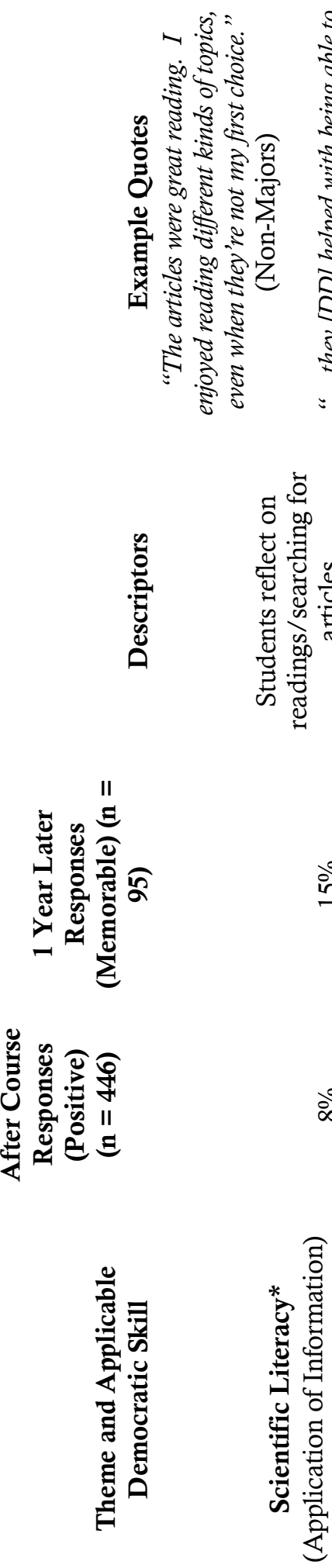


\begin{tabular}{|c|c|c|c|c|c|}
\hline $\begin{array}{l} \\
0 \\
0 \\
0 \\
0 \\
0 \\
\text { : } \\
\text { : } \\
\text { a }\end{array}$ & 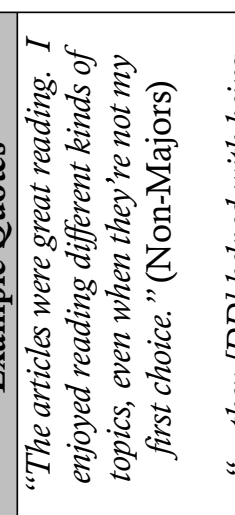 & 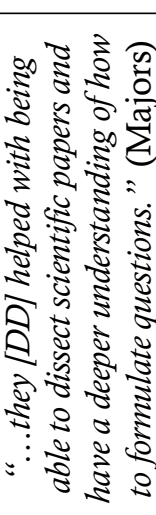 & 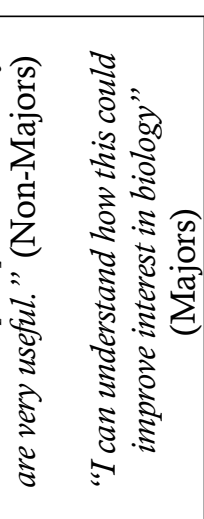 & 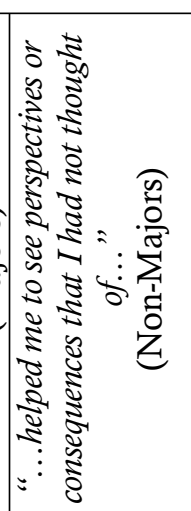 & 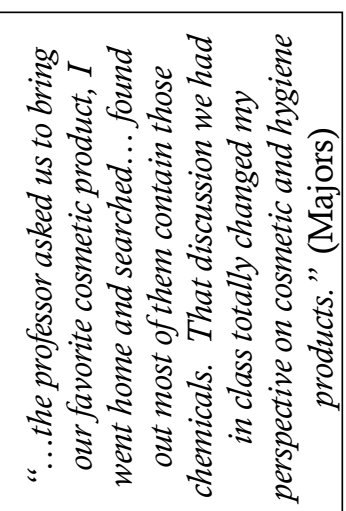 \\
\hline 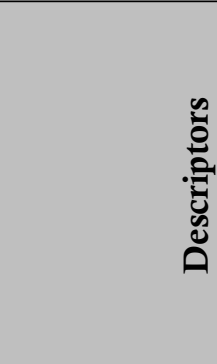 & 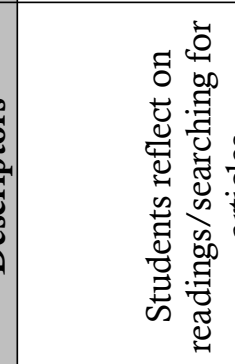 & & 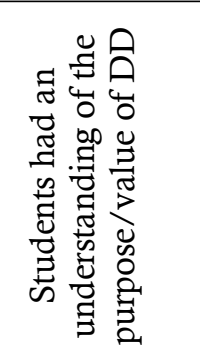 & & 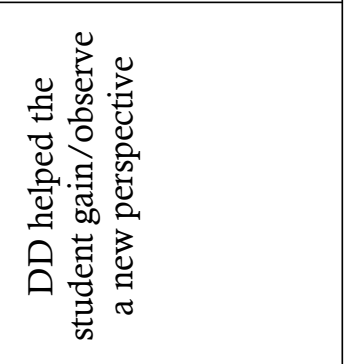 \\
\hline 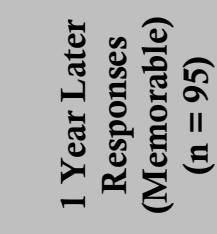 & 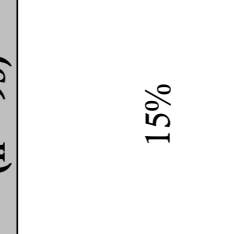 & & $\overleftrightarrow{\text { z }}$ & & $\stackrel{0}{\infty}$ \\
\hline 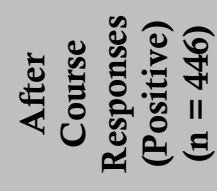 & 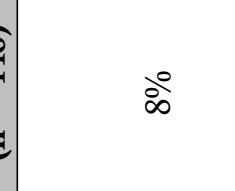 & & $\stackrel{\circ}{\beth}$ & & $\frac{\ll}{z}$ \\
\hline 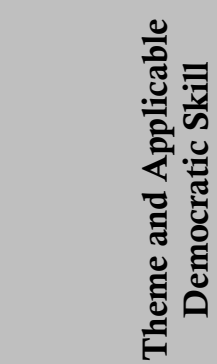 & 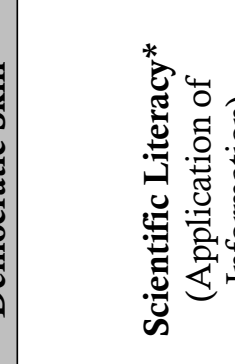 & & 党 & & 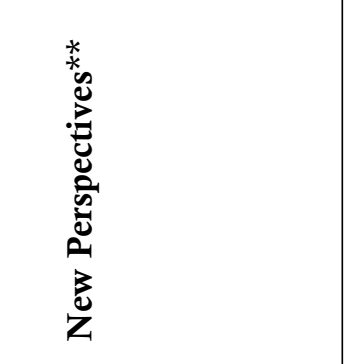 \\
\hline
\end{tabular}


Table 2.3 Aggregated biology students' negative and frustrating perceptions of DD themes and the applicable democratic skill that aligns with each theme. Significant differences in proportion of responses that fell into a particular category between the two time points are indicated: by ${ }^{*} p \leq 0.05{ }^{* *} p \leq 0.0001$. Students often had responses that fell into more than one theme.

\begin{tabular}{|c|c|c|c|c|c|c|c|c|}
\hline 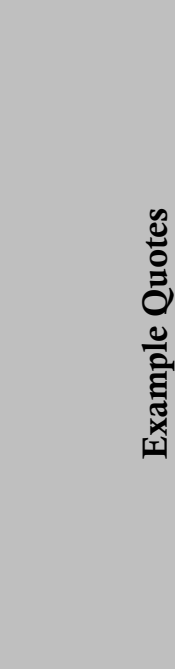 & 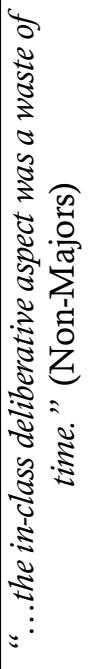 & 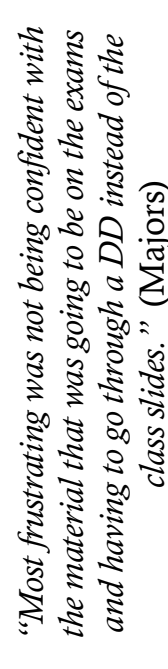 & 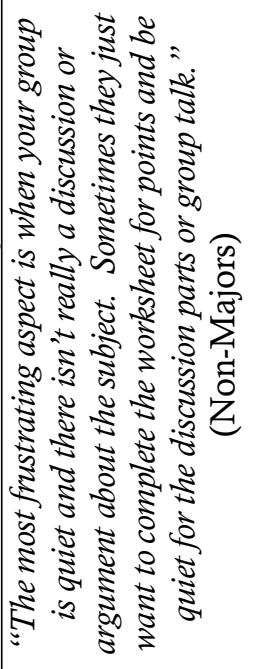 & 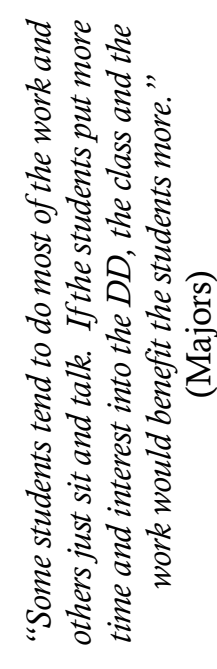 & 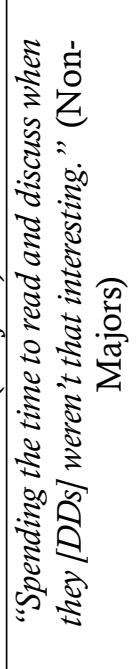 & 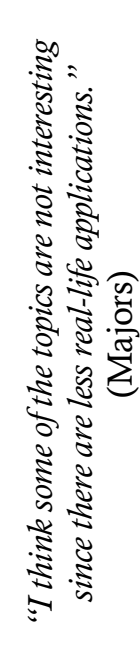 & 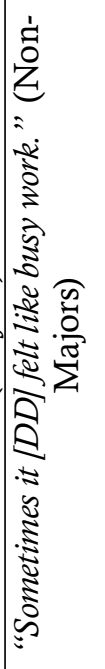 & 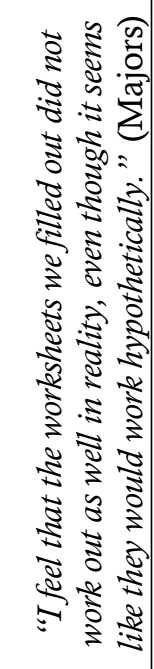 \\
\hline 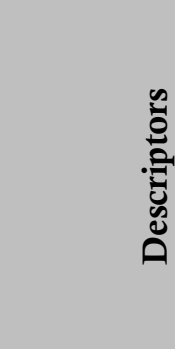 & 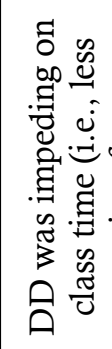 & 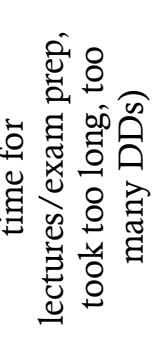 & 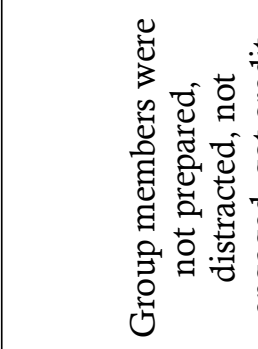 & 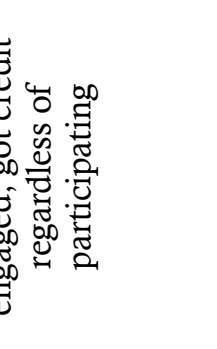 & 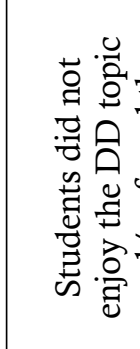 & 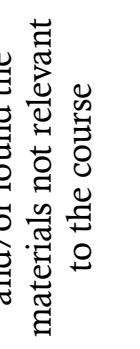 & \multicolumn{2}{|c|}{ 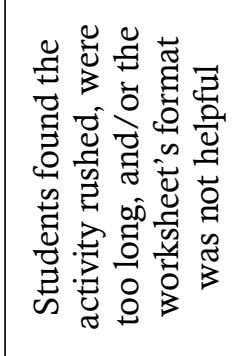 } \\
\hline 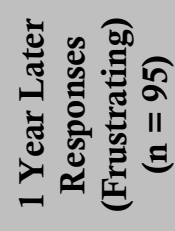 & & ळ̊ & \multicolumn{2}{|l|}{ ì } & \multicolumn{2}{|c|}{ ڤ̊ } & \multicolumn{2}{|r|}{ ळ̊ } \\
\hline 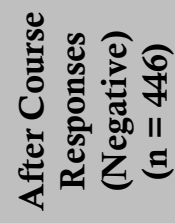 & & ㅇำ & \multicolumn{2}{|l|}{ ஸे } & \multicolumn{2}{|c|}{$\stackrel{\circ}{\infty}$} & \multicolumn{2}{|r|}{$\infty_{\infty}^{\circ}$} \\
\hline 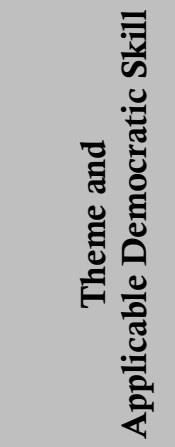 & & 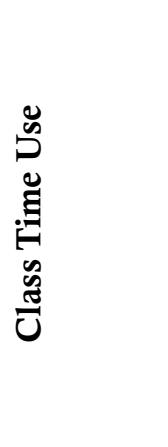 & \multicolumn{2}{|c|}{ 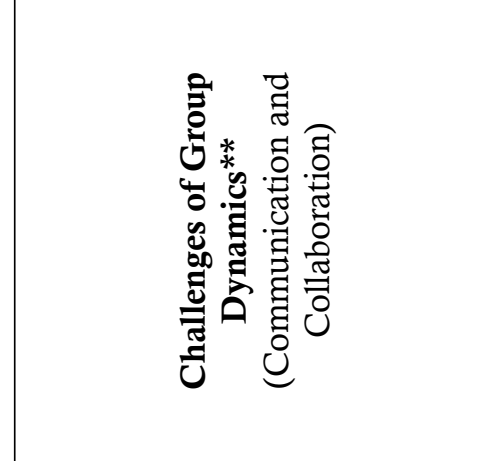 } & & & \multicolumn{2}{|c|}{ 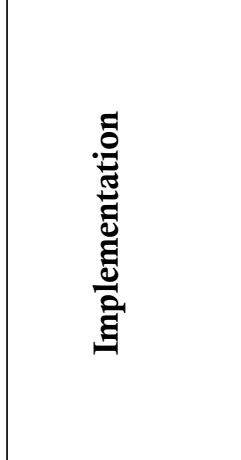 } \\
\hline
\end{tabular}




\section{Students' Perceptions of DD a Year Later}

A year later, 95 students responded to our survey $(\mathrm{n}=63$ majors; $\mathrm{n}=32$ non-majors, $14 \%$ response rate). Of those, a total of $98 \%(n=93)$ answered the question regarding what was memorable about $\mathrm{DD}$, and $96 \%(\mathrm{n}=91)$ answered the prompt regarding what they remembered as frustrating about DD. In total, $79(83 \%)$ of respondents answered both questions. We report the themes as explained previously. Table 2.2 describes the salient themes of memorable perceptions. A new theme arose ("New Perspectives"), while the theme "Valuable" was dropped during open-coding. Table 2.3 describes the salient themes of frustrating perceptions. Two themes of the memorable and three of the frustrating perceptions did not align explicitly with any of the democratic skills outcomes.

\section{Positive and Memorable Perceptions by Course Type}

Pearson's Chi Square tests indicated significant differences between the majors and non-majors courses in 3 of 6 themes for positive (memorable) perceptions (Figure 2.1). Descriptions of each theme can be seen in Table 2.2. 

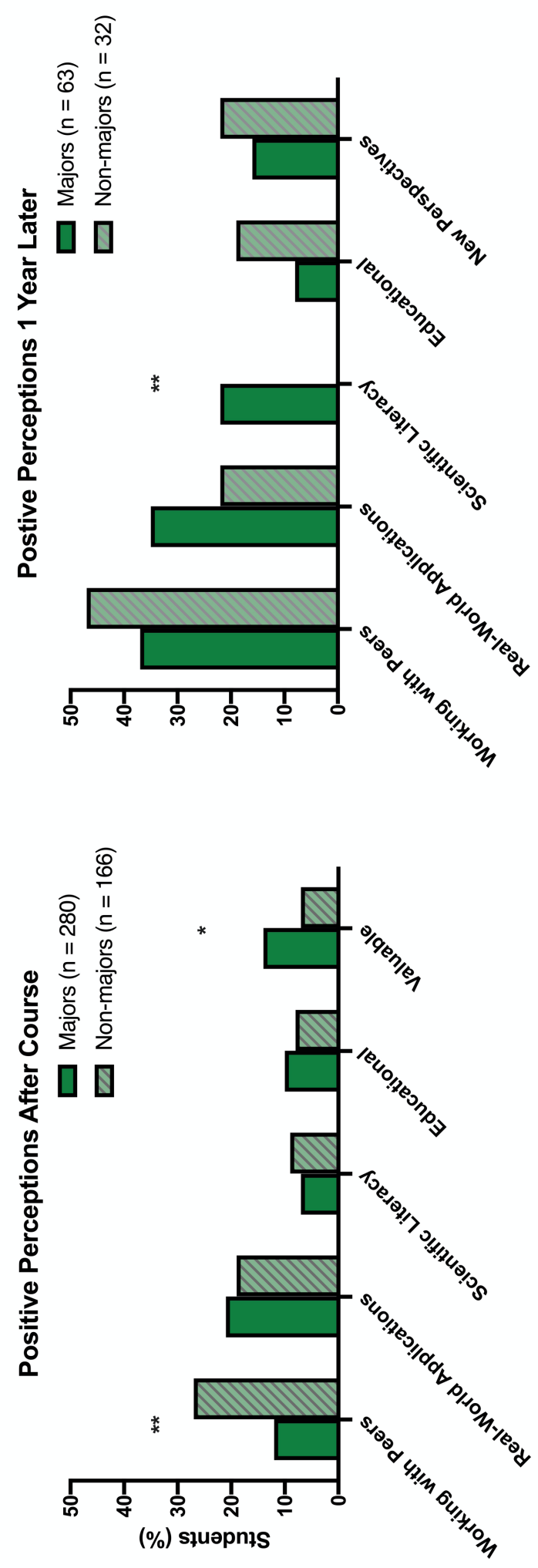
Figure 2.1 Changes in students' positive and memorable perceptions by course-type. Significant differences among responses by course, Chi-sq., Pearson Correlation test of significance * indicates $p \leq 0.05$; ** indicates $p \leq 0.0001$. Note: many students had responses that fell into more than one theme.

Negative and Frustrating Perceptions by Course Type

Pearson's Chi Square tests indicated significant differences between majors and nonmajors courses in 3 of 4 themes for negative perceptions (Figure 2.2). Descriptions of each theme can be seen in Table 2.3. 

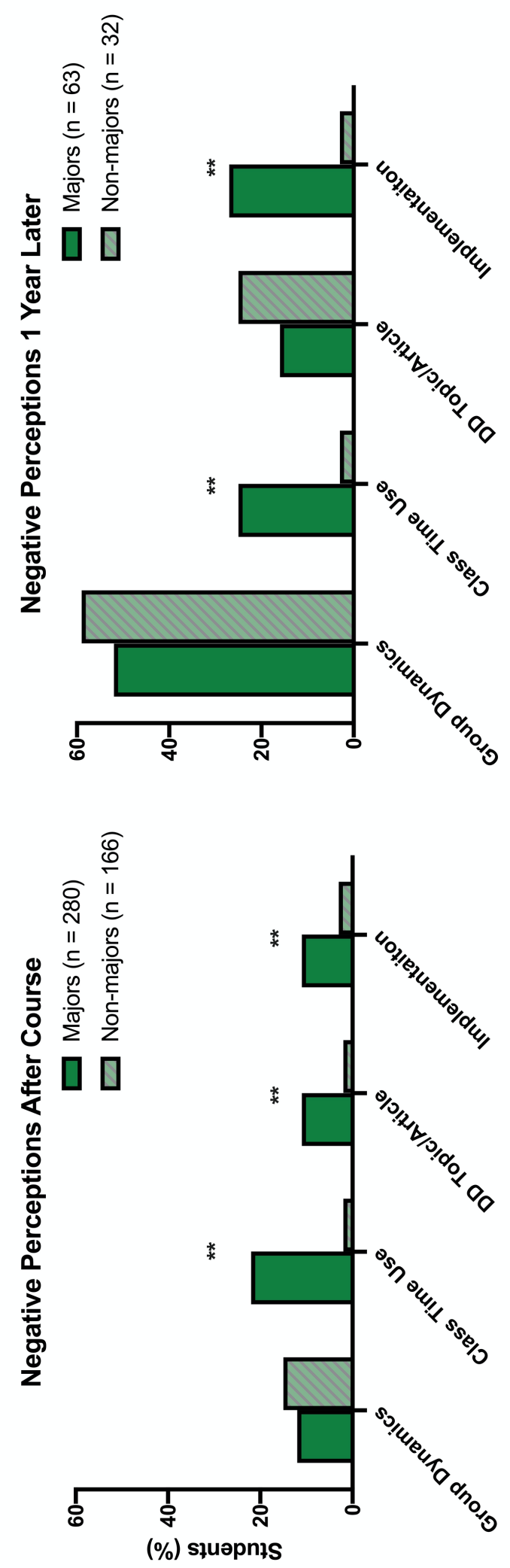

Figure 2.2 Changes in students' negative and frustrating perceptions by course-type. Significant differences among 
responses by course, Chi-sq., Pearson Correlation test of significance ** indicates $p \leq 0.0001$. Note: many students had responses that fell into more than one theme.

Student Interviews

We conducted semi-structured interviews with students ( $\mathrm{n}=19$ total; $\mathrm{n}=13$ majors; $\mathrm{n}=6$ non-majors). Themes and example quotes can be found in Table 2.4. 
Table 2.4 Student interview $(n=19)$ responses reflected the salient themes from the survey responses of perceptions of $D D$ (refer to Tables 2.2 and 2.3 for theme descriptors).

\begin{tabular}{|c|c|}
\hline $\begin{array}{c}\text { Theme and } \\
\text { Applicable } \\
\text { Democratic Skill }\end{array}$ & Example Quotes \\
\hline $\begin{array}{l}\text { Working with } \\
\text { Peers } \\
\text { (Communication } \\
\text { and } \\
\text { Collaboration) }\end{array}$ & $\begin{array}{c}\text { "It [DD] was interesting. The classes were really large, so a lot of people had different } \\
\text { thoughts about it. And we all came from different backgrounds which was also interesting } \\
\text { because it was a non-majors course. So, we definitely didn't have the same way of } \\
\text { thinking about things." } \\
\text { (Non-Majors) } \\
\text { "There was one group where we all started, none of us understood much of anything. So, } \\
\text { when we started going through the questions and then going back through the article, we } \\
\text { were all just back and forth-everyone going around—and then we all finally figured it } \\
\text { out. And it was just fantastic."(Majors) }\end{array}$ \\
\hline $\begin{array}{l}\text { Challenges of } \\
\text { Group Dynamics } \\
\text { (Communication } \\
\text { and } \\
\text { Collaboration) }\end{array}$ & $\begin{array}{c}\text { "A lot of the time people not being accountable for their own work and the discussions } \\
\text { sometimes falling flat because people weren't engaging well... you didn't do the work and } \\
\text { now this [worksheet] becomes more of a burden on two people in the group rather than } \\
\text { four."(Non-Majors) } \\
\text { "There's always going to be some people who aren't contributing as much, and that may } \\
\text { be frustrating...contributing as in they're just not really trying very hard. They bring } \\
\text { back sources that aren't good for your second day when you're trying to craft your policy } \\
\text { statement..."(Majors) }\end{array}$ \\
\hline $\begin{array}{c}\text { Scientific } \\
\text { Literacy } \\
\text { (Application of } \\
\text { Information) }\end{array}$ & $\begin{array}{l}\text { "DD has helped because it has introduced you to understanding, even if you don't } \\
\text { understand, specifically all the language used in the research article-I can kind of get the } \\
\text { overall idea and can use the abstract to help me navigate. I can always look up terms, so I } \\
\text { can at least, if not fully, understand it - the main idea is so great!" (Non-Majors) } \\
\\
\text { "...it [DD] totally showed me how to do it [literature search] and I didn't even know the } \\
\text { format of scientific papers - so for us as we go through these sections on "how you write it } \\
\text { and how it is read", it makes a lot more sense. Now I can understand."(Majors) }\end{array}$ \\
\hline $\begin{array}{c}\text { New } \\
\text { Perspectives }\end{array}$ & $\begin{array}{l}\text { "People would like to express opinions that I had never heard before, that I didn't share } \\
\text { with them. And so just having a discussion with someone that I didn't agree with is } \\
\text { exposure to just an idea-even if it's not something I agreed with-it was an exchange of } \\
\text { information." (Non-Majors) } \\
\text { "It [DD] was good. It was definitely eye opening because we had a problem, had to try to } \\
\text { come up with our own solutions -which is how science works - so it was like a very real- } \\
\text { real example... made the class less like a class and more of like an experience." (Non- } \\
\text { Majors) } \\
\text { "...I think by the end of the class period, there was a short moment of "well, I can see how } \\
\text { this added value for the world as a whole going forward", now there's } 200 \text { people who } \\
\text { have experienced this [DD] and clearly thought that fertilizer had no point other than to } \\
\text { create algae blooms or something." (Majors) } \\
\text { "That one [EDCs DD] definitely made me far more aware: what we actually consume } \\
\text { and how that affects us." (Maiors) }\end{array}$ \\
\hline
\end{tabular}




\section{Discussion}

Here we examined how students perceived a deliberative pedagogy and if student perceptions of the pedagogy persisted and/or shifted over time. The intention of DD modules was to facilitate students working on important democratic skills including: communication, collaboration, and application of information (Thomas, 2010). We found that students were, without specific prompting, reflecting on the intended outcomes of DD after the course, both immediately, and one year later. With these data, we can understand the most salient aspects of a students' experiences in a DD activity. Moreover, students self-reported that they gained a new awareness of, or perspectives on, big, real-world problems.

Many students will continue on to careers and/or engage in civic activities that will require them to work and interact in a collaborative setting. Our study shows that students working with their peers is a key aspect of DD. Many students reflected positively on gaining the opportunity to discuss and collaborate with other students with various perspectives (see Tables 2.2 and 2.4). Jones et al.'s study (2014) made a similar finding about the appreciation for working with peers. We were not surprised to find that challenges of group dynamics was a top negative theme with many responses describing how other students did not contribute to group efforts (see Tables 2.3 and 2.4). Equal contribution of group members has been found to be an important aspect of group learning (i.e., Chang and Brickman, 2018; Livingstone and Lynch, 2000). Although this is a reported negative aspect of $\mathrm{DD}$, it is not necessarily due to the modules, but because of group dynamics itself - which could be an unavoidable 
aspect in some group learning settings, and important for instructors to consider, especially as it relates to students having equitable conversations (Tanner et al., 2003).

Most undergraduates have little experience reading and using scientific literature, although it may be a crucial skill for their future endeavors (Janick-Buckner, 1997; Rehorek and Dafoe, 2018). Both majors and nonmajors found the article and literature search components could be positive aspects of DD. For example, students spoke of reading and dissecting peer-reviewed literature (see Tables 2.2 and 2.4). Although, a year later only the majors students continued to mention this, there is evidence that DD has created a positive association of the scientific literature for some of our students. We believe this outcome could be a product of the one-day versus two-day DD module design, as the majors course did the two-day modules during Winter and Spring terms. Encouragingly, DD can present an avenue by which to engage students with peer-reviewed literature.

Additionally, we found that DD is a platform for students to collaborate and apply the course content to the real-world, even in a large classroom. Evidence of this is clear when students describe gaining an awareness and/or new or changed perspectives on science and society. We did not explicitly expect this outcome, but it is salient to some students as described here:

"...I always thought it was absolutely absurd not to get vaccinated. But looking at that, getting more perspective on why people don't, I still do vaccinate but being able to understand the other side instead of just shooting it down was definitely huge." 
Implementing DD in biology can help students see how course content applies to their own lives, as well as gain an appreciation of other people's perspectives. We imagine that this outcome extends beyond the classroom and will affect their future life choices.

\section{Suggestions for Instructor Implementation}

We found that closely aligning the DD topic to the course content may lead to a more successful module. Our study shows that students care about how their time is being spent in the classroom, especially the majors biology students. If instructors align course content and include DD material on exams, students may have an increased appreciation and use for DD modules.

Challenges of group work dynamics may be difficult to remedy but are part of the real-world. Addressing the importance of collaboration in your class from the beginning, especially as students enter the workforce (WEF, 2016), may help increase student buy-in. Further, assigning student roles may encourage equitable participation, however support from instructors or LAs is important for these roles to be used to their fullest (Chang and Brickman, 2018).

\section{Limitations of the Study}

It is important to note that these data are self-reported and thus can be subject to both inflation and/or understating students' actual experiences (Bowman, 2011), however our findings show repeated salient themes in our study. We would like to also note that course-specific differences may be due to different implementation styles (e.g., 
one- versus two-day module types). We did not control for this aspect in our study. Further, these data may not be representative of biology students at other institutions.

\section{Conclusion}

We found that students' perceptions of DD were generally positive, with room for improvements in implementation. The perceived outcomes largely aligned well with the intended goals of deliberative pedagogy, as well as national calls for students to understand the relationship between science and society. The study design allowed us to identify that there are long-term perceptions of $\mathrm{DD}$ which students retain over the course of a year. Particularly salient were students reports of how working in groups can have memorable positive and negative effects. Using brief, policy-oriented DD modules in introductory biology presents a mechanism to encourage active learning and increase communication, collaboration, and application skills. 
Table 2.5 (supplemental) List of DD Topics used by non-majors and majors biology courses in 2016/2017.

\begin{tabular}{|c|c|c|c|}
\hline Course & Course Content & DD Topic & Real-world Problem/Question \\
\hline \multirow{9}{*}{$\begin{array}{l}\text { Non- } \\
\text { Majors } \\
\text { Biology }\end{array}$} & $\begin{array}{l}\text { Cellular } \\
\text { Respiration }\end{array}$ & $\begin{array}{l}\text { High Fructose Corn } \\
\text { Syrup (HFCS) versus } \\
\text { Sugar }\end{array}$ & $\begin{array}{l}\text { Is HFCS unhealthy enough to warrant } \\
\text { government regulation? }\end{array}$ \\
\hline & $\begin{array}{l}\text { Patterns of } \\
\text { Inheritance }\end{array}$ & $\begin{array}{l}\text { Genetic Testing \& } \\
\text { Privacy }\end{array}$ & $\begin{array}{l}\text { How much \& what type of control the } \\
\text { government should have over genetic } \\
\text { testing? }\end{array}$ \\
\hline & $\begin{array}{c}\text { DNA } \\
\text { Technology }\end{array}$ & $\begin{array}{c}\text { Zika Virus \& } \\
\text { Genetically Modified } \\
\text { Mosquitos }\end{array}$ & $\begin{array}{l}\text { Should genetically modified mosquitos be } \\
\text { used to combat the Zika virus epidemic? }\end{array}$ \\
\hline & Body Defenses & Vaccines & $\begin{array}{l}\text { Should protection of public health or } \\
\text { personal freedom be of higher priority to } \\
\text { the government? }\end{array}$ \\
\hline & $\begin{array}{c}\text { Reproduction \& } \\
\text { Development }\end{array}$ & $\begin{array}{l}\text { In Vitro Fertilization } \\
\text { (IVF) }\end{array}$ & Ethics of IVF \\
\hline & Ecology & Environmental Policy & Economy versus environment costs/ethics \\
\hline & \multirow[t]{2}{*}{ Evolution } & Antibiotic Resistance & $\begin{array}{l}\text { What are the roles and responsibilities } \\
\text { of the government in regulating the use of } \\
\text { antibiotics in patient care and in } \\
\text { agriculture? }\end{array}$ \\
\hline & & Evolution \& Diversity & $\begin{array}{l}\text { What are the roles and responsibilities } \\
\text { of the government in regulating factors } \\
\text { which affect biodiversity? }\end{array}$ \\
\hline & Angiosperms & Pesticides & $\begin{array}{l}\text { What are the roles and responsibilities } \\
\text { of the government in regulating the use of } \\
\text { fertilizers and pesticides? }\end{array}$ \\
\hline \multirow{5}{*}{$\begin{array}{l}\text { Majors } \\
\text { Biology }\end{array}$} & $\begin{array}{l}\text { Cellular } \\
\text { Respiration }\end{array}$ & $\begin{array}{l}\text { High Fructose Corn } \\
\text { Syrup versus Sugar }\end{array}$ & $\begin{array}{l}\text { Is HFCS unhealthy enough to warrant } \\
\text { government regulation? }\end{array}$ \\
\hline & Cell Cycle & Hela Cells & $\begin{array}{l}\text { Ethics and privacy around using human } \\
\text { samples }\end{array}$ \\
\hline & Biotechnology & $\begin{array}{l}\text { Genetic Engineering } \\
\text { (CRISPR Cas-9) }\end{array}$ & Ethics of using gene editing on humans \\
\hline & $\begin{array}{c}\text { Population } \\
\text { Evolution }\end{array}$ & $\begin{array}{l}\text { Salmon Populations } \\
\text { (Farmed versus Wild) }\end{array}$ & $\begin{array}{c}\text { Should state and federal agencies continue } \\
\text { to supplement wild salmon populations } \\
\text { with hatchery-reared salmon? }\end{array}$ \\
\hline & Gas Exchange & Coastal Dead Zones & $\begin{array}{l}\text { What policies/regulations should be } \\
\text { put in place to decrease the occurrence of } \\
\text { coastal dead zones? }\end{array}$ \\
\hline
\end{tabular}




\begin{tabular}{|c|c|c|c|}
\hline & $\begin{array}{c}\text { Chemical } \\
\text { Signaling }\end{array}$ & $\begin{array}{c}\text { Endocrine Disrupting } \\
\text { Chemicals (EDC) }\end{array}$ & $\begin{array}{c}\text { Should there be regulation on cosmetics } \\
\text { that contain EDCs? }\end{array}$ \\
\hline
\end{tabular}

CHAPTER 3: To Implement or Not to Implement? Investigation of a Deliberative Pedagogy's Impacts on Introductory Biology and Chemistry Course Students

\section{Abstract}

There have been multiple national calls for curricular reform in higher education science, technology, engineering, and mathematics (STEM), including a need to instill democratic skills in students. Democratic skill building can be embedded in STEM classrooms through intentional "deliberative pedagogies" which include: communication, collaboration, and application. We developed and implemented a deliberative pedagogy, Deliberative Democracy (DD), across introductory majors STEM courses and took a longitudinal, qualitative, research approach to understand our students' experiences and perceptions of DD. We tracked a cohort of both introductory biology and chemistry students over one academic year (2017-18). Via online surveys, we asked students to respond to open-ended prompts about their experiences and perceptions of DD modules used in their courses. These prompts asked students to reflect on their beliefs on why their instructor chose to use DD in their class, the applications of science to the real-world, and their confidence in application of science and communication with their peers. The top two reasons 
students believed their instructor was using DD was 1) to introduce real-world applications of science-especially if it was tied to course content and 2) to build community in the classroom with peer interaction and discussions. Overall, students reported that DD had positively impacted their views of real-world applications and had increased their scientific literacy plus other important skills. DD was described by many students as an opportunity to build their own discourse skills, an experience otherwise not usually provided during an introductory STEM lecture course. Furthermore, we wanted to examine what led to a successful DD module being implemented. We found that the course content and real-world problem presented must be closely aligned. Also, providing the students a chance to have an open forum to talk about these problems during class in small groups and as a collective has positive impacts on students' DD experiences. Evidence suggests that our strategy of a DP module development and implementation can be easily adopted by other instructors in their own introductory STEM courses. 


\section{Introduction}

There is a great amount of time and effort being put forth to reform STEM higher education in order to meet the national calls for engaging and retaining students (National Research Council, 2003; President's Council of Advisors on Science and Technology (PCAST), 2012). Given that we are educating members of society, it is equally important to engage students not just with STEM content, but also with democratic and civic skills. It is thought that younger generations have fewer opportunities to participate in civic activities (Thomas, 2010). Furthermore, in higher education biology, Vision and Change (2009) prescribes that students understanding the relationship between science and society is a core competency. Instilling "democratic skills and culture" into higher education has been a key goal for many:

(e.g. CIRCLE, 2010; Colby and Sullivan, 2009; Association of American Colleges and Universities, 2007; Kirlin, 2003). For example, Thomas (2010) summarized these multiple calls into three essential democratic skills that college students should obtain. For this research, I have deemed these skills as communication, collaboration, and application. 
1. Communication: Effective communication skills (written and oral) in a variety of contexts and among diverse groups of people.

2. Collaboration: Effective dialogue, deliberation, public reasoning, and collaborative decision-making skills.

3. Application: Competent understanding and critical analysis of knowledge and information.

One way to integrate these important skills into a college classroom is to employ a "deliberative pedagogy" (DP). DP has been described as a "democratic educational process and a way of thinking that encourages students to encounter and consider multiple perspectives, weigh trade-offs and tensions, and move towards action through informed judgment" (Shaffer et al., 2017). K-12 instructors have been using DP in their classrooms to attempt to engage students with discourse, civility, and policy making (e.g. Luskin et al., 2007; Alfaro 2008). DP activities are beginning to be used and researched in STEM higher education (Jones et al, 2014; Drury, 2015; Weasel and Finkel, 2016; Komperda et al., 2018; Shortlidge et al., 2018). The first example is a DP activity revolving around nanotechnology used at the University of WisconsinMadison (Jones et al., 2014). A goal of the activity was to engage the public with introductory non-majors chemistry students to bring an improved understanding of nanotechnology. During the activity, people from the public and students joined in small groups and deliberated on a hypothetical nanotechnology project. The groups needed to come to consensus on a research project. Jones et al. (2014) found that participants showed an increase in nanotechnology knowledge after the activity. Moreover, the students showed an increase interest in nanotechnology. The 
participants also described that they appreciated the opportunity to have a real-world discussion with others. In another example of a DP used in a non-majors biology course, students deliberated about global climate change in a two-day activity (Drury, 2015). With the use of pre- and post-deliberation surveys, the researchers found that having a DP in their non-majors course gave students an opportunity to cultivate communication skills, consider real-world problems, and use critical thinking.

Both of the previous examples were conducted as single DP activities integrated into STEM courses for nonscience majors. At Portland State University, a specific DP called "Deliberative Democracy" (DD) was developed to transform a large ( 200 students) introductory non-majors biology course (Weasel and Finkel, 2016). Unlike the previous examples, the entire course was reorganized around the DD activities over a 10-week course. Deliberation topics included: regulation of sizes of soft drinks, genetic testing, and genetically modified organisms. A key component of DD was students were expected to find supporting literature through their own research, to bring to class during their deliberations. Weasel and Finkel (2016) intentionally designed the DD modules to engage students with reading and evaluating sources of scientific information. Each DD module was designed as a two-day activity. The first day's class period is utilized to introduce the topic, form small groups, form an initial stance on the topic as a group, and determine what information was to be researched to form a final consensus. On the second day of the module, students return to their small groups with the information they collected and continue their deliberation until they reach their final consensus. Weasel and Finkel (2016) found that the DD modules had increased students' course content knowledge as well as the DD topics, especially 
from the media readings. Students also reported on receiving the opportunity to develop skills to read/evaluate scientific literature during their course.

The success of DD modules in this introductory non-majors biology course at PSU led to an expanded, HHMI-funded initiative to develop and implement DD modules for PSU majors biology, chemistry, and physics courses. Goals of this initiative included engaging and retaining STEM students, but also providing students the opportunity to gain important democratic skills such as communication, collaboration, and application of information.

To prepare for implementing DD modules in our large, introductory STEM courses, summer workshops were held that included both instructors and graduate teaching assistants. During the workshops, participants learned more about DD modules, including: intended outcomes of $\mathrm{DD}$, how to facilitate deliberations, and how to connect modules to specific course content. They were allotted the tie time to brainstorm potential topics that would work well in their specific courses. After the workshop, the graduate teaching assistants met weekly to develop DD module materials for the courses including: lecture presentations, reading quizzes, reading materials, and worksheets. All materials were reviewed and edited by the course instructors.

An additional goal to developing and employing the DD modules in our introductory STEM courses, we wanted to prepare each module as a shareable "unit" that could be distributed to other instructors and institutions. The success of these propagation efforts rely on understanding how DD activities are impacting students. I took a qualitative approach to study the impacts of DD on students in majors 
introductory biology and chemistry courses. To identify how DD is impacting students, I asked them directly about their perceptions of DD. Here I explore the following research questions:

1. Why do students believe that their instructors use DD activities in the classroom?

2. What do students perceive they gain from participating in DD activities, and does this differ among course-types?

3. How can we use these data to make recommendations for broader implementation of DD modules? 


\section{Methods}

\section{Institutional Context}

This study was conducted at Portland State University (PSU), a large, commuter university located in downtown Portland, Oregon. PSU serves approximately 28,000 students. The average student age is 27 years old; the majority are transfer students and are Pell eligible. (Snapshot of PSU, 2019).

\section{Courses Surveyed}

The STEM courses included in this study were surveyed across the 2017-18 academic year: one section of a 200-level introductory biology (for science majors) course (BI $211,212,213$ ) and two sections of a 200-level introductory chemistry (for science majors) course ( $\mathrm{CH} 221,222,223)$ each term (Fall, Winter, and Spring). The biology course section had a different instructor each term. The two chemistry sections had two different instructors who each taught their section for the entire year. The biology course was held Monday, Wednesday, and Friday mornings for 65-minute lectures. 
One section of Chemistry was held Monday, Wednesday, and Friday mornings for 65-minute lectures, and the other section was Tuesday and Thursday mornings for 110-minute lectures. Both courses and all sections implemented the deliberative groupwork activity called "Deliberative Democracy", (DD) (Weasel \& Finkel, 2016; Komperda et al., 2018; Shortlidge et al., 2018).

\section{Survey and Survey Open-ended Item Development}

To collect data for this research, I asked four open-ended prompts at the end of a larger post-course survey that was disseminated across all introductory PSU STEM courses during the last week of each term during the academic year. A representative from the research team visited each class with an IRB-approved recruitment announcement to inform the students about the survey. All instructors offered extra credit points to students who accessed the survey. The survey was administered online via Qualtrics software and the survey link was emailed to students by the research team. Student demographics were also collected during the survey and included: gender, race/ethnicity, age, major, university status (post-baccalaureate or undergraduate), and transfer status (if student had transferred to PSU from a two-year college). Students also self-reported the number of DD activities that they had participated in each class. Students who had consented for their information and data to be used in this research are represented in this study. This study was approved by PSU's IRB (\#153524).

To begin to understand qualitatively student perceptions of DD, I developed four open-ended prompts. The original wording of the prompts were as follows: 
1) Why do you believe your instructor chose to use Deliberative Democracy in this course?

2) Have the Deliberative Democracy activities in this class influenced how you view the applications of science? Please explain why or why not.

3) Have the Deliberative Democracy activities in this class had an effect on your confidence using your scientific knowledge beyond the coursework (e.g., quizzes, homework, or exams)? Please explain why or why not.

4) Have the Deliberative Democracy activities in this class had an effect on your confidence communicating about scientific topics with your peers? Please explain why or why not.

During the first round of coding student responses (Fall 2018), I found that a small subset of students were not answering three of the four prompts clearly or as intended, indicating that in order to collect valid data from as many students a possible, I needed to revise the prompts. For example, the third question had the phrase "beyond the course" and students did not understand the intent of it, as they answered the prompt in regard to their course. The first prompt was functioning as intended, but items 2-4 were iteratively revised by the research team in the Winter and Spring resulting in the following revised prompts:

1) Why do you believe your instructor chose to use Deliberative Democracy in this course?

2) How did participating in the Deliberative Democracy activities in this class impact your thinking regarding the role of science as it applies to real world problems? Please explain. 
3) How did participating in DD in this class impact your confidence in applying scientific knowledge to real world problems? Please explain.

4) How did participating in the Deliberative Democracy activities in this class impact your confidence in communicating scientific topics with your peers? Please explain.

\section{Survey Data Analysis}

Content analysis was used to identify emergent themes from student responses to each open-ended prompt individually. Responses from participants that were ambiguous or illustrated that they did not interpret the question as intended (mostly from Fall) were dropped from the analysis. Two researchers independently analyzed and noted all perceptions arising from the student responses. The researchers reconvened and discussed all emergent themes then worked to group similar themes together, collapsing redundant themes as needed. This led to an initial coding rubric which was used by two researchers to complete initial coding of a sub-set (20\%) of student responses $(\mathrm{n} \sim 150)$. The coding rubric was iteratively developed into a final coding rubric. To assess reliability and objectivity in the coding of responses, we performed inter- rater reliability via Cohen's Kappa until we reached a value of 0.61 or greater (substantial agreement) (Cohen, 1960). One researcher completed coding the rest of the student responses while remaining in contact with the other researcher for questions and/or new themes. Codes were divided into either positive, negative or neutral. Once coding was completed, we summed the number of codes that fell into 
our final theme categories and expressed them as a percentage out of participants (students). I will discuss student perceptions of DD by term as each term as there were course-level context specific factors to be considered including different instructors in biology. I collapsed the two chemistry sections into one 'chemistry' course as the curriculum did not differ, average final grades were similar, and I found no significant differences among the sections.

\section{Course Observations}

Video and audio recordings of DD activity lectures were captured digitally via Echo 360. Consent for recording was gathered from instructors, teaching assistants, and students. I observed recordings and noted similarities and differences across the two disciplines and among courses, including: who implemented modules (instructor, teaching assistant), length of modules, presentation/lecture used, etc.

\section{Statistical Analysis}

Pearson's Chi Square tests were used when comparing two groups (contingency analyses). Significance was indicated by Pearson's Correlation coefficient. All reported significance was determined by $p$-values $\leq 0.05$. Statistical analyses were performed on statistical software (SAS JMP Pro, 2012, Cary, NC). 


\section{Results and Discussion}

Here I will report results and discussion by academic term.

\section{Implementation Across Courses}

Both biology and chemistry utilized ideas and materials created during a graduate student-led summer DD workshop. These materials include short PowerPoint presentations with a consistent layout, and are meant to guide students to successful deliberation and to follow the worksheets. DD presentations used similar language and style (i.e., deliberation: "a long and careful consideration or discussion"). Learning Assistants (LAs) were present during all courses' DD activities and during chemistry's Process Oriented Guided Inquiry Learning (POGIL) activities. LAs are undergraduate or postbaccalaureate students who had successfully completed the series and returned to serve as peer-leaders during group-work activities. All DD topics had a human-health related focus. Each course utilizes student response polling to gauge student understanding during activities and lecture. 


\section{Fall 2017 Implementation}

There was variation in DD implementation across the biology and chemistry courses in the Fall term (Table 3.1). In biology, the DD topics covered were 1) metabolic differences between high fructose corn syrup and sucrose, 2) personalized medicine, and 3) CRSPR-Cas9 and its potential use for altering embryo genes. In Chemistry, the topic was on chemicals found in sunscreen and how they are connected to the electromagnetic spectrum. There were a few key differences in implementation of DD across the biology and chemistry courses. The biology course had three one-day activities during the term and chemistry had a single two-day activity. The biology course's activity had a corresponding worksheet with guiding questions for students to answer based on the media and peer-reviewed article readings. Chemistry utilized the two-day module which has a corresponding worksheet for each session, each with open-ended questions for students to answer based on their brainstorming, research findings, and their small-group's final consensus. Instructors were present for all activities; however, their participation level was different across courses. In biology, the instructor was the leader of the activity with support from the teaching assistant whereas in chemistry, a graduate research assistant would attend and lead the DD activity days. DD activities were worth different amounts of the final grades, and were graded differently. In biology, worksheets were graded based on attendance/completeness and in chemistry they were graded based on quality of answers on worksheets. Other active learning strategies were utilized in both courses. Biology had in-class worksheets that the instructor provided in which students could 
complete alone or in small groups. Chemistry had weekly POGIL exercises. In both courses, these additional active learning exercises were not graded.

Table 3.1 Fall 2017 DD activity details for each course type.

\begin{tabular}{|c|c|c|}
\hline 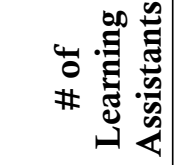 & $\simeq$ & $\begin{array}{l}\stackrel{0}{1} \\
1 \\
+1\end{array}$ \\
\hline 岂 & 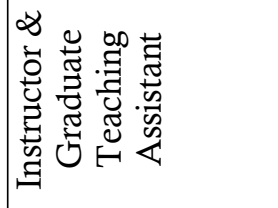 & 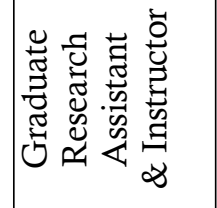 \\
\hline 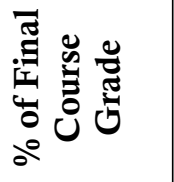 & ڤે̀ & லి \\
\hline 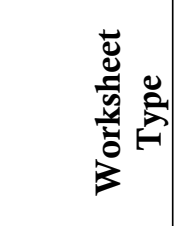 & 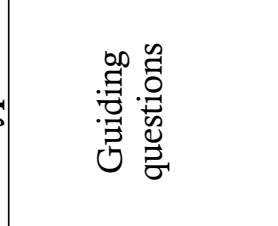 & 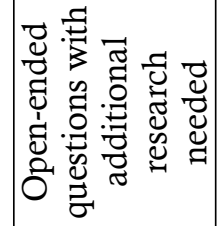 \\
\hline 莺 & 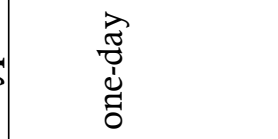 & 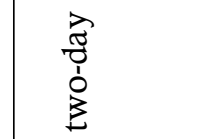 \\
\hline : & 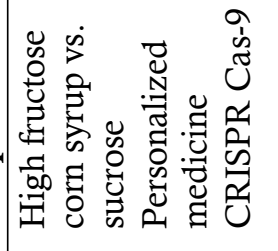 & 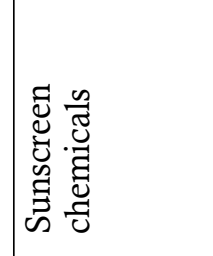 \\
\hline & $\bullet \quad \bullet \quad \bullet$ & • \\
\hline
\end{tabular}




\section{Fall 2017 Student Demographics}

In total, 648 individual students are represented in the Fall 2017 data set $(n=272$ biology; $\mathrm{n}=473$ chemistry). There were 97 students co-enrolled in biology and chemistry at the same time that responded to the survey. Therefore, overall the surveys were accessed 745 times in Fall 2017. I deemed a "usable response" as 1) the student consented to research and 2) they completed at least one of the four open-ended prompts. If a student's response did not seem to match the prompt's intent it was disregarded in the dataset. The surveys were designed to capture course-specific DD perceptions, so each usable response per course was counted as an individual data point

Table 3.2 describes the sample demographics of the Fall 2017 data set as follows: gender; race/ethnicity as either non-URM (white/Caucasian and Asian/Pacific Islander) or URM (African American/Black, Latino/a, Middle 
Eastern, Native American, and multiracial); university status as either undergraduate or postbaccalaureate, and their transfer status. Students ages were grouped together based on Choy's (2002) description of "traditional" age (18-22 years old) and "nontraditional" age (23+ years old). Student majors were grouped into four categories: Biology, Chemistry, other STEM (general science, engineering, computer science, environmental studies, geology, health/pre-health, mathematics, and physics), and Non-STEM (art, business, psychology, sociology, political science, geography, economics, and English).

The biology and chemistry courses used in this study had similar proportions of gender, race/ethnicity, and transfer status. The biology course had a higher percentage of biology majors (54\%) than the chemistry course (32\%). The chemistry course had a higher percentage of traditional age (18-22 years) students (72\%) and a lower percentage of non-traditional age (23+ years) students (28\%) than the biology course. This difference may be due to the biology course having a higher proportion of postbac students (14\%), as many of these students are taking biology as part of a pre-health track. 
Table 3.2 Fall 2017 sample demographics composed of 648 individual students.

\begin{tabular}{|c|c|c|c|c|c|}
\hline نे & \multicolumn{2}{|c|}{ గิ $\sim$ ลิ } & กิ & $\varnothing$ & ले \\
\hline 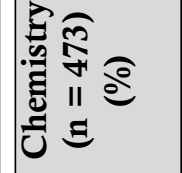 & \multicolumn{2}{|c|}{$\tilde{N} \cap g+\infty$} & $\varrho$ & 8 & లే \\
\hline 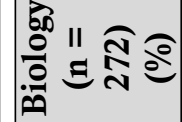 & \multicolumn{2}{|c|}{ 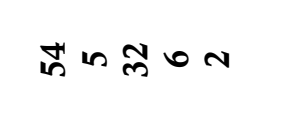 } & $\Xi$ & $\infty$ & ले \\
\hline Uू & \multicolumn{5}{|c|}{ 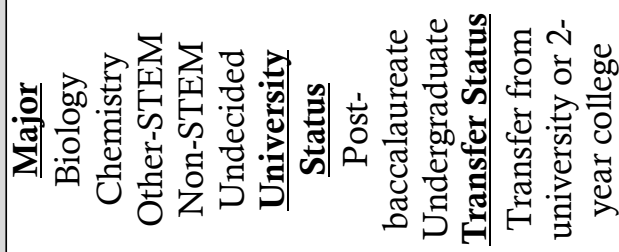 } \\
\hline 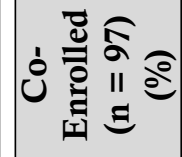 & țర & 88 & in & & 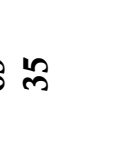 \\
\hline 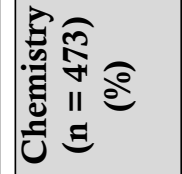 & in \& & $B:$ & $=$ & & $\stackrel{\infty}{\sim}$ \\
\hline 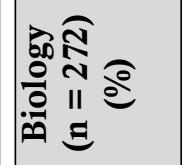 & in F- & oิ̀ & + & & 恶 \\
\hline
\end{tabular}




\section{Fall 2017 Student Perceptions of DD Activities}

\section{Reasons students believe their instructors are utilizing deliberations in their classrooms}

The first open-ended survey question addressed student perceptions as to why they believed their instructor was using DD in their class. I found that there were a fairly consistent set of factors contributing to student beliefs about the reasoning that instructors use DD activities (Table 3.3). Figure 3.1 illustrates the proportion of students that expressed statements that fell into the top themes (themes that comprise $>5 \%$ of total responses) across biology, chemistry, and disaggregated by course.

Table 3.3 Top themes and their definitions regarding "Why do you believe your instructor used Deliberative Democracy in this class?"

\begin{tabular}{|c|c|}
\hline Theme & Definition \\
\hline Community & DD was used to increase peer interactions and discussion \\
\hline
\end{tabular}




\begin{tabular}{|c|c|}
\hline Skills & DD was a platform to give students skills (i.e. critical thinking) \\
\hline Scientific Literacy & DD was a platform to introduce science literature to students \\
\hline Real-world Application & $\begin{array}{l}\text { DD was a platform to introduce real world applications of science } \\
\text { to students }\end{array}$ \\
\hline Mandatory & Student states that they believe that DD is mandatory for PSU \\
\hline Pedagogical & $\begin{array}{l}\text { Student states that they believe the instructor chose DD for } \\
\text { pedagogical reasons (i.e. group work, points) }\end{array}$ \\
\hline Don't Know & $\begin{array}{l}\text { Student states that they are not sure why the instructor chose this } \\
\text { strategy }\end{array}$ \\
\hline
\end{tabular}

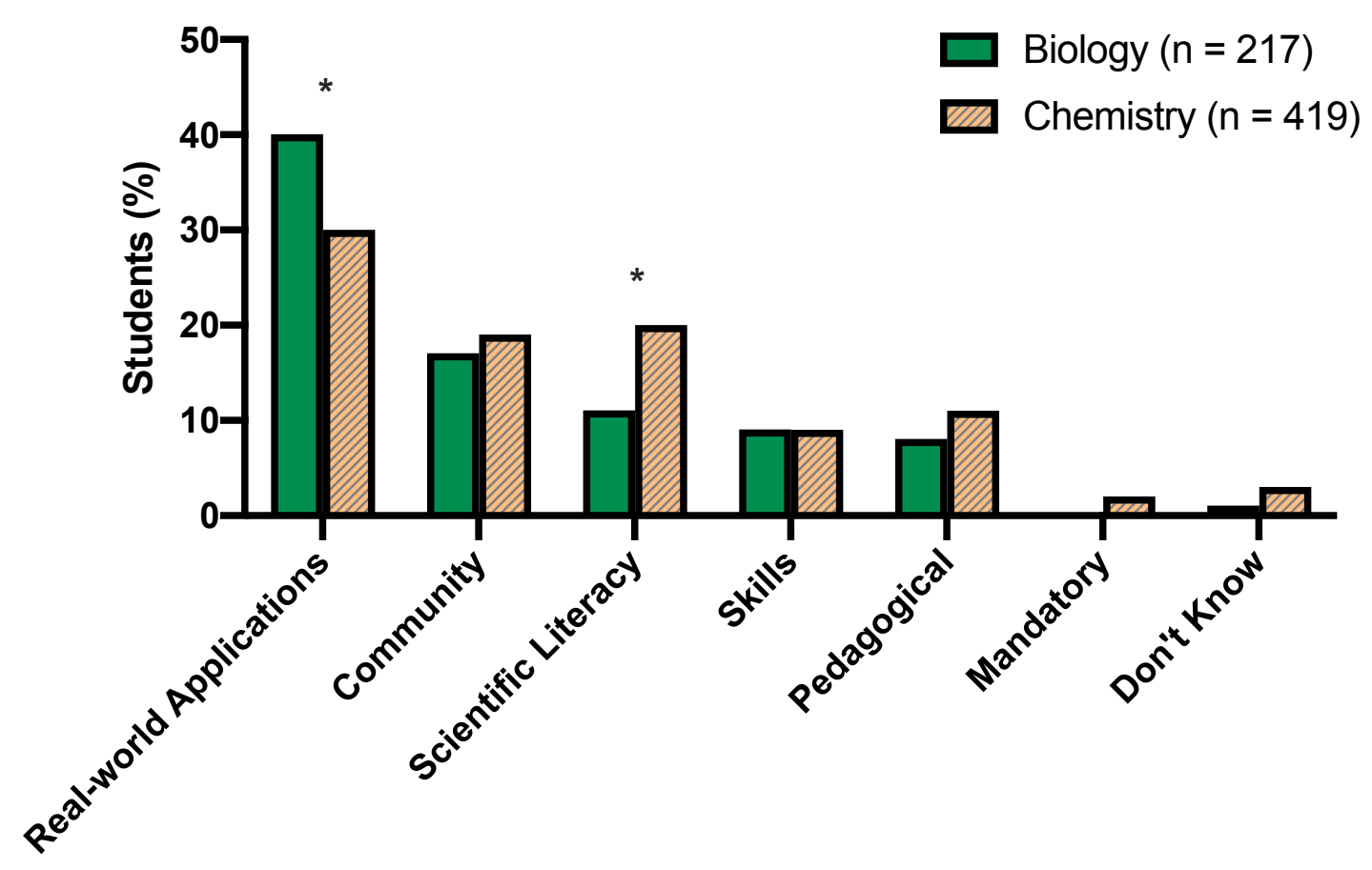

Figure 3.3 Top themes for Fall 2017 term for the prompt: "Why do you believe your instructor used Deliberative Democracy in this class?". 


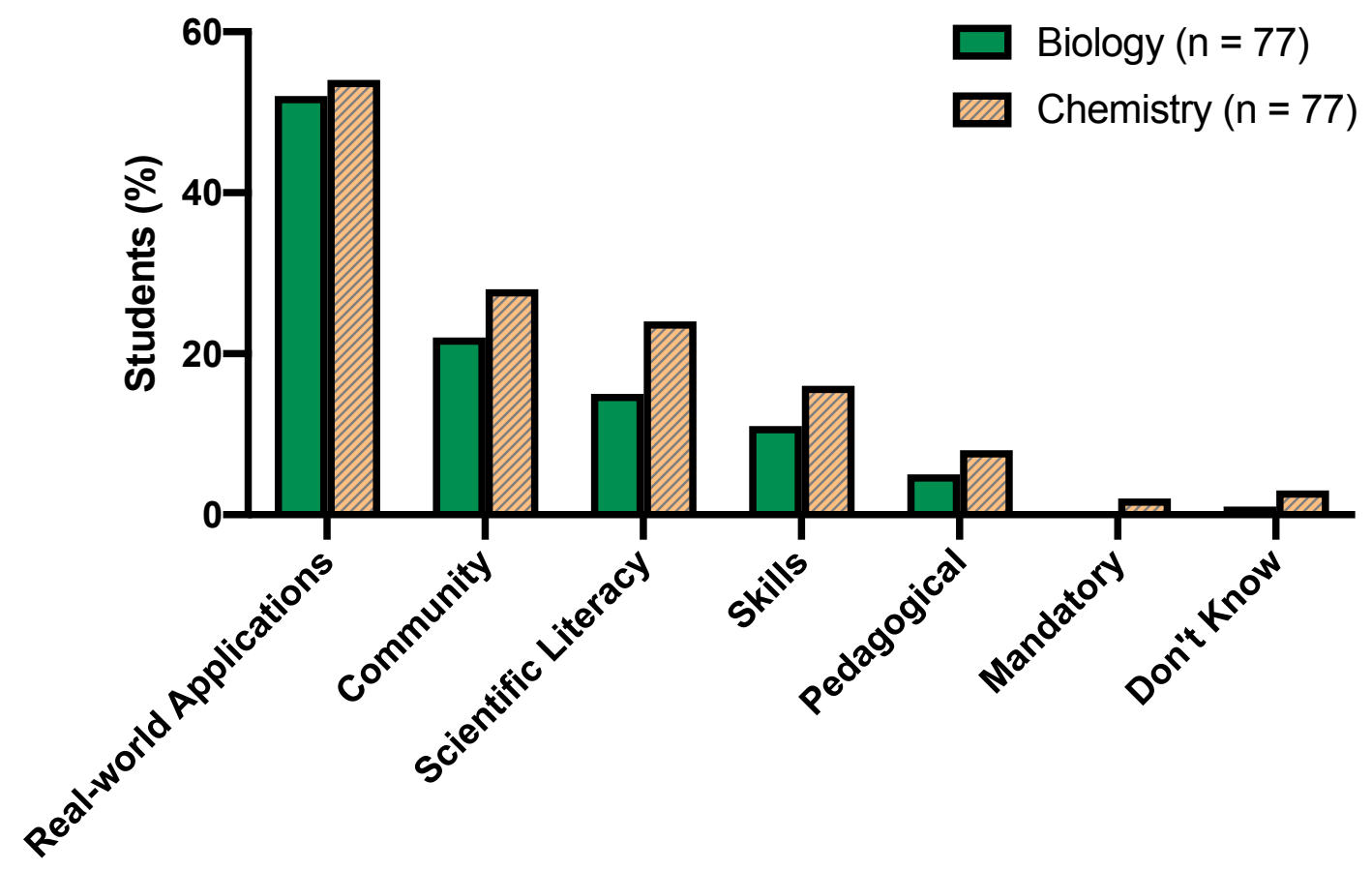

Figure 3.4 Top themes for Fall 2017 term for the prompt: "Why do you believe your instructor used Deliberative Democracy in this class?". Results are shown in only biology course and only chemistry course co-enrolled students (students who were taking the courses simultaneously).

The most salient theme in students' responses for why they thought instructors use DD activities in their class was to introduce "real-world applications" of the course content. Real-world applications are a key intention of DD modules. Though it is unsurprising that students are echoing the intent, it is reassuring that the intentions of DD are clear to students.

Example quotes portraying this theme:

"It's helpful to see real world applications of what we are learning in class." - Biology student " [DD is] to get us to think about broader implications for science and how science can affect policy decisions." - Chemistry student

The second most salient theme was that instructors were using DD to build/support their classroom "community". Here, students described examples of 
numerous opportunities to work with and have discussions with their peers-an opportunity which does not typically occur in large lecture halls.

"I believe the purpose of $D D$ is to give students a chance to get a break from lecture and be able to collaborate with other students on an important subject/topic in order to get to know the people in the course and hear different points of views." -Biology student

"[DD] encourages us to bounce ideas off of each other and work together to problem solve, which helps us have a better understanding of the material." -Chemistry student

During the DD discussions; the instructors, graduate assistants, and LAs walk around the room and join the student small groups during deliberations. One study found that LAs were a great support system to undergraduates, especially face-to-face time with peers during lecture time (Talbot et al., 2015). Other studies have found that instructors/assistants walking round the room during group work may be less important than the group work activity and worksheet itself (Weir et al 2019). I have yet to explore the specific impact of LAs in our classrooms.

Themes including "skills" and "scientific literacy" also arose from student responses regarding reasons why instructors may be using DD activities. The theme "skills" refers to a variety of skills students reported that DD helped them to develop (e.g., approaching research, critical thinking) and "scientific literacy" describes how students' found the searching for and reading/assessing of articles to be an outcome from their DD experiences. Many undergraduates have little experience practicing reading and using the scientific literature (Janick-Buckner, 1997; Rehorek and Dafoe, 2018), yet, I found that DD activities may present a way to get students interested in science, and to encourage them to engage with the scientific literature earlier in their STEM education than they might otherwise. For example, students reflected: 
"I think my professor chose to do DD in order to help us develop critically thinking skills as well as helping us understand scientific journals..." -Biology student

"[DD is] to demonstrate how the average student can find and use scientific information to come to a logical conclusion on a given subject..." -Chemistry student

Lastly, some students believed that instructors were using DD for reasons that were "pedagogical" and/or "mandatory". These were the least prevalent themes, but important to discuss as they are more neutral/negative views of why students believe their instructors are using DD activities. Pedagogical reasons were interesting because students were reflecting on their instructor's choice of teaching strategies, for example: "To mix it [the course] up a bit." - Biology student

"To break up lecturing all the time..." - Chemistry student

I detected two differences between the biology and the chemistry students in why they thought their instructors were using DD activities in their course: 1) introduce students to real-world applications and 2) DD activities were mandatory for the course. I noticed that students in the biology course had a higher proportion of real-world application reasoning than chemistry students. I hypothesize this may be due to the close alignment of DD activities to course content and implications for human health (see Table 3.1). The Chemistry DD module also had a human health component, but not as emphasized as the biology modules were. The majority of students in these courses are on a pre-health track, therefore this is not particularly surprising that they are interested in things that they may relate to. The idea of DD as a mandatory activity required by the university or other external mandate were only observed in the chemistry course responses. For example, this student explains: "I'm not sure why actually, maybe [the university] is requiring DD?" - Chemistry student 


\section{Fall 2017 - What Do Students Perceive They Are Gaining From DD Activities?}

I asked three additional open-ended survey questions that addressed student perceptions of: 1) how they view applying science to real-world problems, 2) their confidence in applying scientific knowledge to real-world problems, and 3) their confidence in communicating science to their peers. There were several consistent factors that students reflected on in response to each prompt, and many overarching themes reoccurred across the three survey responses (Table 3.4). Some students may have made statements that fell into more than one theme. Figures 3.3 and 3.4 illustrate the proportion of students that expressed statements that fell into the top themes (themes that comprise $>5 \%$ of total responses) across biology, chemistry, and disaggregated by course.

Table 3.4 Top themes and their definitions regarding 1) "How did participating in the DD activities in this class impact your thinking regarding the role of science as it applies to real-world problems?" 2) "How did participating in the DD activities in this class impact your confidence in applying scientific knowledge to real-world problems?" and 3) "How did participating in the DD activities in this class impact your confidence in communicating scientific topics with your peers?". Note that themes may repeat across responses from the different prompts.

\begin{tabular}{|c|c|}
\hline Theme & Definition \\
\hline Real World Example & $\begin{array}{c}\text { Student spoke of and/or provided real-world examples when } \\
\text { explaining their answer }\end{array}$ \\
\hline $\begin{array}{c}\text { Peer Interaction } \\
\text { Example }\end{array}$ & $\begin{array}{l}\text { Student gave examples of working with their peers during DD (i.e. } \\
\text { collaboration, discussion) }\end{array}$ \\
\hline Personal Impact & $\begin{array}{c}\text { Student expressed the personal impacts that DD made on their own } \\
\text { lives }\end{array}$ \\
\hline Gained Skills & $\begin{array}{l}\text { Student described the diverse skills DD helped them develop (i.e. } \\
\text { research, critical thinking) }\end{array}$ \\
\hline Scientific Literacy & $\begin{array}{l}\text { Student found the readings/searching/assessing articles to be } \\
\text { beneficial from their DD experience }\end{array}$ \\
\hline Own Discourse Skills & $\begin{array}{l}\text { Student describes examples of the opportunities they had to work on } \\
\text { their own communication skills }\end{array}$ \\
\hline Educational & $\begin{array}{c}\text { Student describes DD as interactive, informative, and/or tied well to } \\
\text { the course materials }\end{array}$ \\
\hline
\end{tabular}




\begin{tabular}{|c|c|}
\hline Already Viewed & $\begin{array}{l}\text { Student already viewed the real-world applications of science prior to } \\
\text { DD }\end{array}$ \\
\hline $\begin{array}{l}\text { Already Had } \\
\text { Confidence }\end{array}$ & $\begin{array}{l}\text { Student already had confidence in application/communication prior } \\
\text { to DD activities }\end{array}$ \\
\hline No Impact & Student states that DD did not impact them in any way \\
\hline
\end{tabular}

\section{DD brings relevant, real-world awareness into the classroom}

In general, for biology students $(\mathrm{n}=202), 85 \%$ of responses were positive about how DD influenced their views of the application of science (Figure $3.3 \mathrm{~A}$ ), $15 \%$ of responses fell under a theme of "no impact", and 17\% of responses were categorized as the students felt that they had "already understood" the real-world applications of science. For chemistry students $(n=398), 74 \%$ of responses were positive (Figure $3.3 \mathrm{~A}), 26 \%$ of responses fell under a theme of "no impact", and $18 \%$ of responses were categorized as the students felt that they had "already understood" the real-world applications of science. 


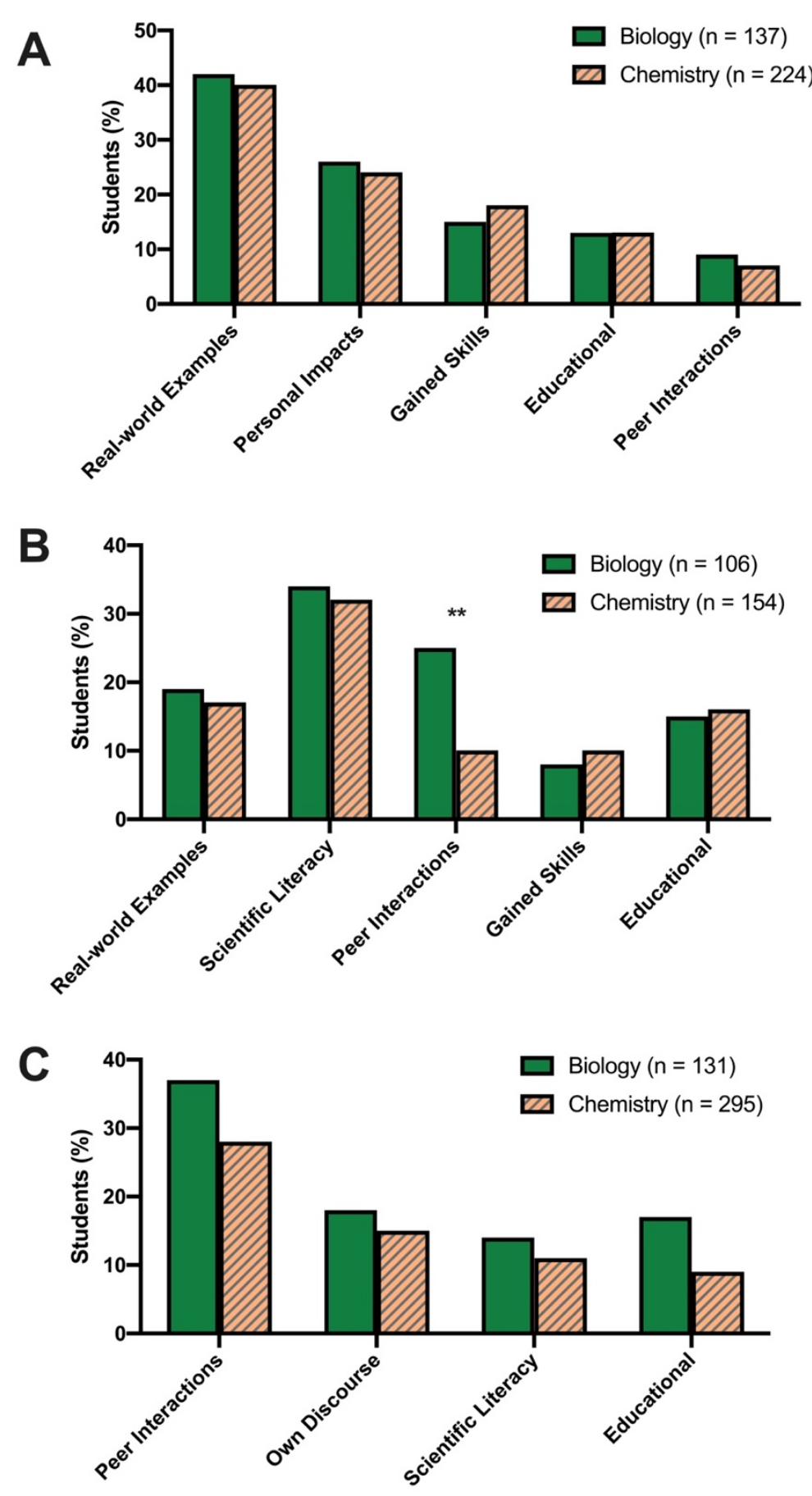

Figure 3.5 Top themes for Fall 2017 term for the prompts: A) "How did participating in the DD activities in this class impact your thinking regarding the role of science as it applies to real world problems?", B) "How did participating in the DD activities in this class impact your confidence in applying scientific knowledge to real world problems?", and C) "How did participating in the DD activities in this class impact your confidence in communicating scientific topics with your peers?". Significant differences among responses by course, Chi-sq., Pearson Correlation test of significance * indicates $p \leq 0.05$; ${ }^{* *}$ indicates $p \leq 0.0001$. Note: many students had responses that fell into more than one theme. 

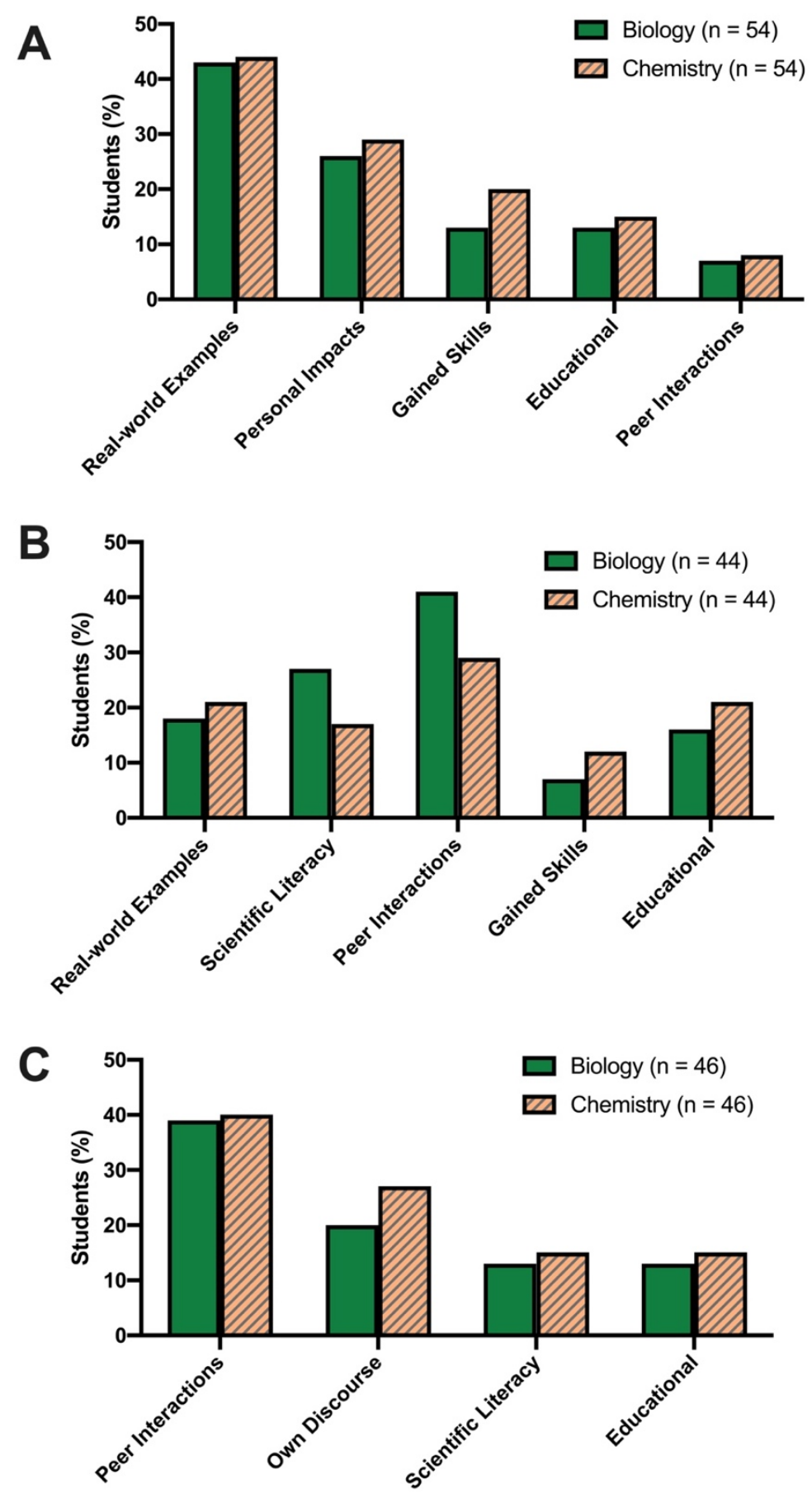

Figure 3.4 Top themes for Fall 2017 term for the prompts: A) "How did participating in the DD activities in this class impact your thinking regarding the role of science as it applies to real world problems?", B) "How did participating in the DD activities in this class impact your confidence in applying scientific knowledge to real world problems?", and C) "How did participating in the DD activities in this class impact your confidence in communicating scientific topics with your peers?". Results are shown in only biology and only chemistry co-enrolled students (students who were taking the courses simultaneously). 
The most prevalent theme of "real-world examples" included students referencing specific examples of the various application case-studies and examples that they were exposed to during the DD activities as well as ones they found on their own or spoke of during peer discussions. Students described their real-world examples on social impacts, current events, everyday life, consumerism, and human health. For example, this student reflected on the CRISPR Cas-9 DD activity they participated in: "I am more aware of the scientific research that is currently being conducted and how it directly relates to the issues we are learning about. I liked learning about the research that was being done at [local hospital] because it's so close to us!' -Biology student

This student reflected on learning about sunscreen and their everyday life:

"Often complicated and seemingly unimportant details have serious effects on our everyday lives."-Chemistry student

"Personal impacts" was another important theme that arose for students. I found that students were directly applying the real-world applications they learned in class to their own lives. For example, this student reflected on their own future after participating in the CRISPR Cas-9 module:

"They [DD] have affected how I view the application of science and how it affects our everyday lives and possibly the future. We just finished doing the $[D D]$ on genetic mutation/splicing, and it made me realize that my boyfriend's family has a history of breast cancer and there is a high chance that he carries that gene and could pass it down to his kid. Genetic engineering could be something that one day will affect my future." -Biology student

After participating in the sunscreen module, students in the chemistry course focused on their own health and daily choices. For example,

"[DD] was a good reminder to pay more attention to the common products we use and what they're made of. I like making informed decisions about what I'm using instead of just doing what everyone else is doing." -Chemistry student 
Giving students a chance to engage with real world applications of science and their connections to the course content may be key to persistence in a STEM major, as holding interest in what they are learning seems to be an indicator of perseverance (PCAST, 2012). Weasel and Finkel (2016) found that using DD led to favorable student perceptions and increased engagement with the course. Furthermore, I found in a previous study (Shortlidge et al, 2018) students reporting that their personal interest in subjects/topics impacted their learning and interest in their science classes ( $9 \%$ and $32 \%$ percentages of responses, respectively).

\section{Scientific literacy exposure impacts students' confidence in applying science}

Overall, for biology students $(n=160), 76 \%$ of responses were positive and were coded into further themes in regards to their confidence in applying science (Figure 3.3B), $24 \%$ of responses fell under a theme of "no impact", and $9 \%$ of responses were categorized as "already having confidence in applying science". For chemistry students $(n=314), 65 \%$ of responses were positive and were coded into further themes (Figure 3.3B), 35\% of responses fell under a theme of "no impact", and 14\% of responses were categorized as "already having confidence in applying science".

The most prevalent way that students felt DD impacted their confidence in applying scientific knowledge was that they learned to find, read, and use scientific literature (I have grouped these codes into the theme "scientific literacy"). As stated previously, undergraduate students do not have many opportunities in courses to gain these skills, so I were pleased to see students reflecting on this theme (Janick-Buckner, 
1997; Rehorek and Dafoe, 2018). Some students reflected on how to find and identify credible sources:

"This [DD] did allow me to look into some [university] available sources that I was not otherwise aware of - which has increased my confidence in locating and using these credible materials."

-Biology student

Other students spoke of the benefits of learning how to read the primary literature:

"Completing the $[D D]$ activities have increased my confidence in finding credible sources such as peer-reviewed articles, and how to read them properly." -Chemistry student

It is reassuring for us to learn that many students were reflecting on their scientific literacy skills, as early exposure to these competencies can increase students' applications skills, an important civic skill as described by Thomas (2010).

\section{DD influences students' confidence in their own discourse skills}

Overall, for biology students $(n=189), 81 \%$ of responses regarding their confidence in discourse skills were positive and were coded into further themes (Figure 3.3C), 19\% of responses fell under a theme of "no impact", and $12 \%$ of responses were categorized as "already having confidence in communicating science to their peers". For chemistry students $(n=371), 69 \%$ of responses were positive and were coded into further themes (Figure 3.3C), 31\% of responses fell under a theme of "no impact", and $18 \%$ of responses were categorized as "already having confidence in communicating science to their peers".

Two salient themes for students' confidence in communication were "peer interactions" and students' "own discourse" skills. There has been evidence in the importance of having discussion in science classrooms, particularly with application 
of information and discourse (Kuhn, 2005). Many students reflected on these experiences of discussion and learning from their peers during DD activities. For example, this student reflected on the diversity of people in the classroom:

"The DD exercises helped me... it was great to meet and work with different kinds of people, in different kinds of ways." -Biology student

Students also reflected on the opportunity to work in groups during their lecture course:

"It [DD] helped in conversing with peers, as we had to work in groups." -Chemistry student

Group work is a commonly used active learning strategy in STEM courses. Students' experiences with their peers within the DD module had an overall positive affect on their confidence in communicating, thus supporting the notion that group work is an important feature of students' learning experiences. Moreover, collaborating with peers is one of the intended outcomes of DD and civics, further solidifying DD as a valuable experience for students to gain confidence in communication.

Another emergent communication theme was students reflecting on practicing their "own discourse" skills. For example:

"I think the DD did positively help with my confidence communicating about science topics with peers. I was able to form my own opinions, argue about various policy with sufficient evidence, and learn from the sources gathered in a group setting." -Biology student

"It made me more confident because the discussions helped me formulate an idea and come up with what I actually wanted to say." -Chemistry student

Our findings are supported by another study, in which students reflected positively on the opportunities they had to practice their own communication skills during a 
deliberation exercise (Drury, 2015). This result suggests that having a deliberation in the classroom is a helpful way to have students practice these essential skills.

\section{Differences found between biology and chemistry perceptions during Fall 2017}

I detected two distinct differences in the proportion of themes between the biology and the chemistry students in how DD impacted their confidence in communication: 1) examples of the opportunities of working with peers and 2) how educational (or aligned) the DD content was with the course. In the biology course, there was a higher proportion of responses that corresponded to working with their peers. I hypothesize that this may be attributed to the novelty of the one-day DD activities implemented in the biology course versus the large amount of groupwork (POGIL) that students additionally complete in the chemistry sections. That is, chemistry students may be more used to groupwork, and thus, the novelty of DD may be less apparent compared to students enrolled in biology. With regard to the content alignment, I also found that co-enrolled chemistry course students found the DD activities to be more educational (Figure 3.4C). A sub-population of students enrolled in chemistry are on a pre-health track; therefore, the DD activity topic in chemistry (chemicals found in sunscreen) may have supported engagement and interest in these specific students.

For the other prompts, I did not detect any significant differences in proportions of top themes across the populations in this study (biology course, chemistry course, co-enrolled students) (Figures 3.3 and 3.4). This suggests that regardless of course enrollment, these prevalent themes are uniformly perceived across both biology and chemistry courses. This result is important because it implies that the DD activities 
are impacting students equally, also suggesting that no specific populations are being negatively affected. DD seems to be "working" evenly across courses.

\section{Winter 2018 DD Implementation}

There were similarities and differences in implementation of DD across the biology and chemistry courses in the Winter 2018 term (Table 3.5). The materials, language, and use of LAs was similar as the Fall term. Both courses implemented a two-day module once during the term.

The DD topic in biology was pertaining to salmon populations (wild versus farmed salmon) and in chemistry the topic was about water desalination. In biology, the instructor was the leader of the activity with support from the teaching assistant whereas in chemistry, a graduate research assistant would attend and lead the DD activity days. In one of the chemistry sections, the instructor was absent, therefore the TA was the lead instructor during this term. DD activities were worth different final grade percentages and graded differently. In biology, worksheets were graded based on attendance and in chemistry they were graded based on quality of answers on worksheets. Other active learning strategies were utilized in both courses. Biology had an additional groupwork activity that was not DD. Chemistry had weekly Process Oriented Guided Inquiry Learning (POGIL) exercises. 
Table 3.5 Winter 2018 DD activity details for each course type.

\begin{tabular}{|c|c|c|}
\hline 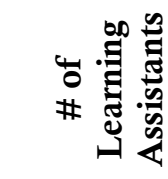 & $\simeq$ & $\begin{array}{l}0 \\
1 \\
1 \\
+1\end{array}$ \\
\hline 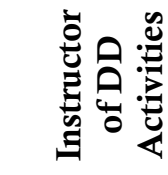 & 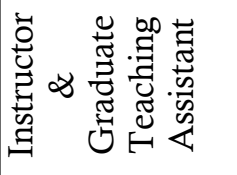 & 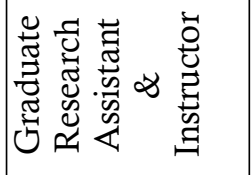 \\
\hline 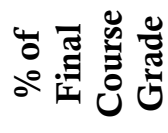 & in & ذें \\
\hline 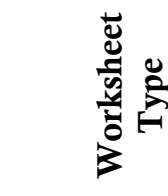 & 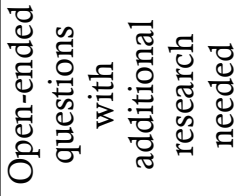 & 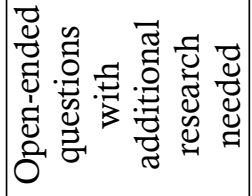 \\
\hline 苛 & 完 & 它密 \\
\hline : & 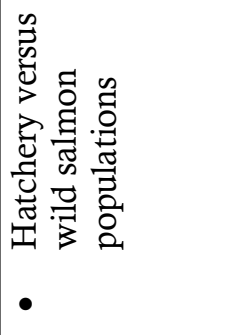 & 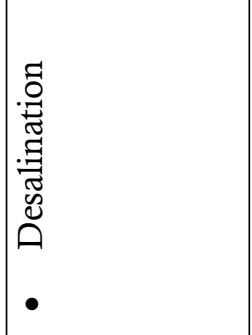 \\
\hline 佥: & - & - \\
\hline ن & 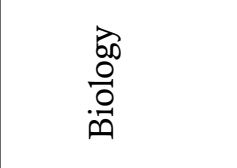 & 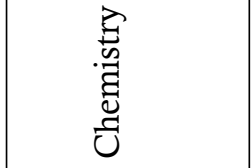 \\
\hline
\end{tabular}


Table 3.6 Winter 2018 sample demographics composed of 629 individual students.

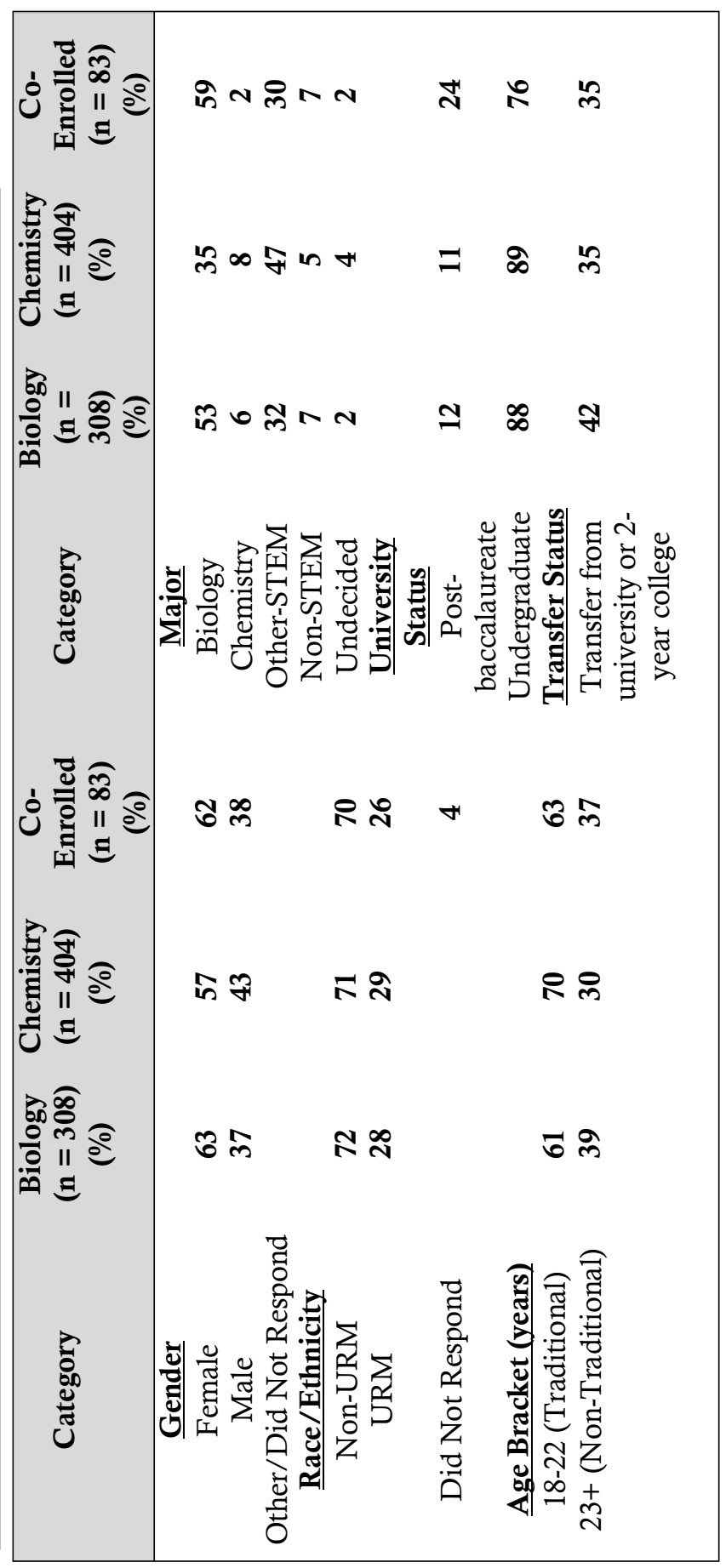




\section{Winter 2018 Student Demographics}

Winter 2018 student demographics were collected in the same manner as Fall 2017 data collection (Table 3.7). In total, 629 individual students are represented in the Winter 2018 data set $(n=308$ biology; $n=404$ chemistry). There were 83 students co-enrolled in biology and chemistry at the same time that responded to the survey.

\section{Winter 2018 Student Perceptions of DD Activities}

\section{Students are starting to believe that DD activities are mandatory curriculum}

For the Winter 2018 data, the same top themes emerged regarding why students believed their instructors were using DD in their STEM courses (Figure 3.5). There were two themes that arose more frequently during this term: 1) that DD was mandatory and 2) DD gives students an opportunity to work on skills. Students thinking that DD modules are a "mandatory" pedagogy at PSU may be due to the students participating in them in the Fall and noticing the modules in their other introductory STEM courses. 


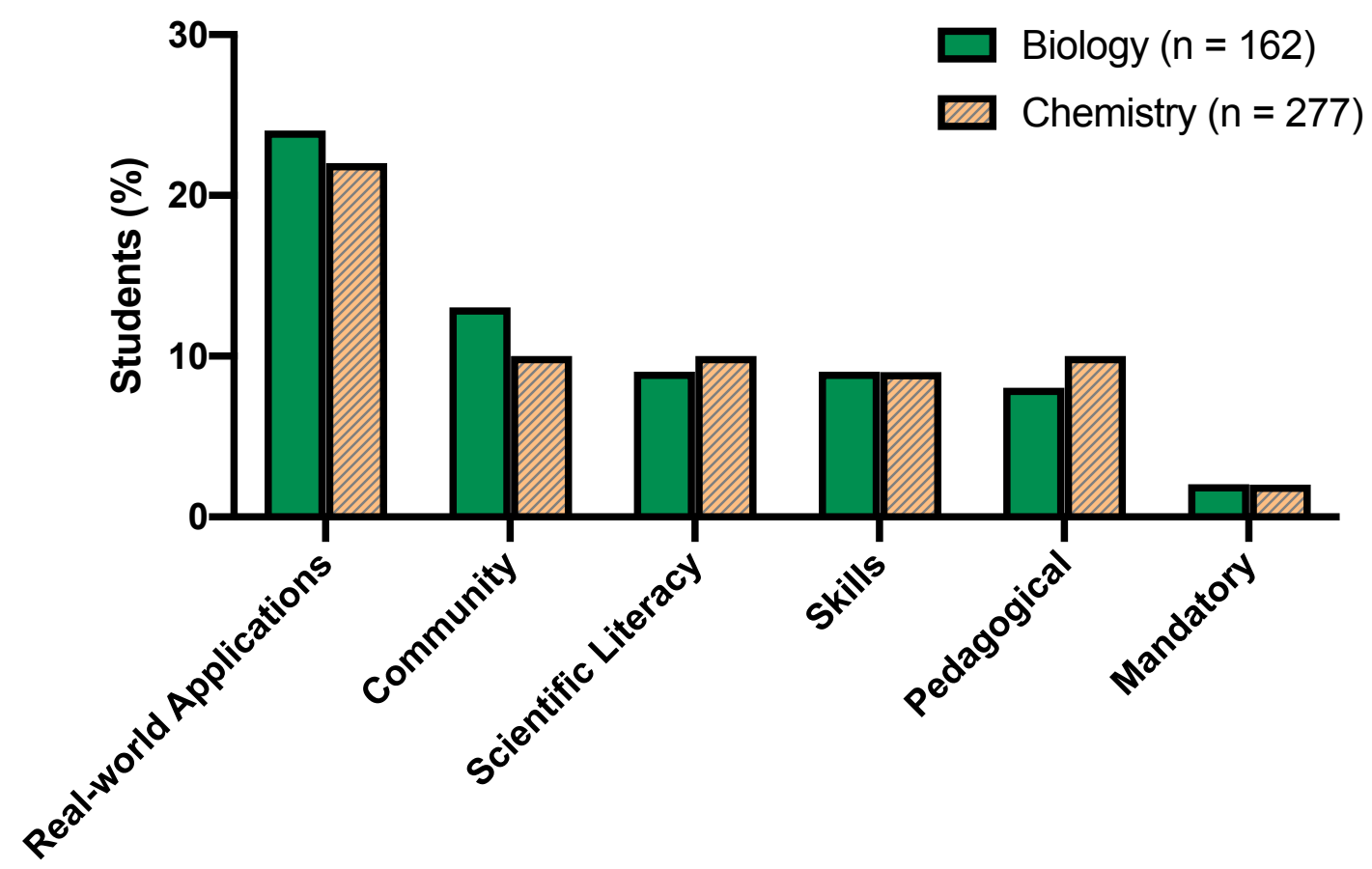

Figure 3.5 Top themes for Winter 2018 term for the prompt: "Why do you believe your instructor used Deliberative Democracy in this class?".

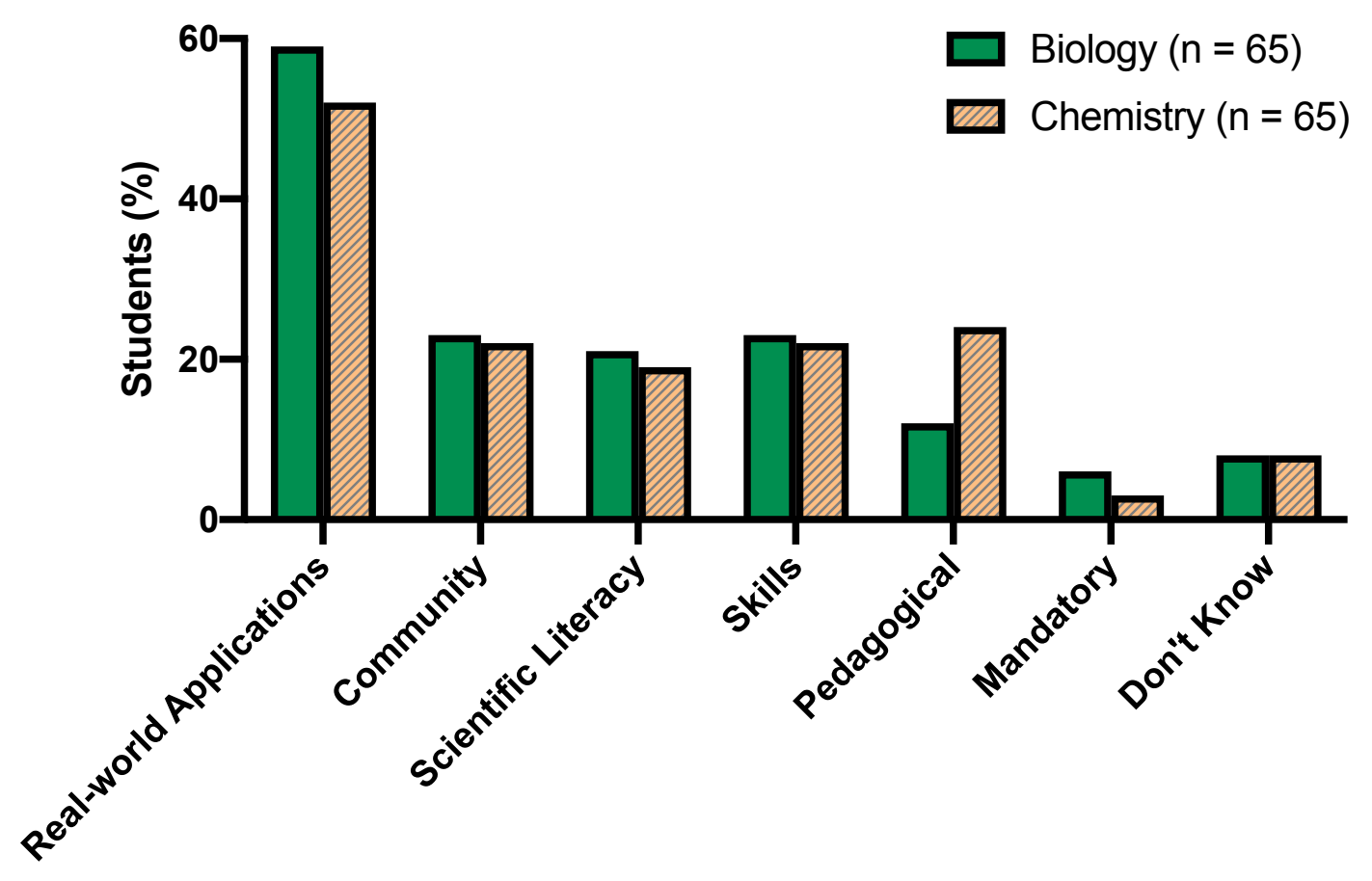


Figure 3.6 Top themes for Winter 2018 term for the prompt: "Why do you believe your instructor used Deliberative Democracy in this class?". Results are shown in only biology course and only chemistry course co-enrolled students (students who were taking the courses simultaneously).

Winter 2018 - What Do Students Perceive They Are Gaining From DD Activities?

I asked students the same survey prompts during the Winter term. The proportions of themes found in the top (themes that are $>5 \%$ of total responses) are reported in Figures $3.7-3.8$. 


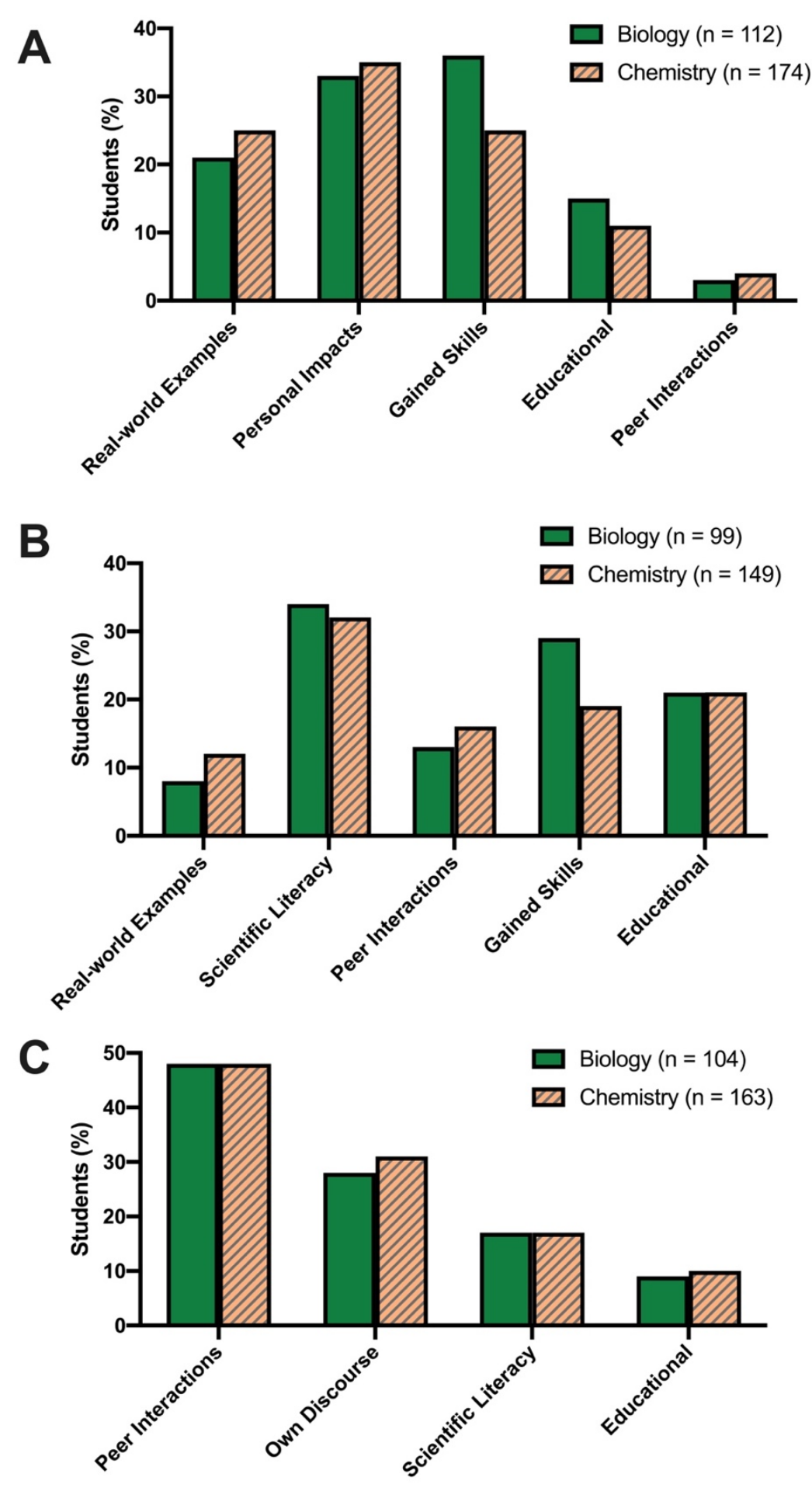

Figure 3.7 Top themes for Winter 2018 term for the prompts: A) "How did participating in the DD activities in this class impact your thinking regarding the role of science as it applies to real world problems?", B) "How did participating in the DD activities in this class impact your confidence in applying scientific knowledge to real world problems?", and C) "How did participating in the DD activities in this class impact your confidence in communicating scientific topics with your peers?". 


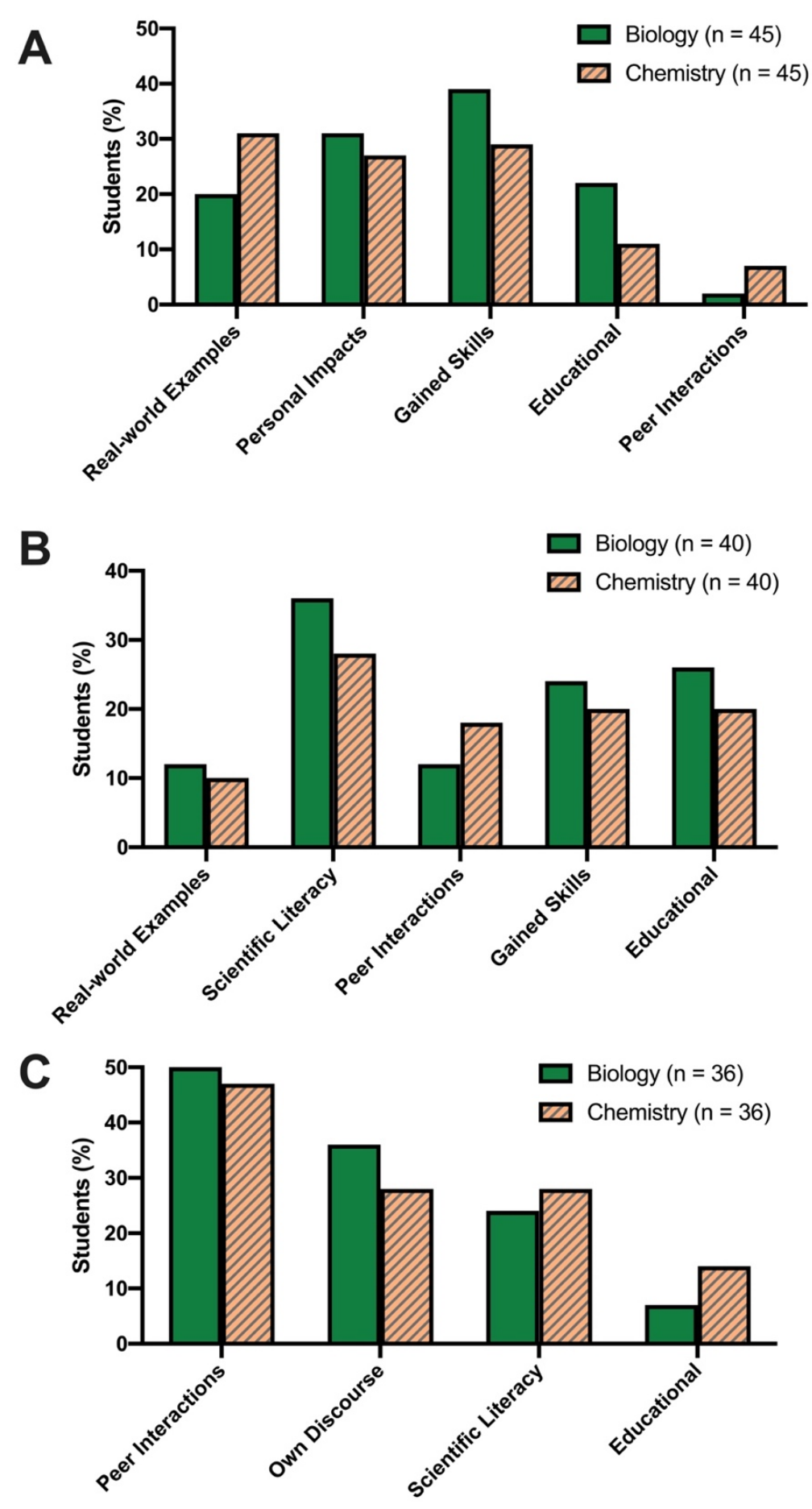

Figure 3.8 Top themes for Winter 2018 term for the prompts: A) "How did participating in the DD activities in this class impact your thinking regarding the role of science as it applies to real world problems?", B) "How did participating in the DD activities in this class impact your confidence in applying scientific knowledge to real world problems?", and C) "How did participating in the DD activities in this class impact your confidence in communicating scientific topics with your peers?". Results are shown in only biology and only chemistry co-enrolled students (students who were taking the courses simultaneously). 


\section{Evidence for the importance of alignment of course content and the real-world}

For the second prompt, how DD impacted students' thinking about real-world applications, I found biology student responses $(n=150)$ were $85 \%$ positive and were coded into further themes (Figure 3.7A). Additionally, 15\% of responses fell under a theme of "no impact" and 10\% of responses were categorized as "already had viewed the real-world applications of science". For chemistry students $(\mathrm{n}=260), 80 \%$ of responses were positive and were coded into further themes (Figure 3.7A), 20\% of responses fell under a theme of "no impact", and 14\% of responses were categorized as "already had viewed the real-world applications of science".

For the Winter 2018 data, I found the same top themes on DD impacts on students view of real-world applications (Figure 3.7A). However, there was a decrease in students describing the specific topics they learned about. I hypothesize that perhaps the DD topics were not as engaging and/or human health-focused as they were in the Fall term. The biology DD topic was salmon farming and the chemistry topic was desalination methods. These topics did not seem to resonate with students in their reflections as the Fall term topics did. Interestingly, I found that the "personal impacts" theme was higher this term. This suggests that even though the topics did not seem as applicable to the majority pre-health students, they were still able to make connections of the topics to their own lives. A student example quote of this theme:

"I already knew about the fish hatchery issue, so it helped make me realize how to connect information in class to my life." - Biology student

I also found biology students reflecting of the various other skills they obtained increased during the Winter term. I believe that this increase is due to the biology 
course using the two-day DD modules, which include the at-home research component and bringing their research efforts together to come to a consensus.

\section{Similar perception trends continue for students' confidence in scientific application}

Overall, for biology students who reported confidence in applying science to the realworld $(n=148), 82 \%$ of responses were positive and were coded into further themes (Figure 3.7B), 18\% of responses fell under a theme of "no impact", and $14 \%$ of responses were categorized as "already having confidence". For chemistry students $(n=256), 74 \%$ of responses were positive and were coded into further themes (Figure 3.7B), $26 \%$ of responses fell under a theme of "no impact", and $14 \%$ of responses were categorized as "already having confidence in applying science".

\section{Similar perception trends continue for students' confidence in science communication}

Overall, for biology students who reported confidence in communicating science ( $\mathrm{n}=$ 146), $79 \%$ of responses were positive and were coded into further themes (Figure $3.7 \mathrm{C}), 21 \%$ of responses fell under a theme of "no impact", and $8 \%$ of responses were categorized as "already having confidence in communicating science to their peers". For chemistry students $(n=253), 71 \%$ of responses were positive and were coded into further themes (Figure 3.7C), 29\% of responses fell under a theme of "no impact", and $7 \%$ of responses were categorized as "already having confidence in communicating science to their peers". 


\section{Two-day DD modules support specific skills}

I detected one statistical difference between the biology and chemistry student perceptions during the Winter term. This difference was biology had an increased proportion of "gained skills" (34\%) than chemistry (25\%) for DD influencing their view of real-world applications (Figure 3.7A) This was also the case for their confidence in real-world applications $($ biology $=28 \%$ and chemistry $=19 \%)($ Figure 3.7B). I believe, the reasoning for this finding as described previously is that biology students participated the two-day module, which introduced them to more research and collaboration skills.

\section{Spring 2018 DD Implementation}

There were similarities and differences in implementation of DD across the biology and chemistry courses in the Spring 2018 term (Table 3.6). The materials, language, and use of LAs were similar as the Fall/Winter terms. Both courses implemented a two-day module. Biology did two modules, and chemistry did one module.

There were a few differences in implementation of DD across the biology and chemistry courses. The DD topics in biology were pertaining to human health implications such as 1) water with added electrolytes, and 2) endocrine disrupting chemicals found in everyday products. In Chemistry the topic was about the effectiveness of road-side cocaine detection tests. Instructors were present for all activities; however, their participation level was different across courses. In biology, the instructor was the leader of the activity with support from the teaching assistant whereas in chemistry, a graduate research assistant would attend and lead the DD 
activity days. DD activities were worth different final grade percentages and graded differently. In biology, worksheets were graded based mostly on attendance and completeness, and in chemistry they were graded based on quality of answers on worksheets. Other active learning strategies were utilized in both courses. Biology had additional groupwork activities that were not DD. Chemistry had weekly POGIL exercises. 
Table 3.7 Spring 2018 DD activity details for each course type.

\begin{tabular}{|c|c|c|}
\hline 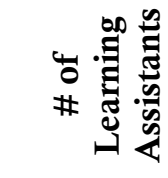 & $\simeq$ & $\begin{array}{l}0 \\
1 \\
+\end{array}$ \\
\hline 总合造 & 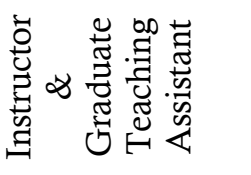 & 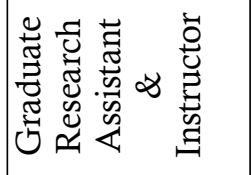 \\
\hline 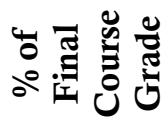 & ठ̊ำ & ปे \\
\hline 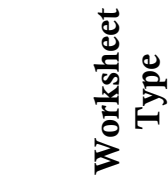 & 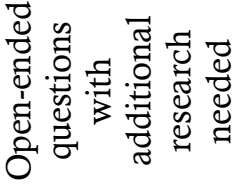 & 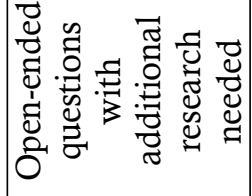 \\
\hline 旁 & 完 & 官总 \\
\hline : & 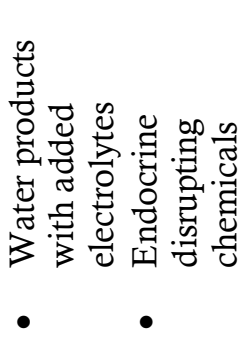 & 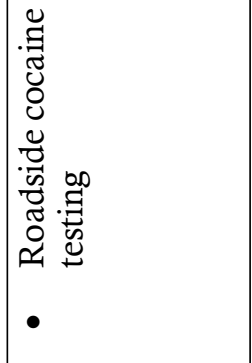 \\
\hline 周: & $\sim$ & $\neg$ \\
\hline نे & $\begin{array}{l}00 \\
0 \\
0 \\
010\end{array}$ & 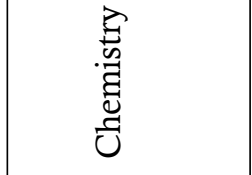 \\
\hline
\end{tabular}




\section{Spring 2018 Student Demographics}

Spring 2018 student demographics were collected in the same manner as the Fall 2017 and Winter 2018 data collections (Table 3.8). In total, 513 individual students are represented in the Spring 2018 data set $(\mathrm{n}=293$ biology; $\mathrm{n}=300$ chemistry). There were 80 students co-enrolled in biology and chemistry at the same time that responded to the survey. 
Table 3.8 Spring 2018 sample demographics composed of 513 individual students.

\begin{tabular}{|c|c|c|c|c|}
\hline 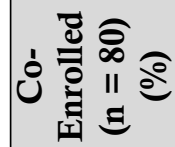 & : $0 \stackrel{\sim}{N} \nleftarrow m$ & 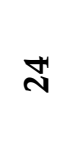 & 운 & กั \\
\hline 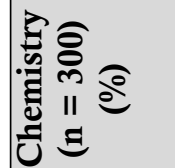 & भ응 요 nm & $\ddot{2}$ & $\infty$ & $\stackrel{\infty}{\infty}$ \\
\hline 商 & 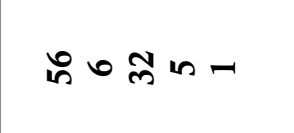 & $\ddot{2}$ & $\infty$ & $F$ \\
\hline 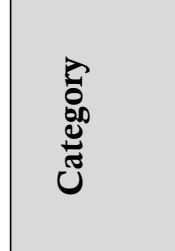 & \multicolumn{4}{|c|}{ 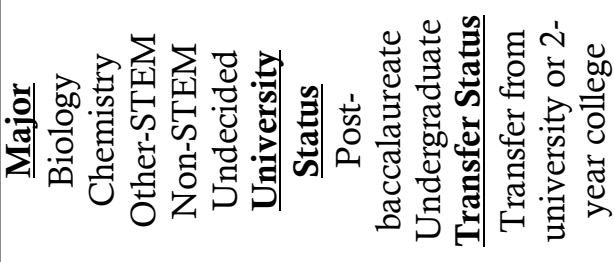 } \\
\hline 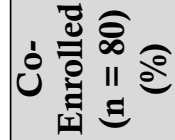 & กิ & 0 & & 구 \\
\hline 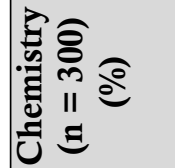 & 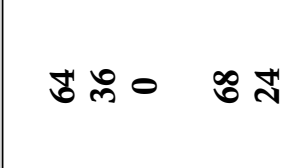 & $\infty$ & & m \\
\hline 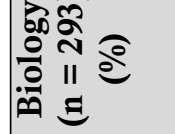 & చ̊ $\stackrel{\infty}{N}$ & in & & iे \\
\hline 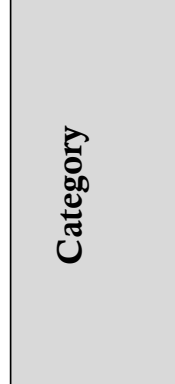 & 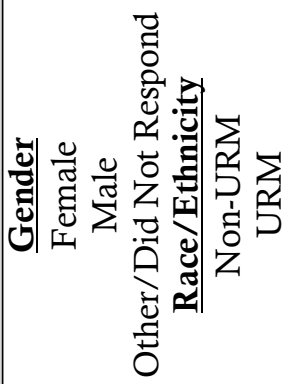 & 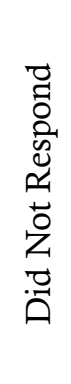 & 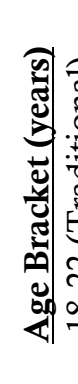 & 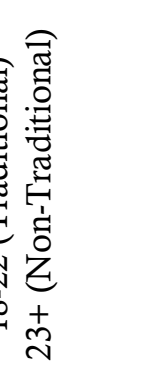 \\
\hline
\end{tabular}




\section{Spring 2018 Student Perceptions of DD Activities}

Reasons students believe their instructors are utilizing deliberations in their classrooms

For the Spring 2018 data, I found the same top themes on why students believed their instructors were using DD in their STEM courses (Figure 3.9).

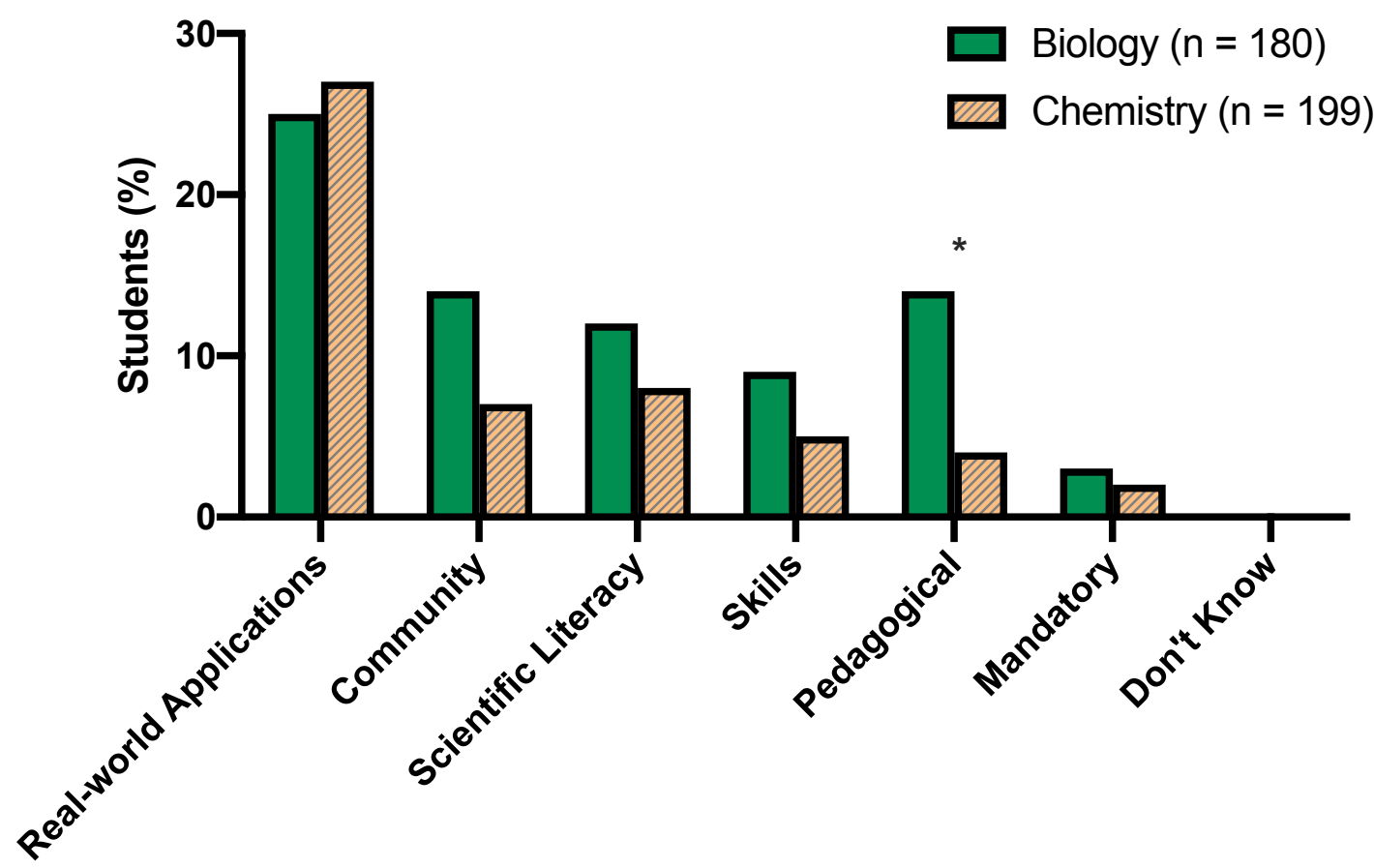

Figure 3.9 Top themes for Spring 2018 term for the prompt: "Why do you believe your instructor used Deliberative Democracy in this class?". 


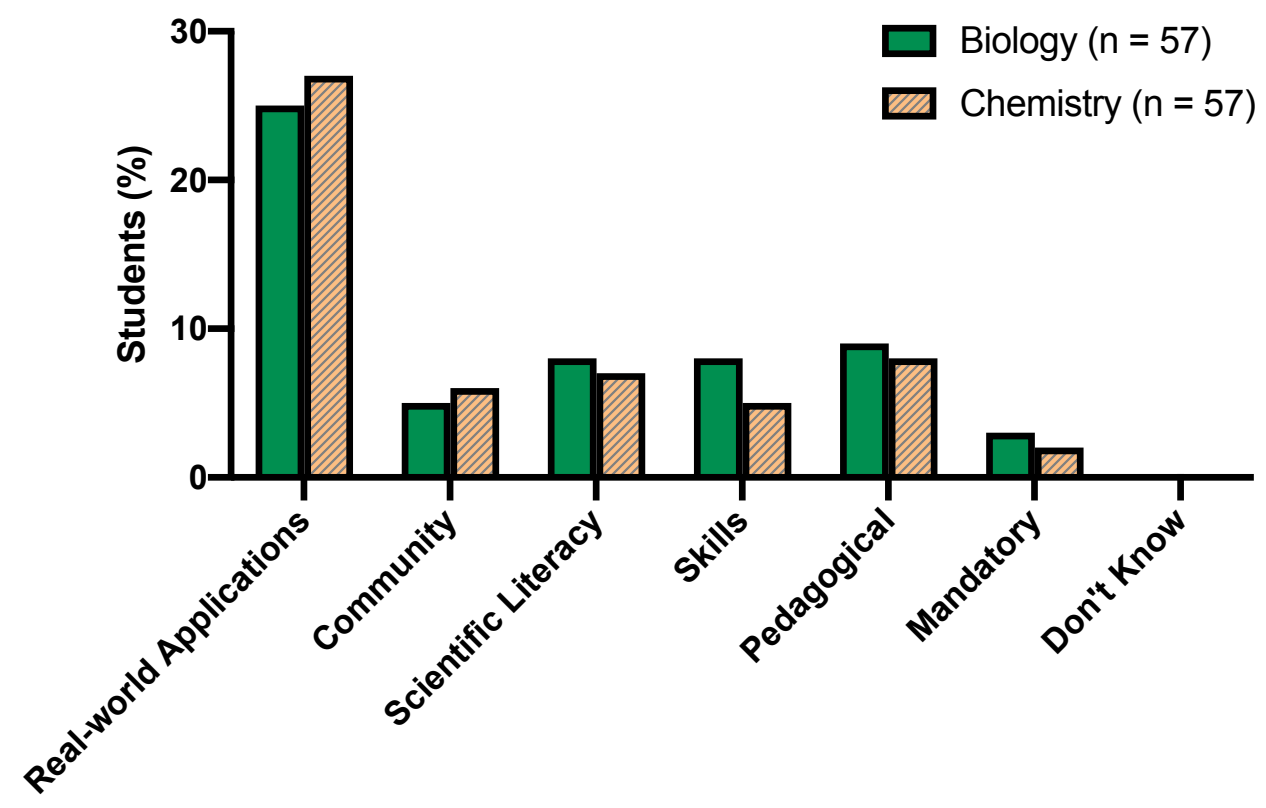

Figure 3.10 Top themes for Spring 2018 term for the prompt: "Why do you believe your instructor used Deliberative Democracy in this class?". Results are shown in only biology course and only chemistry course co-enrolled students (students who were taking the courses simultaneously).

\section{Spring 2018 - What Do Students Perceive They Are Gaining From DD Activities?}

I asked students the same survey prompts during the Spring term. The proportions of themes found in the top themes (themes that are $>5 \%$ of total responses) are reported in Figure 3.11. 

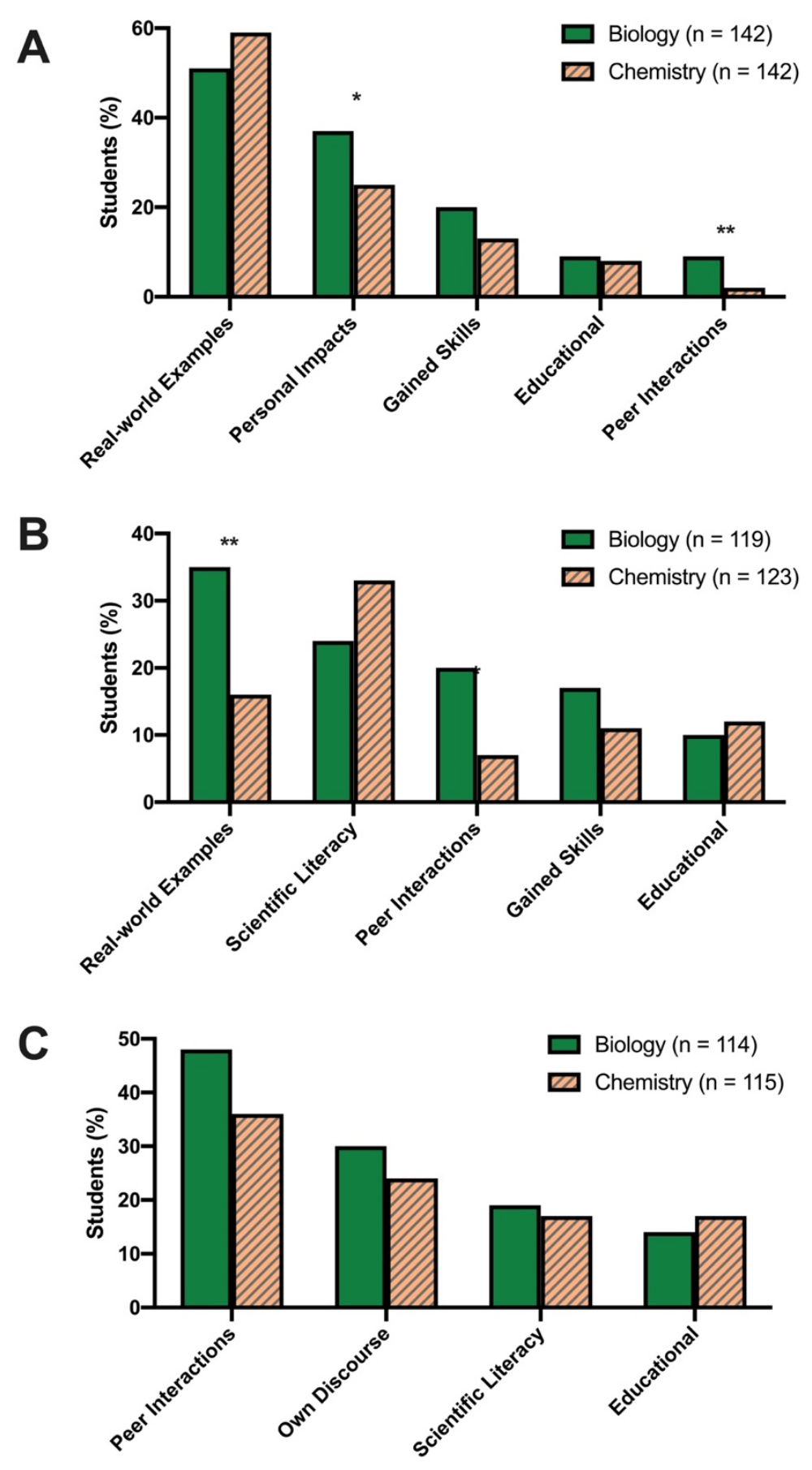

Figure 3.11 Top themes for Spring 2018 term for the prompts: A) "How did participating in the DD activities in this class impact your thinking regarding the role of science as it applies to real world problems?", B) "How did participating in the DD activities in this class impact your confidence in applying scientific knowledge to real world problems?", and C) "How did participating in the DD activities in this class impact your confidence in communicating scientific topics with your peers?". Significant differences among responses by course, Chi-sq., 
Pearson Correlation test of significance * indicates $p \leq 0.05 ;{ }^{*}$ indicates $p \leq 0.0001$. Note: many students had responses that fell into more than one theme.

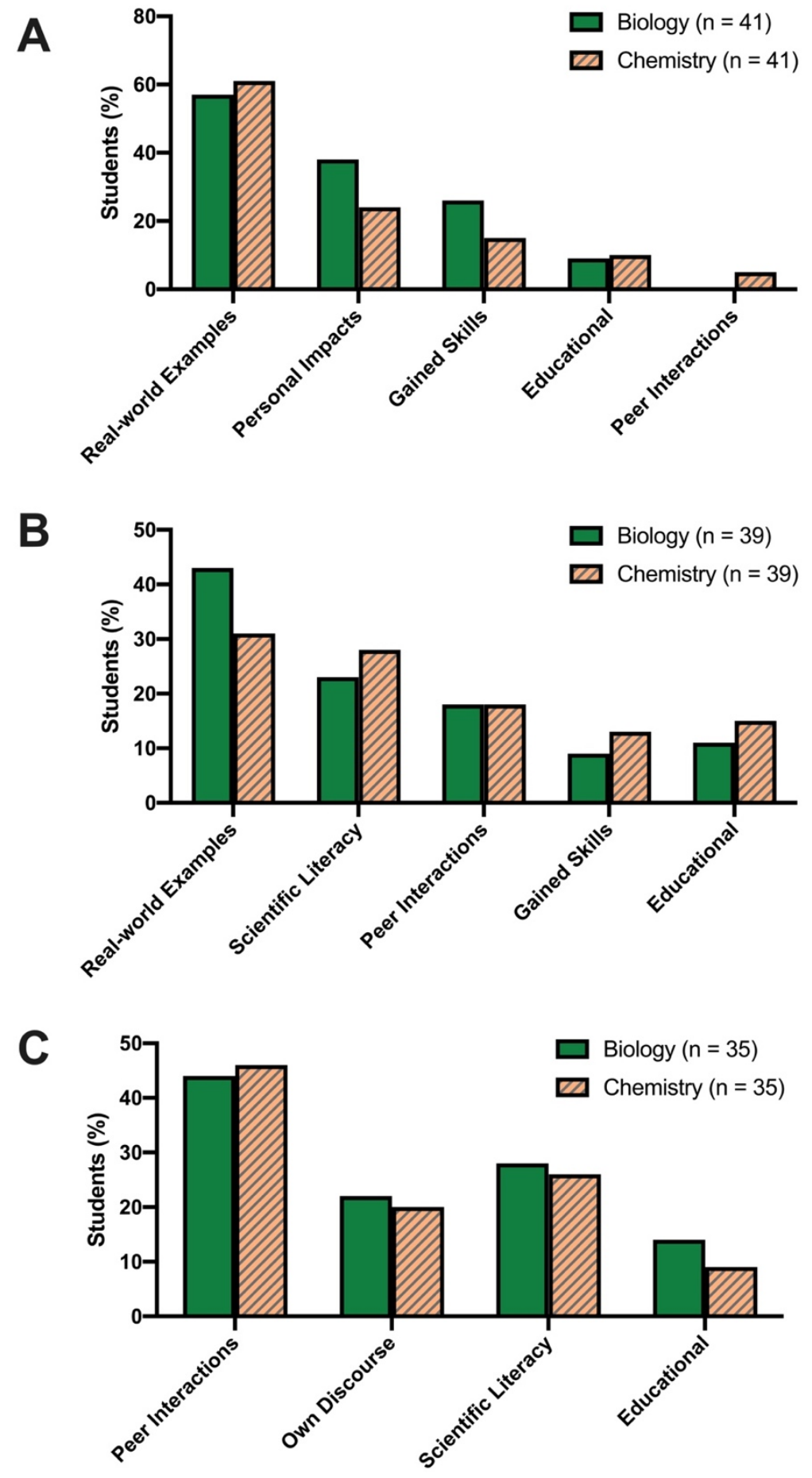

Figure 3.12 Top themes for Spring 2018 term for the prompts: A) "How did participating in the DD activities in this class impact your thinking regarding the role of science as it applies to real world problems?", B) "How did participating in the DD activities in this class impact your confidence in applying scientific knowledge to real world problems?", and C) "How did participating in the DD activities in this class impact your confidence in 
communicating scientific topics with your peers?". Results are shown in only biology and only chemistry co-enrolled students (students who were taking the courses simultaneously).

\section{Similar impacts on students' thinking about real-world applications}

In regards to how DD impacted students' thinking about real-world applications, for biology students ( $\mathrm{n}=164), 94 \%$ of responses were positive and were coded into further themes (Figure 3.11A), $6 \%$ of responses fell under a theme of "no impact", and $8 \%$ of responses were categorized as "already had viewed the real-world applications of science". For chemistry students $(\mathrm{n}=184), 86 \%$ of responses were positive and were coded into further themes (Figure 3.11A), 14\% of responses fell under a theme of "no impact", and 9\% of responses were categorized as "already had viewed the real-world applications of science".

\section{Similar perception trends continue for students' confidence in scientific application}

For the impacts on scientific application prompt, biology students $(n=148), 92 \%$ of responses were positive and were coded into further themes (Figure 3.11B), $8 \%$ of responses fell under a theme of "no impact", and 11\% of responses were categorized as "already having confidence". For chemistry students $(n=170), 82 \%$ of responses were positive and were coded into further themes (Figure 3.11B), 18\% of responses fell under a theme of "no impact", and $10 \%$ of responses were categorized as "already having confidence in applying science".

\section{DD continues to impact students' discourse skills}


Overall, for biology students $(n=189), 81 \%$ of responses regarding their confidence in discourse skills were positive and were coded into further themes (Figure 3.11C), 9\% of responses fell under a theme of "no impact", and 17\% of responses were categorized as "already having confidence in communicating science to their peers". For chemistry students $(n=169), 76 \%$ of responses were positive and were coded into further themes (Figure 3.11C), 24\% of responses fell under a theme of "no impact", and $8 \%$ of responses were categorized as "already having confidence in communicating science to their peers".

\section{Instructors' transparency of pedagogical choices is observed by their students}

I found a noteworthy difference in why students believed their instructor was using DD between the biology and chemistry courses during the Spring term. Biology students were reporting a higher proportion of "pedagogical" reasoning than chemistry ( $14 \%$ versus $4 \%$, respectively, $\mathrm{p}<0.05)$. This may be due to the instructor's explicit transparency on why they employ groupwork in the classroom.

Some example quotes from these students:

"Because [instructor] believes in building a strong group work environment because once people start their careers in the real world, there is a lot of collaboration that goes into any job that is available in society." - Biology student

"[Instructor] wanted to make the class more interactive."-Biology student

\section{Overall, Did DD Implementation Style Affect Students?}


I found that both biology and chemistry courses had overwhelmingly positive perceptions of DD modules over the entire academic year (2017-18). The same three themes rose to the top of the data set over the three terms during open-coding of student responses. It is important to note that these perceptions did not seem to rely on the type or how long the modules were (during the Fall 2017 term). The chemistry course had one two-day module, whereas the biology course had three one-day modules. What seems to matter the most to students is: 1) having an opportunity to read/use primary literature, 2) learning about the world's problems--especially if it aligns well to course content and/or their own lives, and 3) working collaboratively with peers. These three aspects of DD are employed regardless of which module type you use, one-day versus two-day. Furthermore, I found that it did not seem to matter who led the DD modules - the instructor or graduate students. Students still reported similar top themes to the prompts.

I also considered students who were co-enrolled. These subsets of students were those who were taking both the biology and chemistry courses during the same term. Examining students who were experiencing both courses, thus both implementation styles could potentially help us understand any implementationspecific differences in perception. I found that overall, the co-enrolled students were perceiving the DD activities similarly in their biology and chemistry courses. Importantly however, the co-enrolled students were not simply saying the same thing about each course in each course's survey, their responses varied, but not consistently or specifically. 


\section{Is there the potential for our DD modules to be used by others in their courses?}

I gathered student perceptions regarding the DD modules implemented in our majors introductory biology and chemistry courses. Using this information and the data I collected from observations, I wanted to understand if and how we could recommend DD modules for other instructors and other institutions' use. Student data helped us to learn important lessons regarding what may lead to successful implementation of DD modules. The data from this study supports that although there were differences in: implementation styles, DD topics used, and module length, I found that there were similar student perceptions across courses. These data indicate that an instructor from a different institution could likely use, modify, or develop their own DD module in their course, resulting similar student perceptions/outcomes.

First, I found that course content and DD topic alignment matters to students. The DD format allows instructors to fairly easily find topics that align with their course content. Here I provide student responses demonstrating the importance of the course content aligning with the module:

"[DD] helped me learn the concepts more and understand how to use them in the future. Many people forget content once they have learned it, but [DD] uses real life problems to link science and the real world to reinforce learning." - Biology student

"Doing the EDCs $[D D]$ was exciting because we were learning about hormone signals, so having that real-world anchor to why we are learning this helps!" - Biology student

"[DD] provides depth to the material from class" - Chemistry student

"The DD assignments often inform us about interesting real-world problems. It is important to relate this to our classwork." - Chemistry student

Another example, in biology, when discussing the endocrine system and hormones, developing a module exploring endocrine disrupting chemicals was a natural match 
(https://www.pdx.edu/stem/deliberative-democracy). Instructors can use the linked information to find suggested articles, questions for students, and discussion ideas for their own DD activity. One of the key intentions of DD was to make the modules easily accessible and pliable for instructors' individual needs in their own course.

Next, I found that having an open forum for discourse in a large lecture setting is impactful to students. DD modules are typically tied to a question that combines cutting-edge science and policy; thus, the topics can raise political and ethical issues that do not have clear-cut answers. The DD topics are intentionally designed to be open-ended, allowing for deliberation and consensus forming. This may cause apprehension for some instructors, but many students appreciated the opportunity to and discuss sometimes sensitive topics with their peers. Some students spoke of DD giving them a "safe space" to freely discuss their thoughts about the real-world problems at hand, while others reflected on the discourse skills they built. For example:

"Although the actual in-class discussions can be at times tedious, this exercise would be ineffective without the community forum component. Also, I think it is necessary to expose people to points of common contention in a setting (such as the classroom) where ideas hold weight based on merit, not volume." - Biology student

"There's many variables to take into consideration when forming a consensus in your group. It opened my mind and changed my way of thinking. These aren't always black or white, or good orbad."

-Biology student

"It [DD] improved my confidence by giving me a safe space to talk about real world science problems and hear other people's ideas about it." -Chemistry student

"Within these activities and being given a safe space to practice communicating about science I would say these activities positively impacted my confidence in communicating about science with my peers. I was allowed to have a voice and be corrected and learn from that." -Chemistry student 


\section{Conclusion}

Overall, students responded positively to the DD activities developed and implemented in biology and chemistry courses. Students mostly have a clear understanding of why their instructors implement deliberation in the classroom. Evidence of DD learning objectives are being met, for example, students are reporting gaining skills in communication and applying their scientific knowledge through DD modules. Students evoked real-world examples "connecting science to society" that they were exposed to through $\mathrm{DD}$, thus meeting national call for undergraduate biology reform as outlined in Vision and Change's core competencies (2009). We did not identify differences in student perceptions between the one-day versus the two-day modules, thus DD is amenable to a variety of classrooms and structures. Careful course content alignment, engaging topics, and giving students an opportunity to talk to one another can to successful DD implementation. 
CHAPTER 4: Discussion - Final Conclusions, Limitations, \& Future Research In this Masters' project, I used qualitative research methods to understand student experiences as participants in Deliberative Democracy modules (DD) in introductory science courses. DD is an active learning pedagogy where students collaborate and deliberate on a real-world problem typically based in their course's content (Weasel and Finkel, 2016). DD is also a mechanism by which to instill democratic skills such as communication, collaboration, and application of information (Thomas, 2010) and make the connections between science and society for students (AAAS, 2011). My research was guided by the following five research questions:

Research Question 1: a. What were the similarities and/or differences in students' perceptions of DD immediately after their course and a year later? b. How were these self-reported perceptions aligned with expected DD outcomes/democratic skills?

To answer this research question, I gathered students' perceptions via an online survey (Qualtrics) at the end of the term from six introductory biology courses (three majors and three non-majors). I asked students the open-ended prompt: "How do you 
feel about the Deliberative Democracy strategy used in this class?". I then recruited participants from the same courses one year later by having them answer two survey prompts about their memorable and frustrating experiences with DD. I also conducted 19 semi-structured interviews. I found that students' perceptions of DD were generally positive and without specific prompting students reflected on intended outcomes/democratic skills of DD during both surveys and the interviews.

I found that when asked about DD a year after their course, students' positive perceptions of "working with peers" during DD was statistically higher than it was directly after the courses with DD. Jones et al.'s study (2014) made a similar finding about the appreciation for working with peers, however that was immediately after the activity. I hypothesize while students are reflecting on their past DD experiences, the positive aspects of group work (e.g., discussions, making friends) could have been more memorable because of the positive emotion associated with those experiences. I also found this occurrence in regard to responses about negative aspects and challenging aspects of group work. It has been shown that emotion has influence on learning and memory, specifically when it comes to attention and memory (Tyng et al., 2017). Designing DD modules to have content/components that produce an emotional or meaningful experiences may allow for a more engaging experience.

Research Question 2: Which of these perceptions (findings from Research Question 1) differ by course type (majors vs. non-majors biology courses)?

To answer this research question, I examined the student responses from the surveys I disseminated over two academic years and sorted them by course type 
(majors biology versus non-majors biology). I found that students from the majors biology course described DD as a "valuable" experience immediately after the term. This was an intriguing finding, especially since when this theme was coded, it was usually paired with a negative theme. For example, a student could be describing a negative group experience but also mention that they understand why they are doing group work (the value of it). Another interesting finding was non-majors students mentioned decidedly cite "working with peers" as a positive aspect of $\mathrm{DD}$, whereas.... I hypothesize this was because the non-majors course is an amalgam of majors, so meeting new people and gaining new perspectives during group work is novel. The following year I found that non-majors students still had a higher percentage of responses that fell under "working with peers", however this was not a significant finding.

Lastly, majors students described on their survey how the "class time use" was associated negatively with DD, both immediately after the course and one year later. They described that they wish the class time was used differently, especially in preparation for final exams. This may have occurred in the majors course because there is a higher percentage of post-baccalaureate and pre-health track students at Portland State University (Snapshot of PSU, 2019; Shortlidge et al., 2018). In a previous study, we found that post-baccalaureate students outperformed all other student groups in their biology and chemistry courses (Shortlidge et al., 2018). Although there were performance gaps (as determined by grades), there were no significant differences in postbac perceptions of the course as compared to their peers' perceptions. We attributed post-baccalaureate success to the fact they already hold a 
bachelor's degree, have clear career goals, and are likely more metacognitive about their learning. In the other study, we took a course-grained approach to understanding student perceptions of active learning strategies used in their course. At the time, we binned responses into positive, negative, and neutral bins. Moving forward with my master's research, I took a finer-grained approach and found more specific reasons on what exactly made students responses positive or negative. I looked for significant differences between post-baccalaureates and undergraduates perceptions of DD and did not find any due to a lack of statistical power.

Research Question 3: Why do students believe that their instructors use DD activities in the classroom?

To answer this research question, I gathered students' perceptions via an online survey (Qualtrics) at the end of the term (Fall, Winter, and Spring from the academic year 2017-18) from majors biology and majors chemistry courses. I asked students the open-ended prompt: "Why do you believe your instructor chose to use Deliberative Democracy in this course?". Responses were iteratively coded and organized into overarching themes. I found that students beliefs aligned well with many of the intended reasons why instructors use DD (e.g., introduce real-world problems that align with course content, implement group-work in the course).

Further, I noticed an interesting finding in the biology course Spring data. In the beginning of the term, the instructor included in their lecture the importance of collaboration and having active learning in the classroom. The instructors' transparency about why they were implementing active learning/DD seemed to impact the students responses. For example, "pedagogical" reasoning for DD was 
significantly higher in biology than in chemistry ( $14 \%$ versus $4 \%$, respectively). This finding may help us start to understand why it may be important to explain to students why you are using the pedagogies/strategies in your course. For example:

"Because [instructor] believes in building a strong group work environment because once people start their careers in the real world, there is a lot of collaboration that goes into any job that is available in society." - Biology student

Research Question 4: What do students perceive they gain from participating in DD activities, and does this differ among course-types?

To answer this research question, I gathered students' perceptions via an online survey (Qualtrics) at the end of the term (Fall, Winter, and Spring from the academic year 2017-18) from majors biology and majors chemistry courses. I asked students the three open-ended prompts: 1) "How did participating in the Deliberative Democracy activities in this class impact your thinking regarding the role of science as it applies to real world problems?", 2) "How did participating in DD in this class impact your confidence in applying scientific knowledge to real world problems?", and 3) "How did participating in the Deliberative Democracy activities in this class impact your confidence in communicating scientific topics with your peers?". Overall, I found that the same top themes reoccurred throughout the responses to the survey prompts and over the academic year (Table 3.4), the most interesting of which are discussed further. First, biology students in the Fall and Spring terms for the second prompt (see above) had a significantly higher proportion of responses about "peer interactions" than chemistry students. I hypothesize this occurred because in addition to DD activities, students in the chemistry courses also participate in Process Oriented Guided Inquiry 
Learning (POGIL) exercises every week, which is a group work activity. Because of the weekly POGIL, working with their peers may not have been as novel to the chemistry students as it was to the biology students.

Another intriguing finding was that both the biology and chemistry courses were reporting the same top themes each term. I found this remarkably interesting because the DD modules were different and the courses are also different (e.g., discipline, instructor, etc.). In a previous study (Shortlidge et al., 2018), we examined student perceptions across both biology and chemistry courses and found that chemistry students attributed group-work activities (POGIL) as having a stronger influence on their learning of the course content than biology students. Yet, biology students attributed group-work activities (DD) as having a stronger influence on their interest in the course content significantly more than chemistry students. With my Master's research, I am finding similar themes across both biology and chemistry courses when it comes to students' perceptions of DD activities. I hypothesize this lack of course-specific differences in perceptions may be due to the types of questions we asked (e.g.; How did participating in the DD activities in this class impact your confidence in applying scientific knowledge to real-world problems?). These questions were more specific than the past questions, which broadly asked students what influenced their learning/interest in the subject. We may be seeing the same perceptions across both biology and chemistry courses because the DD module and outcomes are properly aligned. This may elucidate why DD can be a successful groupwork activity for introductory STEM courses. 
Research Question 5: How can we use these data to make recommendations for broader implementation of DD modules?

To answer this research question, I examined student responses and course observations, and extrapolated from those data combined the potential aspects that may make DD a positive and meaningful experience. In particular, I think there are a few key aspects of DD that can facilitate broader implementation of DD modules, including in other institutions.

First, I have found it is important to introduce real-world problems/policy questions that closely align with course materials. Students often reflected specifically on modules that were reinforcing their learning of course content. For example: "[DD] helped me learn the concepts more and understand how to use them in the future. Many people forget content once they have learned it, but [DD] uses real life problems to link science and the real world to reinforce learning." - Biology student

It also matters to students to be able to tie what they are learning to their own lives, as we found with the endocrine-disrupting chemicals module:

"That one [EDCS DD] definitely made me far more aware: what we actually consume and how that affects us." - Biology student

Further, students are decidedly opinionated about how their time is being used in the classroom, so choosing engaging DD topics supports student buy-in of DD activities. I also found that instructors' transparency to the students on why they are using groupwork in their class may assist in buy-in.

Second, assigning the media articles and peer-reviewed literature readings seems to be an important aspect of DD. Many students have little experience 
practicing reading and using the scientific literature (Janick-Buckner, 1997; Rehorek and Dafoe, 2018), yet, I found that DD activities may present a way to get students interested in science, and to encourage them to engage with the scientific literature earlier in their STEM education than they might otherwise. Third, many students reflected positively on gaining the opportunity to discuss and collaborate with their peers. Having students work in smaller groups (4-6 students per group) during DD can lead to positive experience for students. Jones et al.'s study (2014) made a similar finding about the appreciation of collaboration.

\section{Suggestions for DD Implementation}

This Master's project contributes to a larger-scale, institution-wide initiative to develop, implement, and assess a deliberative pedagogy called Deliberative Democracy (DD) at Portland State University. Over two academic years, I have collected and analyzed enough data to support me to make informed suggestions for instructors who may want to implement DD in their courses. Here I describe several possible benefits and improvements from our findings to support the use of DD modules broadly in introductory STEM classrooms.

Primarily, DD modules should have closely aligned topics with course materials. Across both studies, students reflected on particular real-world examples and how it helped them engage with the course material, especially in matters of their own life. I also found giving students a chance to practice finding and using scientific literature is a novel and important aspect of DD. DD modules may be an avenue for instructors to assign scientific literature to their students, as many students have little 
experience practicing reading and using the scientific literature (Janick-Buckner, 1997; Rehorek and Dafoe, 2018).

Students reported appreciating the platform DD provided to allow for discussion and collaboration. Group-work can be difficult to employ effectively in college classrooms, however the benefits to students such as discussion and learning new perspectives from peers may lead to a successful group-work activity. Additionally, having students work in smaller groups (4-6 students per group) during DD can lead to positive experience for students. Also, I suggest instructors to have an entire class discussion at the end of each deliberation, as students find that to be a positive and memorable experience.

I also examined varying structures of DD implementation (one-day versus twoday modules). Remarkably, I did not detect any differences between the implementation types. There were many variables: one-day, two-day, different instructors, different teaching assistants, and yet, I still found similar outcomes This finding suggests that a strict fidelity of implementation is not necessary in order to see the outcomes that we have reported.

\section{Limitations}

In both of my studies, I employed open-ended prompts on surveys and collected student responses. These data are self-reported and thus are subject to inflation and/or understatement of students' actual experiences (Bowman, 2011). We felt that allowing students to respond to open-ended prompts, as opposed to a list of possible responses, would be more indicative of the most salient experiences and perceptions. In both of 
our studies, similar themes arose across surveys and interviews, therefore we are confident in what we found most significant and salient themes for our students. Furthermore, although students were reporting their perceptions of DD outcomes, our surveys did not measure the actual outcomes. For example, a student may have reported they had improved confidence in their own ability to communicate science as a result of $\mathrm{DD}$, but we did not have a way to gauge their actual skills in communicating science. The next steps to this work could be developing an assessment tool to measure the skills gained from participating in DD.

These data represent students at only one institution and may not be representative of biology and chemistry students elsewhere. It is important to note that in every classroom there are nuances that may influence student perception and performance. For example, the student body at PSU is largely non-traditional, consequently student experiences and perceptions may be different at a traditional university setting. It should be noted that although specific demographics were not a focus in this study, I did examine for differences for different student groups (e.g., URM versus Non-URM) and most results were insignificant. This could be due to an underpowered sample size, therefore differences between student groups would be undetected. I found some differences between genders when it came to their overall confidence, but I am not including this finding in this study.

\section{Future Work}

Over the course of this research project, ideas and thoughts emerged on how to build off of the work. First, the ability to track students for a longer period of time would 
be greatly beneficial. The longest I tracked the same students was over the course of two academic years. It would be interesting to follow up with the same students later, perhaps after graduation. We could track aspects such as: 1) Are students demonstrating any civic skills they learned from DD modules? If so, how?, 2) What do students remember from their DD experiences?, and 3) What do students remember from their courses in general?.

Second, while sending out online surveys, it would have been interesting and helpful to have added questions to gauge course content knowledge. I thought of this aspect while conducting interviews with students. I noticed that some students remembered a lot of details while describing the real-world problems and the courses' content. It could be helpful to compare and contrast what was most relevant contentwise with what students explicitly remember.

Lastly, I now have an improved sense of what leads to an impactful and successful DD module, so we will be able to refine existing modules and prepare new ones. It will be beneficial to continue brainstorming new real-world problems to stay up to date with current events and science. New and improved worksheets would also be idea, especially if we can add course content questions.

The national call made by the authors of Vision and Change (2011) urges instructors to design courses that allow students to connect science to society. Additionally, there are numerous national calls to instill important democratic skills such as communication, collaboration, and application into college learning outcomes (Thomas, 2010). With my Masters' research, I have found that the DD modules developed, implemented, and assessed at Portland State University may be a way to 
meet these national calls. I have found that students are reflecting on the democratic skills of communication, collaboration, and application without being specifically prompted on them. I also found that students believe that DD is giving them an opportunity to build their confidence in these important skills. With this two-year study, I found that students are reflecting on these outcomes from DD not only immediately after the course, but also after time has passed. Future work will continue to elucidate what makes DD a valuable pedagogy for instructors and students alike.

\section{REFERENCES}

Alfaro, C. (2008). Reinventing teacher education: The role of deliberative pedagogy in the K-6 classroom. In J. R. Dedrick, L. Grattan, \& H. Dienstfrey (Eds.), Deliberation and the work of higher education: Innovations for the classroom, the campus, and the community (pp. 143-164). Dayton, OH: Kettering Foundation Press.

American Association for the Advancement of Science (AAAS) (2009). Conference Homepage. Vision and Change in Undergraduate Biology Education: A View for the 21st Century. www.visionandchange.org (accessed 10 October 2019).

Ames, C. (1992). Classrooms: Goals, structures, and student motivation. Journal of Educational Psychology, 84(3), 261.

Association of American Colleges and Universities, College Learning for the New Global Century. (2007). Retrieved November 21, 2018, from https://www.aacu.org/sites/default/files/files/LEAP/GlobalCentury_final.pdf.

Bonwell, C. C., \& Eison, J. A. (1991). Active learning: Creating excitement in the classroom (1991 ASHE-ERIC higher education reports). Washington, DC: ERIC Clearinghouse on Higher Education. ERIC no. ED336049.

Bowman, N. A. (2011). Validity of college self-reported gains at diverse institutions. Educational Researcher, 40(1), 22-24. 
Brazeal, K. R., Brown, T. L., \& Couch, B. A. (2016). Characterizing student perceptions of and buy-in toward common formative assessment techniques. CBE-Life Sciences Education, 15(4), ar73.

Chang, Y. and Brickman, P. (2018). When Group Work Doesn't Work: Insights from Students. CBE-Life Sciences Education https://doi.org/10.1187/cbe.17-090199.

Center for Information and Research on Civic Learning and Engagement. CIRCLE Fact Sheet, Federal Policy and Civic Skills. Medford, Mass. The Center for Information and Research on Civic Learning and Engagement. (2010). Retrieved November 21, 2018, from https://civicyouth.org/PopUps/FactSheets/FS_10_Civic_Skills_final.pdf.

Cohen, J. (1960). A coefficient of agreement for nominal scale. Educational Psychology Measure; 20: 37-46.

Cohen, D., \& Crabtree, B. (2006). Qualitative Research Guidelines Project. Retrieved January 31, 2019, from www.qualres.org/HomeSemi-3629.html

Colby, A., and Sullivan, W. "Strengthening the Foundations of Students' Excellence, Integrity, and Social Contribution." Liberal Education, 2009, 95(1), 22-29.

Dolan, E. L. (2015). Biology education research 2.0: CBE-Life Sciences Education, 14(4): ed1.

Drury, S. A. M. (2015). Deliberation as Communication Instruction: A Study of a Climate Change Deliberation in an Introductory Biology Course. Journal on Excellence in College Teaching, 26(4), 51-71.

Freeman, S., Eddy, S. L., McDonough, M., Smith, M. K., Okoroafor, N., Jordt, H., \& Wenderoth, M. P. (2014). Active learning increases student performance in science, engineering, and mathematics. Proceedings of the National Academy of Sciences USA, 111(23), 8410-8415.

Haak, D. C., HilleRisLambers, J., Pitre, E., \& Freeman, S. (2011). Increased structure and active learning reduce the achievement gap in introductory biology. Science, 332(6034), 1213-1216.

Janick-Buckner D. Getting undergraduates to critically read and discuss primary literature. J Coll Sci Teach. 1997;27:29-32.

Johnson, D. W., Johnson, R. T., \& Smith, K. A. (1998). Cooperative learning returns to college what evidence is there that it works? Change: The Magazine of Higher Learning, 30(4), 26-35. 
Jones, A. R., Anderson, A. A., Yeo, S. K., Greenberg, A. E., Brossard, D., \& Moore, J. W. (2014). Using a deliberative exercise to foster public engagement in nanotechnology. Journal of Chemical Education, 91(2), 179-187. https://doi.org/10.1021/ed400517q

Kirlin, M. The Role of Civic Skills in Fostering Civic Engagement. CIRCLE Working Paper No. 6. Medford, Mass. The Center for Information and Research on Civic Learning and Engagement. (2003). Retrieved November 21, 2018, from https://civicyouth.org/PopUps/WorkingPapers/WP06Kirlin.pdf.

Komperda, R., Barbera, J., Shortlidge, E. E., \& Shusterman, G. P. (2018). Connecting Chemistry to Community with Deliberative Democracy. In Citizens First! Democracy, Social Responsibility and Chemistry (Vol. 1297, pp. 81-98): American Chemical Society.

Livingstone, D., \& Lynch, K. (2000). Group project work and student-centered active learning: Two different experiences. Studies in Higher Education, 25(3), 325-345.

Luskin, R., Fishkin, J., Malhotra, N., \& Siu, A. (2007). Deliberation in the schools: A way of enhancing civic engagement. Paper present- ed at the biannual general conference of the European Consortium for Political Research at University of Pisa, Pisa, Italy.

Meyers, C., \& Jones, T. B. (1993). Promoting active learning. Strategies for the college classroom. San Francisco: Jossey-Bass. ERIC no. ED358757.

Michael, J. (2006). Where's the evidence that active learning works? Advances in Physiology Education, 30(4), 159-167.

National Research Council (NRC) (2003). BIO2010: Transforming undergraduate education for future research biologists. Washington, D.C.: National Academies Press.

Otero, V., Finkelstein, N., McCray, R., \& Pollock, S. J. (2006). Who is responsible for preparing science teachers? Science, 313(5786), 445-446.

President's Council of Advisors on Science and Technology (PCAST). (2012). Engage to excel: Producing one million additional college graduates with degrees in science, technology, engineering, and mathematics. Washington, DC: U.S. Government Office of Science and Technology.

Prince, M. (2004). Does active learning work? A review of the research. Journal of Engineering Education, 93(3), 223-231. doi: 10.1002/j.2168-9830 .2004.tb00809.x 
Rehorek, S. J. \& Dafoe, N. J. (2018). The Art of Referencing as an Often Overlooked Aspect of Scientific Literacy: Study of a Classroom Intervention. The American Biology Teacher, 80(6), 423-428.

Shaffer, Timothy \& Longo, N.V. \& Manosevitch, I \& Thomas, M.S. (2017). Deliberative pedagogy: Teaching and learning for democratic engagement.

Shortlidge, E. E.; Rain-Griffith, L., Shelby, C., Barbera, J., Shusterman, G. P. (2018). Despite Similar Perceptions and Attitudes, Postbaccalaureate Students Outperform in Introductory Biology and Chemistry Courses. CBE-Life Sciences Education, 18, 1, doi:10.1187/cbe.17-12-0289.

Snapshot of Portland State University (2019). Retrieved January 31, 2019, from https://www.pdx.edu/profile/snapshot-portland-state

Talbot, R. M., Hartley, L. M., Marzetta, K., \& Wee, B. S. (2015). Transforming undergraduate science education with learning assistants: Student satisfaction in large-enrollment courses. Journal of College Science Teaching, 44(5), 24-30.

Tanner, K., Chatman, L. S., \& Allen, D. (2003). Approaches to cell biology teaching: Cooperative learning in the science classroom-beyond students working in groups. Cell Biology Education, 2(1), 1-5.

Thomas, N. L. (2010). Educating for deliberative democracy. San Francisco: Jossey-Bass.

Tyng, C. M., Amin, H. U., Saad, M., \& Malik, A. S. (2017). The Influences of Emotion on Learning and Memory. Frontiers in psychology, 8, 1454. doi:10.3389/fpsyg.2017.01454

Weasel, L. H., \& Finkel, L. (2016). Deliberative Pedagogy in a Nonmajors Biology Course: Active Learning That Promotes Student Engagement with Science Policy and Research. Journal of College Science Teaching.

World Economic Forum (WEF). (2016). The Future of Jobs: Employment, Skills and Workforce Strategy for the Fourth Industrial Revolution. Retrieved July 11, 2019, from http://www3.weforum.org/docs/WEF FOJ Executive Summary Jobs.pdf 
APPENDIX A: Chapter 2 - Extended Methods

\section{Institutional Context}

This study was conducted at Portland State University (PSU), a large, non-traditional university located in downtown Portland, Oregon. One of the largest universities in Oregon, PSU serves approximately 28,000 students. The average student age is 27 years old. (Snapshot of PSU, 2019).

\section{Courses Surveyed}

Two biology courses were surveyed during the 2016-2017 academic year: a 200-level introductory (for non-majors) and a 200-level introductory (for majors). The nonmajors course had the same instructor for the entire academic year, whereas the majors course had a different instructor each term (three instructors total during the academic 
year). Table 1 describes the courses surveyed in this study Both courses implemented a group-work activity called "Deliberative Democracy", (DD) (Weasel \& Finkel, 2016).

Table 1. Course types surveyed and their descriptions

\begin{tabular}{lll}
\hline Course Type & Majors Biology & Non-Majors Biology \\
\hline Number of Students & $\begin{array}{l}\sim 350 \text { students per } \\
\text { quarter }\end{array}$ & $\begin{array}{l}\sim 150 \text { students per } \\
\text { quarter }\end{array}$ \\
\hline Number of Instructors & 3 instructors over 3 & $\begin{array}{l}1 \text { instructor over 3 } \\
\text { quarters }\end{array}$ \\
& quarters & 9 modules over 3 \\
\hline Number of DD & 7 modules over 3 & quarters \\
Modules & quarters & One-day modules \\
\hline Types of Modules & $\begin{array}{l}\text { One- \& two-day } \\
\text { modules }\end{array}$ & \\
\hline
\end{tabular}

\section{Initial Survey}

To begin to understand how students were perceiving DD in their classes, we developed an open-ended prompt aimed at simply asking about their feelings about the pedagogy. This prompt was part of a larger evaluation of strategies being used in our STEM courses (Shortlidge et al., 2018). The wording of the prompt was: How do you feel about the following learning strategies used in this class? This prompt was course specific, so students were able to report on learning strategies such as DD if they did it in their course.

To collect data for this research, we added this open-ended prompt to the end of a larger post-course survey that was given across all introductory PSU STEM 
courses during the last week of each term during the 2016-2017 academic year. A representative from the research team visited each class with an IRB approved announcement to inform the students about the survey. The instructors offered extra credit points to students who accessed the survey. The survey was administered virtually via Qualtrics software and was available to students on their course's online learning site. Student self-reported demographics were collected including: gender, race/ethnicity, age, major, university status (post-baccalaureate or undergraduate), and transfer status (if student had transferred to PSU from a two-year college). Students who had consented for their information and data to be used in this research are represented in this study. This study was approved by PSU's IRB (\#153524).

\section{Initial Survey Data Analysis}

Initially, the open-ended prompt: How do you feel about the following learning strategies used in this class? was sorted into: positive, negative, and neutral bins. After this initial analysis, we disaggregated these into more specific themes (Shortlidge et al., 2018). Although this survey was offered at the end of each term (three terms total), we only considered the students last or only response they reported during the 2016-2017 academic year. The research team used thematic analysis to identify emergent themes from the open-ended prompt. Two researchers independently analyzed and noted all salient perceptions and feelings from the student responses. The research team reconvened and discussed all themes observed and discussed grouping similar themes and collapsing repeated themes as needed. An initial coding rubric was developed and 
was used by two researchers to complete the initial coding with a $20 \%$ sub-set of the responses. The coding rubric was iteratively developed into a final coding rubric when the two researchers reached $>80 \%$ inter-rater reliability. One researcher completed coding the rest of the student responses while remaining in contact with the research team for questions and/or new themes.

\section{Follow-up Survey}

The research team sought to conduct a longitudinal study with the same pool of students to see what was most memorable and/or most frustrating about their past experiences with DD. To collect data for this part of the study, we emailed the survey via Qualtrics to the introductory non-majors/majors biology students from the 20162017 academic year. This survey was sent out during the Winter term of the 20172018 academic year. To increase student participation, we offered an $\$ 50$ Amazon.com gift card as a raffle. Students had to choose the activities they remembered participating in from a list of DD activities. We also surveyed students on two open-ended prompts that we iteratively developed: 1) Reflecting on these activities [DD], what was the most memorable aspect of them and why? and 2) Reflecting on these activities [DD], what was the most frustrating aspect of them and why?

Student demographics was also collected during the survey and included: gender, race/ethnicity, age, major, university status (post-baccalaureate or undergraduate), and transfer status (if student had transferred to PSU from a two-year college). We had the students select from a list of DD activities that they participated in. At the end of the survey, students were asked if they were interested in participating 
in semi-structured interviews at a later date. Students who had consented for their information and data to be used in this research are represented in this study. This study was approved by PSU's IRB (\#184471).

\section{Follow-up Survey Data Analysis}

The research team used thematic analysis to find emergent themes from the two open-ended prompts. Two researchers independently analyzed and noted all salient perceptions and feelings from the student responses. The research team reconvened and discussed all themes observed and discussed grouping similar themes and collapsing repeated themes as needed. An initial coding rubric was developed and was used by two researchers to complete the initial coding with a $20 \%$ sub-set of the responses. The coding rubric was iteratively developed into a final coding rubric when the two researchers reached $>80 \%$ inter-rater reliability. One researcher completed coding the rest of the student responses while remaining in contact with the research team for questions and/or new themes.

\section{Student Interviews}

We conducted semi-structured interviews with 19 participants from the pool of students who answered the first and second survey. These students agreed to being contacted to participate in the interviews. The interview protocol was composed of 12 questions aiming to collect further qualitative data of student perceptions of DD

(Appendix D). These questions were piloted via think-alouds with individuals who were not involved with the project to ensure the questions were being interpreted 
correctly. The interviews were designed to be semi-structured (Cohen and Crabtree, 2006) to allow the interviewer to ask relevant follow up and clarification questions in addition to the 12 interview questions. All interviews were conducted by a single researcher on campus and in person. Interviews were audio recorded (average length of an interview was 25 minutes), de-identified, and transcribed verbatim (Sonix.ai, San Francisco). Students who had consented for their information and data to be used in this research are represented in this part of the study. This study was approved by PSU's IRB (\#184471).

\section{Interview Data Analysis}

Two researchers read batches of interview transcripts (typically one to two transcripts at a time) and each individually created a rubric of the perceptions and reflections of participants during their interviews. These perceptions and reflections were each described as its own code; a short description of the perception/reflection. After the first interview batch, we reconvened and discussed our initial rubrics, making sure to collapse similar findings and discuss differences. We combined our findings into an initial coding rubric. We independently continued until we reached saturation of possible codes and were all added to the initial coding rubric. With the coding rubric, we assigned codes to batches of quotes from all interview transcripts until we reached consensus. We then met with the research team to go over the initial coding rubric. This meeting was used to reorganize the rubric and to collapse redundant codes, creating the final rubric. A single researcher used the final coding rubric to apply codes 
to the remaining interviews and continued to confer with the other researchers. All final coding was completed with the software MAXQDA.

\section{Statistical Analysis}

Pearson's Chi Square tests were used when comparing two groups (contingency analyses). Significance was indicated by Pearson's Correlation coefficient. All reported significance was determined by $p$-values $\leq 0.05$. Statistical analyses were performed on statistical software (SAS JMP Pro, 2012, Cary, NC).

APPENDIX B: Sample demographics for respondents of the survey immediately after their course.

Sample demographics for the first-year survey $(n=446)$

\begin{tabular}{|lclc|}
\hline Category & Percent (\%) & Category & Percent (\%) \\
\hline Gender & & $\underline{\text { Major }}$ & 32 \\
Female & $\mathbf{5 9}$ & Biology & 32 \\
Male & $\mathbf{4 0}$ & Other-STEM & $\mathbf{3 1}$ \\
Other/Did Not Respond & $\mathbf{1}$ & Non-STEM & $\mathbf{5}$ \\
Race/Ethnicity & & Undecided & \\
Non-URM & $\mathbf{7 2}$ & $\underline{\text { University Status }}$ & $\mathbf{1 1}$ \\
URM & $\mathbf{2 7}$ & Post-baccalaureate & $\mathbf{8 9}$ \\
Did Not Respond & $\mathbf{1}$ & Undergraduate & \\
Age Bracket (years) & & $\underline{\text { Transfer Status }}$ & $\mathbf{2 8}$ \\
18-22 (Traditional) & $\mathbf{6 1}$ & Transfer from 2-year college & \\
23+ (Non-Traditional) & $\mathbf{3 9}$ & & \\
\hline
\end{tabular}


APPENDIX C: Sample demographics for respondents of the survey one year after their course.

Student demographics for the follow-up survey $(\mathrm{n}=95)$

\begin{tabular}{|lclc|}
\hline Category & Percent (\%) & Category & Percent (\%) \\
\hline Gender & & $\underline{\text { Major }}$ & $\mathbf{3 8}$ \\
Female & $\mathbf{7 1}$ & Biology & $\mathbf{2 8}$ \\
Male & $\mathbf{2 8}$ & Other-STEM & $\mathbf{2 9}$ \\
Other/Did Not Respond & $\mathbf{1}$ & Non-STEM & $\mathbf{5}$ \\
Race/Ethnicity & & Undecided & \\
Non-URM & 73 & $\underline{\text { University Status }}$ & $\mathbf{1 5}$ \\
URM & 27 & Post-baccalaureate & $\mathbf{8 5}$ \\
& & Undergraduate &
\end{tabular}




\section{APPENDIX D: Spring 2018 Interview Questions}

\section{DD Introduction}

1. Before you had participated in $\mathrm{DD}$, had you heard about it in any way?

2. Can you talk about one specific DD you remember participating in? How was that experience for you?

\section{Research}

3. After participating in $\mathrm{DD}$, did you follow up on any of the topics by doing more research of your own? 
4. Do you do research or read articles about science outside of what is required for you in your classes? Do you feel confident in your ability to do this?

5. Do you think that participating in any of the DD activities had any influence on your reading of research or looking things up on particular topics?

\section{Group Work}

6. How did you feel about working in groups while doing DD? Do you think there is value in doing these types of activities as a group?

7. Were there aspects that went well and/or aspects that did not go so well?

8. How did you feel about doing DD as opposed to a normal class period (lecture)?

9. Did you feel that there was too much, or too little time devoted to DD?

\section{Personal Life}

10. Did participating in DD influence you outside of the classroom in any way?

11. Did participating in DD change your mind or perceptions about anything? If yes, how?

\section{Closing}

12. Is there anything we didn't talk about that you want to discuss? 